\title{
Transition in patients with childhood-onset epilepsy
}

Citation for published version (APA):

Geerlings, R. P. J. (2016). Transition in patients with childhood-onset epilepsy: a long way to adulthood . [Doctoral Thesis, Maastricht University]. https://doi.org/10.26481/dis.20160615rg

Document status and date:

Published: 01/01/2016

DOI:

10.26481/dis.20160615rg

Document Version:

Publisher's PDF, also known as Version of record

\section{Please check the document version of this publication:}

- A submitted manuscript is the version of the article upon submission and before peer-review. There can be important differences between the submitted version and the official published version of record.

People interested in the research are advised to contact the author for the final version of the publication, or visit the DOI to the publisher's website.

- The final author version and the galley proof are versions of the publication after peer review.

- The final published version features the final layout of the paper including the volume, issue and page numbers.

Link to publication

\footnotetext{
General rights rights.

- You may freely distribute the URL identifying the publication in the public portal. please follow below link for the End User Agreement:

www.umlib.nl/taverne-license

Take down policy

If you believe that this document breaches copyright please contact us at:

repository@maastrichtuniversity.nl

providing details and we will investigate your claim.
}

Copyright and moral rights for the publications made accessible in the public portal are retained by the authors and/or other copyright owners and it is a condition of accessing publications that users recognise and abide by the legal requirements associated with these

- Users may download and print one copy of any publication from the public portal for the purpose of private study or research.

- You may not further distribute the material or use it for any profit-making activity or commercial gain

If the publication is distributed under the terms of Article $25 \mathrm{fa}$ of the Dutch Copyright Act, indicated by the "Taverne" license above, 
Transition in patients with childhood-onset

\section{epilepsy}

A long way to adulthood 
(C) Copyright RPJ Geerlings, Maastricht 2016

R.P.J. Geerlings Transition in patients with childhood-onset epilepsy

A long way to adulthood

Layout Tiny Wouters

Cover design Patrick Aspers

Print Ipskamp Drukkers, Enschede

ISBN 978-94-028-0145-3

Financial support for the printing of this thesis was kindly provided by Eisai BV, UCB Pharma BV, the Department of Research and Development Kempenhaeghe and the School for Mental Health and Neurosciences (MHeNS) Maastricht University.

The research presented in this thesis was funded by the province of Noord-Brabant ('Leefbaarheid@Brabant'), The Netherlands, with grant number C2134073.

\section{Kempenhaeghe \\ Trb Inspired by patients. \\ Driven by science.}

\section{Academisch Centrum voor Epileptologie}

Kempenhaeghe \& Maastricht UMC+

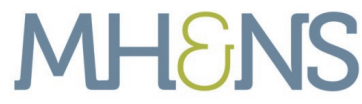

school for

mental health

and neuroscience
Eisai

hive humes Arotite car 


\section{Transition in patients with childhood-onset epilepsy}

A long way to adulthood

\section{Proefschrift}

Ter verkrijging van de graad van doctor aan de Universiteit Maastricht, op gezag van de Rector Magnificus, Prof. Dr. L.L.G. Soete, volgens het besluit van het College van Decanen,

in het openbaar te verdedigen

op woensdag 15 juni 2016 om 12.00 uur

door

Rianne Petronella Johanna Geerlings

Geboren op 25 december 1985 te Beesel 
Promotor

Prof. dr. A.P. Aldenkamp

\section{Copromotores}

Dr. A.J.A. de Louw (Kempenhaeghe, Heeze)

Dr. L.M.C. Gottmer-Welschen (Kempenhaeghe, Heeze)

\section{Beoordelingscommissie}

Prof. dr. R.J. van Oostenbrugge (voorzitter)

Prof. dr. P.A.J.M. Boon (Universiteit van Gent, België)

Dr. M.H.J.A. Debeij-van Hall (Kempenhaeghe, Heeze)

Prof. dr. R.W.H.M. Ponds 


\section{Contents}

Chapter 1 General introduction and outline of this thesis

Chapter 2 Transition to adult medical care for adolescents with epilepsy

RPJ Geerlings, AP Aldenkamp, PHN de With, S Zinger,

LMC Gottmer-Welschen, AJA de Louw.

Epilepsy Behav 2015;10:127-35.

Chapter 3 Evaluation of a multidisciplinary epilepsy transition clinic

for adolescents

RPJ Geerlings, AP Aldenkamp, LMC Gottmer-Welschen,

PHN de With, S Zinger, AL van Staa, AJA de Louw.

Eur J Paediatr Neurol 2016;20:385-92.

Chapter 4 Developing from child to adult: risk factors for poor

psychosocial outcome in adolescents and young adults

with epilepsy

RPJ Geerlings, AP Aldenkamp, LMC Gottmer-Welschen, PHN de With,

$S$ Zinger, AL van Staa, AJA de Louw.

Epilepsy Behav 2015;51:182-90.

Chapter 5 Long-term effects of a multidisciplinary transition intervention

from paediatric to adult care in patients with epilepsy

RPJ Geerlings, AP Aldenkamp, LMC Gottmer-Welschen, AL van Staa,

AJA de Louw. Submitted.

Chapter 6 Failed transition to independence in young adults with epilepsy

RPJ Geerlings, LMC Gottmer-Welschen, JEM Machielse,

AJA de Louw, AP Aldenkamp. Submitted.

Chapter 7 General discussion

Chapter 8 Summary

Chapter 9 Samenvatting (Summary in Dutch)

Chapter 10 Valorisation 

Chapter 1

General introduction

and outline of this thesis 
Chapter 1 


\section{General introduction}

\section{Chronic epilepsy during childhood and adolescence}

Epilepsy is a complex and heterogenic disorder affecting millions of children globally. ${ }^{1-3}$ It is in fact the most common childhood-onset neurological disorder transferring from childhood into adolescence and adulthood. ${ }^{4,5}$

Epilepsy is characterized by recurrent, involuntary and unpredictable seizures. Most patients with epilepsy use antiepileptic drugs (AEDs) to achieve seizure control, but unfortunately some types of AEDs are associated with severe cognitive and other behavioral side effects. ${ }^{6}$ Furthermore, epilepsy is often accompanied by physical, intellectual or behavioral comorbid conditions, e.g., learning disorders or autism spectrum disorders. ${ }^{7}$ Chronic epilepsy, comorbid conditions, and adverse effects of treatment options can all have a profound impact on the patient's daily life. Several studies in the past showed the detrimental effects of epilepsy (with our without comorbid conditions) on future psychosocial outcome. For instance, adolescents with epilepsy (even those without intellectual disabilities) are at risk for academic underachievement. ${ }^{8}$ Completing an education is of utmost importance for the entry of higher education and in the development of future employment and independence. ${ }^{9}$ Therefore, it is no wonder that patients with epilepsy who suffer academic underachievement are more often underemployed or unemployed, and have subsequently lower financial income during adulthood. ${ }^{3}$ Furthermore, patients with epilepsy have an increased risk of psychopathology compared to healthy controls or patients with other chronic conditions. ${ }^{9-12}$ Except for patients themselves, epilepsy also affects the patient's family. Families of patients with epilepsy experience more often relational problems, parenting problems, or social isolation, due to their child's illness. ${ }^{9,10,13}$ Even after multiple decades, the influence of epilepsy on psychosocial outcome persists: Sillanpää and Cross $^{14}$ and Jalava ${ }^{15}$ found that patients with epilepsy have a decreased social participation and experience more social isolation compared to healthy controls even after 35 years of follow-up.

While some types of epilepsy and comorbidities remit during adolescence and emerging adulthood, others will continue for life. ${ }^{3}$ However, some studies suggest that even patients without comorbid conditions and with a 'benign' childhood-onset epilepsy, have adverse social outcomes after seizure remission, compared to patients with other chronic diseases, e.g., asthma., ${ }^{3,12}$ Therefore, medical care should not be focused on seizure reduction only during adolescence and early adulthood, and attention should be paid to the above mentioned specific developmental and agerelated issues in adolescents with epilepsy.

\section{Transition from paediatric to adult medical care}

At a certain point, adolescents with ongoing seizures need to transfer from paediatric to adult care to continue chronic medical health care with regular appointments. ${ }^{1}$ This 
transition from paediatric to adult medical care usually occurs before or around the age of eighteen years when the child reaches adulthood. For several reasons many adolescents aged 18 years or older remain in paediatric care for a longer period of time. ${ }^{16}$ Continuing paediatric health care during adulthood can be related to the health care worker's or to the patient's personal preferences. The main problem is that paediatric health care workers are not specialized in specific adolescent or adult issues, e.g., the interaction between AEDs and contraceptives, developing independence, or driving license regulations. Transition from paediatric to adult care is therefore required. ${ }^{5}$

Transition to adult care consists mostly out of a single handling over by a referral letter (transfer) instead of an organized and gradual process (transition). ${ }^{17} \mathrm{~A}$ frequently reported problem during transition to adult care is that patients with epilepsy suddenly lose contact with the paediatric health care workers they have known for many years. This sudden loss of contact with a familiar paediatrician (and the multidisciplinary paediatric team), often accompanied by insufficient confidence in the new individually-centered adult health care worker, may even result in discontinuity of essential health care, and thus to poor seizure management and psychosocial support.

Furthermore, adolescents with epilepsy have insufficient coping strategies to deal with specific transitional problems during development of autonomy and independence. $^{18}$ As a result, they are prone to develop the above-mentioned psychosocial problems, especially during the years of transition from child to adult.

\section{Epilepsy transition clinic}

Transition clinics have been set up around the globe to cope with transition in health care, and age-specific questions and problems. The first description of an epilepsy transition clinic dates from 1997 by Appleton ${ }^{5}$, and increasing attention is given to the medical transition process in the last years. Transition clinics exist for all types of chronic illnesses, e.g., diabetes, cardiac or renal disease, but seem quite new and unstructured for adolescents with epilepsy. Several descriptions can be found in literature, but there is no consensus nor a clinical guideline for the process and methods of epilepsy transition clinics. ${ }^{19,20}$ Importantly, transitional care for adolescents with epilepsy should not only focus on the re-evaluation of the previously made epilepsy diagnosis, treatment options and side effects, but also pay special attention for the developmental age-related issues, e.g., employment, development of independence, and the transition to adult medical care. 


\section{Current problem}

Up to now, there is no agreement about staffing and procedures among the epilepsy transition clinics described in literature. Little is known about the optimal medical and psychosocial care for patients with epilepsy in transition, the characteristics of patients with an increased risk for poor psychosocial outcome, and the short-term and long-term effects of a transition intervention. Further, it would be interesting to study the medical and psychosocial outcome and the social participation of adults with epilepsy with a failed transition to independence.

\section{Aim and outline of this thesis}

The aim of this thesis is to gain more insight in the medical and psychosocial transitional problems in adolescents and young adults with epilepsy, and in the longterm and long-lasting effects of multidisciplinary transitional care, in order to optimize epilepsy management during the years of transition.

This thesis starts with a literature review in Chapter $\mathbf{2}$ to provide a structural overview of psychosocial and medical transitional issues for adolescents with epilepsy. Chapter 3 illustrates the methods and outcomes of our multidisciplinary epilepsy transition clinic. In Chapter 4, we identify risk factors for long-term poor psychosocial outcome in adolescents and young adults with epilepsy. Chapter $\mathbf{5}$ describes the longterm effects of a multidisciplinary transition intervention from paediatric to adult care in patients with epilepsy. Chapter 6 describes the medical and psychosocial outcome and feelings of loneliness of adult patients with epilepsy with a 'failed transition to independence'. The results of this thesis are reviewed and discussed in Chapter 7. A summary of this thesis is provided in Chapter $\mathbf{8}$ and a Dutch summary in Chapter $\mathbf{9}$. The valorisation and clinical relevance are discussed in Chapter 10. 


\section{References}

1. Lewis SA, Noyes J. Effective process or dangerous precipice: qualitative comparative embedded case study with young people with epilepsy and their parents during transition from children's to adult services. BMC Pediatr 2013; 13:169.

2. Lewis SA, Noyes J, Mackereth S. Knowledge and information needs of young people with epilepsy and their parents: Mixed-method systematic review. BMC Pediatr 2010; 10:103.

3. Camfield PR, Camfield CS. What Happens to Children With Epilepsy When They Become Adults? Some Facts and Opinions. Pediatr Neurol 2014; 51:17-23.

4. Asato MR, Manjunath R, Sheth RD, et al. Adolescent and caregiver experiences with epilepsy. J Child Neurol 2009; 24:562-71.

5. Appleton RE, Chadwick D, Sweeney A. Managing the teenager with epilepsy: paediatric to adult care. Seizure 1997; 6:27-30.

6. Ijff DM, Aldenkamp AP. Cognitive side-effects of antiepileptic drugs in children. Handb Clin Neurol 2013; 111:707-18.

7. Khan A, Baheerathan A, Hussain N, et al. Transition of children with epilepsies to adult care. Acta Paediatr 2013; 102:216-21.

8. Beghi E, Camfield PR, Camfield CS. Epidemiologic aspects: Lost in transition. Epilepsia 2014; 55 Suppl 3:3-7.

9. Rodenburg R, Wagner JL, Austin JK, et al. Psychosocial issues for children with epilepsy. Epilepsy Behav 2011; 22:47-54.

10. Kerr M, Kluger G, Philip S. Evolution and management of Lennox-Gastaut syndrome through adolescence and into adulthood: are seizures always the primary issue? Epileptic Disord 2011; 13 Suppl 1:S15-26.

11. Austin JK, Dunn DW, Huster GA. Childhood epilepsy and asthma: changes in behavior problems related to gender and change in condition severity. Epilepsia 2000; 41:615-23.

12. Ferro MA. Adolescents and young adults with physical illness: a comparative study of psychological distress. Acta Paediatr 2014; 103:e32-7.

13. Camfield P, Camfield C, Nolan K. Helping families cope with the devastation of Dravet syndrome. Eur J Paediatr Neurol 2012; 16 Suppl 1:S9-12.

14. Sillanpaa M, Helen Cross J. The psychosocial impact of epilepsy in childhood. Epilepsy Behav 2009; 15 Suppl 1:S5-10.

15. Jalava M, Sillanpaa M, Camfield $C$, et al. Social adjustment and competence 35 years after onset of childhood epilepsy: a prospective controlled study. Epilepsia 1997; 38:708-15.

16. Iyer A, Appleton R. Transitional services for adolescents with epilepsy in the U.K.: a survey. Seizure 2013; 22:433-7.

17. Camfield P, Camfield C, Pohlmann-Eden B. Transition from pediatric to adult epilepsy care: a difficult process marked by medical and social crisis. Epilepsy Curr 2012; 12:13-21.

18. Reeve DK, Lincoln NB. Coping with the challenge of transition in older adolescents with epilepsy. Seizure 2002; 11:33-9.

19. Carrizosa J, An I, Appleton R, et al. Models for transition clinics. Epilepsia 2014; 55 Suppl 3:46-51.

20. 'Epilepsie'. Richtlijn Epilepsie Nederlandse Vereniging voor Neurologie. 2015; available from: http://epilepsie.neurologie.nl (Last visit: January 8, 2016). 


\section{Chapter \\ 2}

Transition to adult medical care for adolescents with epilepsy

RPJ Geerlings, AP Aldenkamp, PHN de With, S Zinger, LMC Gottmer-Welschen, AJA de Louw

Epilepsy Behav 2015;10:127-35 


\section{Abstract}

\section{Introduction}

During transition to adult medical care, the adolescent with epilepsy is especially prone to emotional, mental, physical, and social developmental difficulties, leading to stigma and poor psychosocial and socioeconomic outcome in the long term.

\section{Objectives}

The aim of this review is twofold: to describe the psychosocial and medical transition from adolescence to adulthood and to evaluate the most effective model for transitional services in adolescents with epilepsy.

\section{Methods}

We searched PubMed for quantitative and qualitative data about transition from adolescence to adulthood in patients with epilepsy.

\section{Results}

A total of 49 articles were retrieved. We reviewed personal, psychosocial and medical issues during transition and their long-term individual and societal consequences. Identifying risk factors for poor transition can lead to appropriate interventions for patients and their family. Although the concept of multidisciplinary transition care for adolescents with epilepsy is widely recognized, only a few transition clinics have been established. There is lack of evidence for their quality and cost-effectiveness.

\section{Conclusion}

In addition to medical problems, more attention should be paid to the risk of psychosocial problems during transition from pediatric to adult care. The implementation of transition care for adolescents with epilepsy is considered beneficial; however, its effectiveness should be further investigated. 


\section{Introduction}

Epilepsy is the most common childhood-onset neurological disorder transferring into adolescence, affecting 15 million children globally. ${ }^{1-4}$ It is a disorder characterized not only by seizures but also by comorbid behavioral, social, physical and intellectual disabilities, making it a heterogeneous and complex condition. ${ }^{1-6}$ Both epilepsy and many of its associated comorbid disabilities can either continue or remit during adolescence and adulthood. ${ }^{6-8}$

In addition to the normal age-related challenges, the adolescent with epilepsy is especially prone to emotional, cognitive, physical, and social developmental difficulties during transition to adulthood, influencing self-identity, autonomy, and thereby psychosocial outcome in the long term. ${ }^{3-5,9-17}$ Moreover, leaving the pediatric care during this transition often leads to discontinuity of chronic care. ${ }^{1,2,5,6,11,12,15}$ Therefore, an emphasis on support during transition seems of utmost importance. $^{1,6,7,13,18,19}$

Although the problem of transition from pediatric to adult care and the concept of multidisciplinary transition care are widely recognized in chronic disease, little quantitative data are available about transition problems and required care in adolescents with epilepsy. ${ }^{1,6,11,13,15,19}$ The aim of this review is therefore twofold: to describe the process of transition to adult medical care in adolescents with epilepsy and to evaluate the most effective model for epilepsy transitional services.

\section{Methods}

Since 'transition in adolescents with epilepsy' is a relatively new concept, found on PubMed since 1997 (Appleton et al. ${ }^{4}$ ), we chose to search PubMed instead of gray literature. It is unlikely that gray literature would provide additional information.

PubMed was searched for quantitative and qualitative data about transition from pediatric to adult care in adolescents with epilepsy (closing date: September $15^{\text {th }}$, 2014), using the MeSH terms epilepsy, seizure, convulsion, and transition to adult care and the text words epilepsy, seizure, and convulsion, combined with paediatric/pediatric, adolescents, teen, youth, underage, junior school, junior high, middle school, high school, senior high, boy/girl, puberty, young people, minors, combined with the text words transition and adult care and adult service. Language restrictions English, Dutch, and German as language restrictions were added, and animal studies were excluded. The full search strategy is shown in Appendix A.

With this search, a total of 757 results were found. 'Transition' is not a standard MeSH term, making it difficult to focus the search. Titles and abstracts of articles were reviewed, and when regarded applicable, the full-text article was retrieved. A total of 49 articles were retrieved for critical appraisal (Table 2.1), and 708 articles were not 
specifically about transition in epilepsy and were thus excluded. All types of articles about transition to adult care in epilepsy were reviewed, including editorials. One article (Parachuri and Inglese ${ }^{20}$ ) remained unavailable, even after full-text retrieving.

Table 2.1 Identified articles, study design, and topics.

\begin{tabular}{|c|c|c|c|}
\hline Author(s) (year) & Title & Study design & Topic \\
\hline $\begin{array}{l}\text { Nabbout and } \\
\text { Camfield }^{45} \text { (2014) }\end{array}$ & $\begin{array}{l}\text { Transition in adulthood: The } \\
\text { challenge of epilepsies }\end{array}$ & Supplement Epilepsia & $\begin{array}{l}\text { Introduction to special } \\
\text { issue of Epilepsia: } \\
\text { 'Transition of epilepsy } \\
\text { care from children to } \\
\text { adults' }\end{array}$ \\
\hline Beghi et al..$^{8}(2014)$ & $\begin{array}{l}\text { Epidemiologic aspects: Lost in } \\
\text { transition }\end{array}$ & $\begin{array}{l}\text { Supplement Epilepsia } \\
\text { Review }\end{array}$ & $\begin{array}{l}\text { Long-term medical and } \\
\text { psychosocial outcome in } \\
\text { patients with epilepsy }\end{array}$ \\
\hline $\begin{array}{l}\text { Chiron and } \mathrm{An}^{21} \\
(2014)\end{array}$ & $\begin{array}{l}\text { Pharmacology aspects during } \\
\text { transition and at transfer in } \\
\text { patients with epilepsy }\end{array}$ & $\begin{array}{l}\text { Supplement Epilepsia } \\
\text { Review }\end{array}$ & $\begin{array}{l}\text { AED treatment during } \\
\text { transition }\end{array}$ \\
\hline $\begin{array}{l}\text { Scheffer and } \\
\text { Dravet }^{22}(2014)\end{array}$ & $\begin{array}{l}\text { Transition to adult life in the } \\
\text { monogenic epilepsies }\end{array}$ & $\begin{array}{l}\text { Supplement Epilepsia } \\
\text { Review }\end{array}$ & $\begin{array}{l}\text { Psychiatric disorders, } \\
\text { movement disorders, and } \\
\text { epileptic } \\
\text { encephalopathies during } \\
\text { transition }\end{array}$ \\
\hline $\begin{array}{l}\text { Camfield et al. } \\
(2014)\end{array}$ & $\begin{array}{l}\text { Transition issues for benign } \\
\text { epilepsy with centrotemporal } \\
\text { spikes, nonlesional focal epilepsy } \\
\text { in otherwise normal children, } \\
\text { childhood absence epilepsy, and } \\
\text { juvenile myoclonic epilepsy }\end{array}$ & $\begin{array}{l}\text { Supplement Epilepsia } \\
\text { Review }\end{array}$ & $\begin{array}{l}\text { Transition in patients with } \\
\text { BECTS, NLFN, CAE, and } \\
\text { JME }\end{array}$ \\
\hline $\begin{array}{l}\text { De Saint-Martin et } \\
\text { al. }^{26}(2014)\end{array}$ & $\begin{array}{l}\text { Epileptic encephalopathy with } \\
\text { continuous spike-waves during } \\
\text { sleep: The need for transition } \\
\text { from childhood to adulthood } \\
\text { medical care appears to be related } \\
\text { to etiology }\end{array}$ & $\begin{array}{l}\text { Supplement Epilepsia } \\
\text { Review }\end{array}$ & $\begin{array}{l}\text { Transitional care for } \\
\text { adolescents with ECSWS }\end{array}$ \\
\hline $\begin{array}{l}\text { Camfield et al. }{ }^{24} \\
(2014)\end{array}$ & $\begin{array}{l}\text { Transition issues for children with } \\
\text { diffuse cortical malformations, } \\
\text { multifocal postnatal lesions, } \\
\text { (infectious and traumatic) and } \\
\text { Lennox-Gastaut and similar } \\
\text { syndromes }\end{array}$ & $\begin{array}{l}\text { Supplement Epilepsia } \\
\text { Review }\end{array}$ & $\begin{array}{l}\text { Transition for children } \\
\text { with diffuse cortical } \\
\text { malformations, multifocal } \\
\text { postnatal lesions, and LGS }\end{array}$ \\
\hline $\begin{array}{l}\text { Thiele et al. } \\
\text { (2014) }\end{array}$ & $\begin{array}{l}\text { Transition into adulthood: } \\
\text { Tuberous sclerosis complex, } \\
\text { Sturge-Weber syndrome, and } \\
\text { Rasmussen encephalitis }\end{array}$ & $\begin{array}{l}\text { Supplement Epilepsia } \\
\text { Review }\end{array}$ & $\begin{array}{l}\text { Transition for children } \\
\text { with TSC, SWS, and RE }\end{array}$ \\
\hline $\begin{array}{l}\text { Cross and } \\
\text { Duchowny }^{35}(2014)\end{array}$ & $\begin{array}{l}\text { Transition in lesional focal } \\
\text { epilepsy, and following epilepsy } \\
\text { surgery }\end{array}$ & $\begin{array}{l}\text { Supplement Epilepsia } \\
\text { Review }\end{array}$ & $\begin{array}{l}\text { Epilepsy surgery during } \\
\text { transition }\end{array}$ \\
\hline $\begin{array}{l}\text { Kossoff et al. } \\
(2014)\end{array}$ & $\begin{array}{l}\text { Transition for patients with } \\
\text { epilepsy due to metabolic and } \\
\text { mitochondrial disorders }\end{array}$ & $\begin{array}{l}\text { Supplement Epilepsia } \\
\text { Review }\end{array}$ & $\begin{array}{l}\text { Transition for patients } \\
\text { with epilepsy with } \\
\text { metabolic or } \\
\text { mitochondrial disorders } \\
\text { Ketogenic diet }\end{array}$ \\
\hline
\end{tabular}


Table 2.1 (continued)

\begin{tabular}{|c|c|c|c|}
\hline Author(s) (year) & Title & Study design & Topic \\
\hline $\begin{array}{l}\text { Nashef et al. } \\
\text { (2014) }\end{array}$ & Transition: Driving and exercise & $\begin{array}{l}\text { Supplement Epilepsia } \\
\text { Review }\end{array}$ & $\begin{array}{l}\text { Driving and exercise in } \\
\text { adolescents with epilepsy }\end{array}$ \\
\hline $\begin{array}{l}\text { Carrizosa et al. } \\
\text { (2014) }\end{array}$ & Models for transition clinics & $\begin{array}{l}\text { Supplement Epilepsia } \\
\text { Review }\end{array}$ & $\begin{array}{l}\text { Models for transition } \\
\text { clinics }\end{array}$ \\
\hline $\begin{array}{l}\text { Nabbout and } \\
\text { Camfield }^{46}(2014)\end{array}$ & $\begin{array}{l}\text { Bringing the transition of epilepsy } \\
\text { care from children to adults out of } \\
\text { the shadows. }\end{array}$ & $\begin{array}{l}\text { Supplement Epilepsia } \\
\text { Opinion }\end{array}$ & Need for transitional care. \\
\hline Devinsky $^{47}(2014)$ & $\begin{array}{l}\text { Transition to adult care for } \\
\text { children with epilepsy: a call for } \\
\text { action }\end{array}$ & $\begin{array}{l}\text { Supplement Epilepsia } \\
\text { Opinion }\end{array}$ & Need for transitional care \\
\hline Borlot et al. ${ }^{6}(2014)$ & $\begin{array}{l}\text { Epilepsy transition: Challenges of } \\
\text { caring for adults with childhood- } \\
\text { onset seizures }\end{array}$ & $\begin{array}{l}\text { Retrospective study } \\
\text { Survey }\end{array}$ & $\begin{array}{l}\text { Transition care for } \\
\text { adolescents with epilepsy. } \\
\text { Neurologists level of } \\
\text { confidence in diagnosis } \\
\text { and treatment }\end{array}$ \\
\hline $\begin{array}{l}\text { Camfield and } \\
\text { Camfield }^{7}(2014)\end{array}$ & $\begin{array}{l}\text { What Happens to Children With } \\
\text { Epilepsy When They Become } \\
\text { Adults? Some Facts and Opinions }\end{array}$ & Topical review & $\begin{array}{l}\text { Seizure remission and } \\
\text { social outcome in adults } \\
\text { with childhood-onset } \\
\text { epilepsy }\end{array}$ \\
\hline $\begin{array}{l}\text { Thomson et al. } \\
\text { (2014) }\end{array}$ & $\begin{array}{l}\text { Life quality and health in } \\
\text { adolescents and emerging adults } \\
\text { with epilepsy during the years of } \\
\text { transition: a scoping review }\end{array}$ & Scoping review & $\begin{array}{l}\text { Challenging domains } \\
\text { during transition to } \\
\text { adulthood in adolescents } \\
\text { with epilepsy }\end{array}$ \\
\hline Ferro $^{43}(2013)$ & $\begin{array}{l}\text { Adolescents and young adults } \\
\text { with physical illness: a } \\
\text { comparative study of } \\
\text { psychological distress }\end{array}$ & Comparative study & $\begin{array}{l}\text { Comparing psychological } \\
\text { distress in adolescents } \\
\text { with asthma vs. epilepsy }\end{array}$ \\
\hline Schor $^{32}(2013)$ & $\begin{array}{l}\text { Life at the interface: adults with } \\
\text { "pediatric" disorders of the } \\
\text { nervous system }\end{array}$ & Review & $\begin{array}{l}\text { Childhood-onset } \\
\text { neurological conditions } \\
\text { including epilepsy, } \\
\text { compared to other } \\
\text { chronic conditions }\end{array}$ \\
\hline $\begin{array}{l}\text { Lewis and Noyes }^{1} \\
\text { (2013) }\end{array}$ & $\begin{array}{l}\text { Effective process or dangerous } \\
\text { precipice: qualitative comparative } \\
\text { embedded case study with young } \\
\text { people with epilepsy and their } \\
\text { parents during transition from } \\
\text { children's to adult services }\end{array}$ & $\begin{array}{l}\text { Qualitative } \\
\text { comparative } \\
\text { embedded case study }\end{array}$ & $\begin{array}{l}\text { Knowledge, information } \\
\text { needs, and } \\
\text { communicational skills in } \\
\text { transitional services for } \\
\text { adolescents with epilepsy }\end{array}$ \\
\hline $\begin{array}{l}\text { Kuchenbuch et al. } \\
\text { (2013) }\end{array}$ & $\begin{array}{l}\text { Transition and transfer from } \\
\text { pediatric to adult health care in } \\
\text { epilepsy: a families' survey on } \\
\text { Dravet syndrome }\end{array}$ & Survey & $\begin{array}{l}\text { Process and satisfaction of } \\
\text { transitional care for } \\
\text { children with DS }\end{array}$ \\
\hline $\begin{array}{l}\text { Parachuri and } \\
\text { Inglese }^{20}(2013)\end{array}$ & $\begin{array}{l}\text { Neurological problems in the } \\
\text { adolescent population }\end{array}$ & Not available & Not available \\
\hline $\begin{array}{l}\text { Camfield and } \\
\text { Camfield }^{44}(2013)\end{array}$ & $\begin{array}{l}\text { Help youth with epilepsy to } \\
\text { become competent and happy } \\
\text { adults: Transition care }\end{array}$ & Editorial & $\begin{array}{l}\text { Editorial (1page) referring } \\
\text { to Iyer and Appleton }{ }^{11}\end{array}$ \\
\hline $\begin{array}{l}\text { Iyer and Appleton }{ }^{11} \\
\text { (2013) }\end{array}$ & $\begin{array}{l}\text { Transitional services for } \\
\text { adolescents with epilepsy in the } \\
\text { UK: A survey }\end{array}$ & Survey & $\begin{array}{l}\text { Presence and methods of } \\
\text { a transition care for } \\
\text { adolescents with epilepsy }\end{array}$ \\
\hline
\end{tabular}


Table 2.1 (continued)

\begin{tabular}{|c|c|c|c|}
\hline Author(s) (year) & Title & Study design & Topic \\
\hline $\begin{array}{l}\text { Camfield et al. } \\
\text { (2013) }\end{array}$ & $\begin{array}{l}\text { Transition from pediatric to adult } \\
\text { epilepsy care: a difficult process } \\
\text { marked by medical and social } \\
\text { crisis }\end{array}$ & Review & $\begin{array}{l}\text { Review importance of } \\
\text { transitional care in } \\
\text { children with epilepsy }\end{array}$ \\
\hline $\begin{array}{l}\text { Kossoff et al. } \\
\text { (2013) }\end{array}$ & $\begin{array}{l}\text { Transitioning pediatric patients } \\
\text { receiving ketogenic diets for } \\
\text { epilepsy into adulthood }\end{array}$ & Case series/study & $\begin{array}{l}\text { Studying process of } \\
\text { transition to adult care in } \\
\text { children with ketogenic } \\
\text { diet }\end{array}$ \\
\hline $\begin{array}{l}\text { Camfield et al. } \\
\text { (2012) }\end{array}$ & $\begin{array}{l}\text { Helping families cope with the } \\
\text { devastation of Dravet syndrome }\end{array}$ & Review article & $\begin{array}{l}\text { Optimizing quality of life } \\
\text { during the different } \\
\text { developmental stages of } \\
\text { DS }\end{array}$ \\
\hline Khan et al. ${ }^{5}(2012)$ & $\begin{array}{l}\text { Transition of children with } \\
\text { epilepsies to adult care }\end{array}$ & Viewpoint article & $\begin{array}{l}\text { Describing transition to } \\
\text { adult care and developing } \\
\text { a framework for transition }\end{array}$ \\
\hline $\begin{array}{l}\text { McRandal et al. } \\
\text { (2012) }\end{array}$ & $\begin{array}{l}\text { Young person's epilepsy transition } \\
\text { clinic }\end{array}$ & $\begin{array}{l}\text { Letter to the editor ( } 1 \\
\text { page) }\end{array}$ & $\begin{array}{l}\text { Describing a transition } \\
\text { clinic for adolescents with } \\
\text { epilepsy in Nottingham } \\
\text { Childrens Hospital }\end{array}$ \\
\hline Schultz $^{12}$ (2012) & $\begin{array}{l}\text { Parental experiences transitioning } \\
\text { their adolescent with epilepsy and } \\
\text { cognitive impairments to adult } \\
\text { health care }\end{array}$ & $\begin{array}{l}\text { Qualitative grounded } \\
\text { theory study. }\end{array}$ & $\begin{array}{l}\text { Developing a grounded } \\
\text { theory by evaluating the } \\
\text { experience of transition to } \\
\text { adult care }\end{array}$ \\
\hline $\begin{array}{l}\text { Shanske et al. }{ }^{19} \\
\text { (2012) }\end{array}$ & $\begin{array}{l}\text { Social workers as transition } \\
\text { brokers: facilitating the transition } \\
\text { from pediatric to adult medical } \\
\text { care }\end{array}$ & Review & $\begin{array}{l}\text { Reviewing the benefit of } \\
\text { social workers during } \\
\text { transition to adulthood }\end{array}$ \\
\hline $\begin{array}{l}\text { Camfield et al. }{ }^{18} \\
\text { (2011) }\end{array}$ & $\begin{array}{l}\text { Strategies for transitioning to } \\
\text { adult care for youth with Lennox- } \\
\text { Gastaut syndrome and related } \\
\text { disorders }\end{array}$ & $\begin{array}{l}\text { Review } \\
\text { Survey }\end{array}$ & Transition in LGS \\
\hline Douglass $^{50}(2011)$ & $\begin{array}{l}\text { Introduction: Transitioning care } \\
\text { for adults with Lennox-Gastaut } \\
\text { syndrome: challenges and } \\
\text { promises }\end{array}$ & Editorial & $\begin{array}{l}\text { Supplement on Camfield } \\
\text { et al. }{ }^{18}\end{array}$ \\
\hline $\begin{array}{l}\text { Rodenburg et al. } \\
\text { (2011) }\end{array}$ & $\begin{array}{l}\text { Psychosocial issues for children } \\
\text { with epilepsy }\end{array}$ & Review & $\begin{array}{l}\text { Reviewing psychosocial } \\
\text { issues in children with } \\
\text { epilepsy }\end{array}$ \\
\hline Kerr et al. ${ }^{29}(2011)$ & $\begin{array}{l}\text { Evolution and management of } \\
\text { Lennox-Gastaut syndrome } \\
\text { through adolescence and into } \\
\text { adulthood: are seizures always the } \\
\text { primary issue? }\end{array}$ & Review article & LGS \\
\hline Lewis et al. ${ }^{2}(2010)$ & $\begin{array}{l}\text { Knowledge and information needs } \\
\text { of young people with epilepsy and } \\
\text { their parents: Mixed-method } \\
\text { systematic review }\end{array}$ & $\begin{array}{l}\text { Mixed-method } \\
\text { systematic review }\end{array}$ & $\begin{array}{l}\text { Information needs for } \\
\text { youth in transition }\end{array}$ \\
\hline $\begin{array}{l}\text { Jurasek et al. }{ }^{13} \\
(2010)\end{array}$ & $\begin{array}{l}\text { Development and implementation } \\
\text { of an adolescent epilepsy } \\
\text { transition clinic }\end{array}$ & Descriptive article & Transition clinic \\
\hline
\end{tabular}


Table 2.1 (continued)

\begin{tabular}{|c|c|c|c|}
\hline Author(s) (year) & Title & Study design & Topic \\
\hline Wu et al. ${ }^{17}(2010)$ & $\begin{array}{l}\text { Quality of life and related factors } \\
\text { in Chinese adolescents with active } \\
\text { epilepsy }\end{array}$ & Case-control study & $\begin{array}{l}\text { Quality of life in } \\
\text { adolescents with epilepsy } \\
\text { in China }\end{array}$ \\
\hline Asato et al. ${ }^{3}$ (2009) & $\begin{array}{l}\text { Adolescent and caregiver } \\
\text { experiences with epilepsy }\end{array}$ & $\begin{array}{l}\text { Cross-sectional online } \\
\text { survey }\end{array}$ & $\begin{array}{l}\text { Studying epilepsy and } \\
\text { related conditions and } \\
\text { issues in adolescents with } \\
\text { epilepsy }\end{array}$ \\
\hline $\mathrm{Mu}^{41}(2008)$ & $\begin{array}{l}\text { Transition experience of parents } \\
\text { caring of children with epilepsy: a } \\
\text { phenomenological study }\end{array}$ & $\begin{array}{l}\text { Phenomenological } \\
\text { study }\end{array}$ & $\begin{array}{l}\text { Transition experience } \\
\text { from parental perspective } \\
\text { in Taiwan }\end{array}$ \\
\hline Ellingford ${ }^{38}(2006)$ & $\begin{array}{l}\text { Short report: refocusing transition } \\
\text { clinics }\end{array}$ & Short report (1 page) & $\begin{array}{l}\text { Short report ( } 1 \text { page) } \\
\text { about transitional services } \\
\text { in general }\end{array}$ \\
\hline Glauser $^{30}(2004)$ & $\begin{array}{l}\text { Following catastrophic epilepsy } \\
\text { patients from childhood to } \\
\text { adulthood }\end{array}$ & Review & $\begin{array}{l}\text { Specific problems in } \\
\text { Infantile spasms, LGS, and } \\
\text { progressive myoclonic } \\
\text { epilepsies }\end{array}$ \\
\hline Smith et al. ${ }^{37}(2002)$ & $\begin{array}{l}\text { A teenager epilepsy clinic: } \\
\text { observational study }\end{array}$ & Observational study & $\begin{array}{l}\text { Describing patients } \\
\text { visiting a transition clinic } \\
\text { for epilepsy }\end{array}$ \\
\hline $\begin{array}{l}\text { Reeve and Lincoln } \\
\text { (2002) }\end{array}$ & $\begin{array}{l}\text { Coping with the challenge of } \\
\text { transition in older adolescents } \\
\text { with epilepsy }\end{array}$ & $\begin{array}{l}\text { Between-group } \\
\text { analysis with } \\
\text { questionnaire }\end{array}$ & $\begin{array}{l}\text { Psychological adjustment } \\
\text { Coping }\end{array}$ \\
\hline Nordli $^{31}$ (2001) & $\begin{array}{l}\text { Special needs of the adolescent } \\
\text { with epilepsy }\end{array}$ & Review & $\begin{array}{l}\text { Most common types of } \\
\text { epilepsy and common } \\
\text { issues during adolescence } \\
\text { in patients with epilepsy }\end{array}$ \\
\hline Appleton $^{51}$ (2001) & $\begin{array}{l}\text { Transition from paediatric clinic to } \\
\text { the adult service }\end{array}$ & Opinion & $\begin{array}{l}\text { Opinion ( } 1 \text { page) about } \\
\text { transitional services in } \\
\text { epilepsy }\end{array}$ \\
\hline $\begin{array}{l}\text { Austin et al. }^{42} \\
(2000)\end{array}$ & $\begin{array}{l}\text { Childhood epilepsy and asthma: } \\
\text { changes in behavior problems } \\
\text { related to gender and change in } \\
\text { condition severity }\end{array}$ & Comparative study & $\begin{array}{l}\text { Comparing behavioral } \\
\text { problems in epilepsy and } \\
\text { asthma }\end{array}$ \\
\hline Warnell $^{15}$ (1998) & $\begin{array}{l}\text { The transition experience of } \\
\text { epilepsy patients/families: results } \\
\text { of a telephone survey }\end{array}$ & Survey & Transitional experience \\
\hline $\begin{array}{l}\text { Appleton et al. }{ }^{4} \\
\text { (1997) }\end{array}$ & $\begin{array}{l}\text { Managing the teenager with } \\
\text { epilepsy: paediatric to adult care }\end{array}$ & Observational study & Transition clinic \\
\hline
\end{tabular}

AED = antiepileptic drugs, BECTS = benign epilepsy with centrotemporal spikes, NLFN = nonlesional focal epilepsy in otherwise normal children, CAE = childhood absence epilepsy, JME = juvenile myoclonic epilepsy, ECSWS = epileptic encephalopathy with continuous diffuse spike-waves during slow-wave sleep, LGS = Lennox-Gastaut syndrome, TSC = tuberous sclerosis complex, SWS = Sturge-Weber syndrome, RE = Rasmussen encephalitis, DS = Dravet syndrome. 


\section{Results}

With this search, we found 49 articles about transition from pediatric to adult care in children and adolescents with epilepsy. Transition has received increasing attention during recent years: thirty-nine of the forty-nine manuscripts were published during the last five years. Recently, Epilepsia published a special issue (Transition of Epilepsy Care from Children to Adults) emphasizing the importance of transition to adult care. All identified articles and their topics and study designs are shown in Table 2.1.

In total, we found 23 reviews regarding several important subjects during transition. For example, Chiron and $\mathrm{An}^{21}$ discussed AED treatment. Transitional issues in specific epilepsy syndromes are described by Scheffer and Dravet ${ }^{22}$, Camfield et al. ${ }^{18,23-25}$, de Saint-Martin et al. ${ }^{26}$, Thiele et al. $^{27}$, Kossoff et al. $^{28}$, Kerr et al. ${ }^{29}$, Glauser $^{30}$, and Nordli $^{31}$.

Psychosocial problems during transition were reviewed by Beghi et al. ${ }^{8}$, Camfield and Camfield ${ }^{7}$, Thomson et al. ${ }^{9}$, Schor ${ }^{32}$, and Rodenburg et al. ${ }^{33}$

Nashef et al. ${ }^{34}$, Cross and Duchowny ${ }^{35}$, and Kossoff et al. ${ }^{36}$ addressed specific adolescent issues, namely, driving and exercise, epilepsy surgery during transition, and the ketogenic diet during transition.

The first observational study about an epilepsy transition clinic was written by Appleton et al. ${ }^{4}$ in 1997, followed by Smith et al. ${ }^{37}$, Ellingford ${ }^{38}$, Jurasek et al. ${ }^{13}$, and McRandal et al. ${ }^{39}$ The importance of transition clinics was reviewed by Carrizosa et al. $^{40}$, Camfield et al. ${ }^{16}$, Khan et al. $^{5}$, Shanske et al. ${ }^{19}$, and Lewis et al. ${ }^{2}$

Several surveys were identified, about satisfaction and experiences of the transitional care (Kuchenbuch et al. $^{10}$, Asato et al. $^{3}, \mathrm{Mu}^{41}$, Schultz ${ }^{12}$, and Warnell ${ }^{15}$ ), and the number or methods of transition clinics (Iyer and Appleton ${ }^{11}$, and Borlot et al. ${ }^{6}$ ).

Comparative studies on coping strategies and behavioral and psychological problems comparing adolescents with epilepsy to patients with other chronic illnesses were conducted by Reeve and Lincoln ${ }^{14}$, Austin et al. ${ }^{42}$, and Ferro. ${ }^{43}$

Because heterogeneity in subject and methodological quality existed, neither a metaanalysis nor a systematic review or analytical framework analysis was possible.

In summary, only limited quantitative data about transition from pediatric to adult care were available from the adult neurologists perspective. Risk of bias is present since retrieved articles often referred to studies also allocated with our search (e.g., Camfield et al. ${ }^{18}$ referred to Jurasek et al. ${ }^{13}$ and Appleton et al. ${ }^{4}$ Furthermore, Camfield and Camfield ${ }^{44}$ referred to lyer and Appleton ${ }^{11}$ and Appleton et al. ${ }^{4}$ )

We aimed to study transition from adolescence to adulthood and to evaluate transitional services in patients with epilepsy. We identified and reviewed the following three major subjects among the retrieved articles: first, epilepsy-related personal, psychosocial, and environmental issues during transition and their longterm individual and societal consequences; second, the medical transition process and transition care; and third, barriers for medical transition from pediatric to adult care. 
To the best of our knowledge, this is the first review giving a complete overview of psychosocial, medical, and societal problems during transition, transitional care, and barriers for medical transition.

\section{Epilepsy-related personal, psychosocial, and environmental issues during transition and their long-term individual and societal consequences}

Transition is defined as a complex and multidimensional process in which the individual gradually moves from a child being cared for to an independent and autonomous young adult with his or her own responsibilities. ${ }^{6,10,16,45}$ During transition to adulthood, adolescents are expected to integrate into society and become completely independent. ${ }^{5}$ This period is especially demanding for adolescents with chronic illnesses, e.g., childhood-onset epilepsy, as the disease itself or cognitive, behavioral, or psychological comorbidities interfere with normal age-specific development. 8

However, having a childhood-onset epilepsy is not the only risk factor leading to poor psychosocial outcome, and long-term outcome cannot be predicted by the epilepsy syndrome alone. ${ }^{7}$ Even remission of epilepsy is no guarantee for better long-term outcome, and continuity of care should also be provided for patients with epilepsy in remission. ${ }^{1,7,8,11,26,40,46}$ Camfield et al. ${ }^{23}$ state that long-term psychosocial outcome of children with benign epilepsy with centrotemporal spikes (BECTS) equals that in the healthy population. Sixty-seven percent of patients with nonlesional focal epilepsy in otherwise normal children (NLFN) have poor social outcomes in terms of educational and vocational status, psychiatric disorders, and social interaction. In addition, De

Saint-Martin et al. ${ }^{26}$ found that transition of patients with epileptic encephalopathy with continuous diffuse spike-wave sleep (ECSWS) depends on the etiology and duration of epilepsy and cognitive and behavioral comorbidities.

Seizure control should not be the only focus during transition, but adequate support for nonmedical concerns is equally important. ${ }^{2,8,12,16,29,33,37,45}$ A few domains which deserve attention in adolescents with epilepsy are, for example, psychosocial functions (e.g., emotional functions, participation in daily life by getting educated and employed), environmental factors (e.g., social support, stigma, peer acceptance), and personal factors (e.g., autonomy, self-acceptance, coping strategies, and adaptive behavior). ${ }^{7,9,16}$

\section{Academic and vocational achievement}

Children with epilepsy, even those without intellectual disabilities, are at risk for academic underachievement. For example, cognitive and behavioral disorders and interactive psychosocial factors can be either causes or consequences of academic 
underachievement. Proper education is important not only for entry into higher education and subsequent employment but also for developing self-esteem and independence. $8,29,33$

Camfield and Camfield ${ }^{7}$ compared Finnish, Japanese, Dutch, and Canadian (Nova Scotia) studies to review social outcome for patients with epilepsy and normal intelligence. Although no clear consistency was found among these studies, patients with epilepsy, even those without intellectual disabilities, are at risk for academic underachievement and higher unemployment and underemployment rates, with subsequently lower financial means, more frequent substance use, and social isolation.

\section{Intellectual disability}

Not only devastating encephalopathies but also 'benign' spectrum childhood epilepsies can suppress one's intellectual capacity. ${ }^{8}$ Intellectual disability is associated with behavioral problems, and both phenomena are more common among children with epilepsy compared to children with other chronic conditions. ${ }^{42}$ It is hypothesized that seizures, adverse effects of antiepileptic drugs (AEDs), or a primary underlying brain network dysfunction induce learning disabilities and behavioral problems. ${ }^{8}$ Both have major consequences for the adolescents development by influencing peer relationships and housing, impairing self-esteem, independency, and autonomy, and limiting educational and thereby vocational opportunities. ${ }^{9}$

Although many adult patients still live at home with their parents, early decisions concerning living arrangements and financial guardianship are recommended, because patients tend to outlive their parents. ${ }^{24}$

\section{Psychiatric disorders}

Patients with epilepsy have a greater risk of psychopathology compared to healthy peers or patients with other chronic illnesses (e.g., asthma or diabetes). ${ }^{29,33,42,43}$ Ferro ${ }^{43}$ conducted a 10 -year follow-up longitudinal study to investigate psychological distress during transition from adolescence to adult care in patients with asthma, patients with epilepsy, and healthy controls. In adolescents with epilepsy, psychological distress was constantly present, but highest immediately after transition to adult care. A probable explanation is that adolescents with epilepsy have insufficient coping strategies to deal with the physical and social consequences of epilepsy during transition to adulthood..$^{29,42,43}$

Rates of internalizing problems (e.g., anxiety, depression) are indeed relatively high among adolescents with epilepsy, compared to externalizing problems (e.g., aggression). ${ }^{9,29,33,42}$ However, mood and behavioral disorders are probably underrated in adolescents with epilepsy, as, especially those with intellectual disability may present with atypical symptoms. ${ }^{29,33}$ 
In relation to gender, Austin et al. ${ }^{42}$ found that girls with high seizure severity were most likely to have behavioral problems at baseline and after a 4-year follow-up. Austin et al. ${ }^{42}$ suggest that poor coping strategies, increased social stigma, and negative self-esteem may increase the risk of behavioral problems.

\section{Stigma}

Feeling accepted is very important to adolescents, and stigma against people with epilepsy is a worldwide problem. ${ }^{17,29}$ Even after adequate seizure control is achieved, the consequences of stigma may persist. ${ }^{29}$

Lack of knowledge of epilepsy and its unpredictable nature may cause stigma and rejection by peers. ${ }^{2,9,39}$ Subsequently, rejection negatively influences social interaction and thereby self-esteem and self-identity. ${ }^{7,14,29}$ As a consequence of poor interaction with peers, adolescents with epilepsy might end up in social isolation, leading to increased risk for depressive mood disorders. ${ }^{1,9} \mathrm{Wu}$ et al. ${ }^{17}$ recognized that social support is impaired in patients with epilepsy, but the degree of stigma also depends on society's cultural background. Evidence is conflicting, however, as Reeve and Lincoln ${ }^{14}$ found no significant difference in self-esteem when they compared patients with epilepsy aged 16-21 years with healthy controls.

Providing information about epilepsy to patients, their family, and society can decrease stigma and increase understanding of epilepsy. ${ }^{2,33,39,41}$ Improving social interaction by meeting peers increases social support and thereby decreases related mood and anxiety disorders. ${ }^{2,13,18}$

Parental authority and restrictions on daily activities can also increase stigma. By reducing authority and restrictions on adolescents, parents can play a role in protecting their child from stigma and consequential psychosocial problems. ${ }^{3}$

\section{Family environmental problems}

The unpredictability of epilepsy, its comorbidities, and its demanding care tend to affect the patient's entire family. ${ }^{29,33}$ Environmental problems (e.g., relational and parenting problems, social isolation) are more common among families of a child with epilepsy compared to other chronic illnesses. ${ }^{25,29,33}$ Besides, parenting plays an important role in many psychosocial domains of children with epilepsy, but the relationship between the child's issues and family is bidirectional. ${ }^{33,39,41}$ Schultz $^{12}$ studied these complex and widespread interactions between parents, cognitively impaired adolescents with epilepsy, and the health-care system during the years of transition. She developed a theoretical model in which the interactions between five major parental reactions, the adolescent's epilepsy, and the health-care system are intertwined. The main result regarding transition is that an adolescent's medical or social transitional problems impair parental coping strategies. If no adequate support for this stress is given by health-care providers, parents may feel rejected by the health-care system. As a result, transition to adult care is often further postponed, 
and finally takes place unplanned when a certain patient's age limit is reached. Moreover, parents experiencing insufficient support tend to overprotect their child. As mentioned before, overprotection can increase stigma. Therefore, support must not be restricted to patients only, as parental stress and coping strategies are important aims for future interventions to prepare patients and their families to accept a lifelong chronic disability. ${ }^{27,33}$

\section{Coping strategies}

Epilepsy and its associated conditions also interfere with a patient's coping strategies. ${ }^{14,33,42}$ Reeve and Lincoln ${ }^{14}$ conducted a study comparing coping styles and psychological adjustment between adolescents with epilepsy and healthy controls. Patients with epilepsy showed more nonproductive coping compared to controls, but no significant between-group difference was found on psychological adjustment. However, psychological adjustment was related to coping in the patient's group, meaning a stressful situation (e.g., transition, learning problems, or peer pressure) causes maladaptive coping in patients with epilepsy. ${ }^{14}$

\section{The medical transition process}

Adolescence in patients with chronic disease is also marked by the process of closing pediatric care and the start of adult care. In contrast to transition, transfer is the single handing over of care, often accompanied by a referral letter, and can be a part of the transition process. ${ }^{12,18}$ This transfer from pediatric to adult care has shortcomings and often provides adult neurologists with insufficient information about the patient's past and current medical conditions. ${ }^{32,45,47}$ Subsequently, discontinuity of required health care may lead to irreversible medical, social, and societal problems. ${ }^{40}$ Although transitional services have been described to provide continuity of care and ease the process of transition in children with chronic disease (e.g., diabetes, asthma), only limited information is available for children with epilepsy. Different models and definitions of transition care have been described. ${ }^{4-}$ $6,11,13,37,40$ The objectives of transition care include assessment of psychosocial and medical conditions and provision of adequate information and interventions or skills training. ${ }^{9}$

\section{Organization and staffing}

Transitional services have been described in tertiary pediatric or specialized epilepsy centers and children's hospitals. ${ }^{10,11,13,40}$ In literature, the staffing of such a transition clinic differs, ranging from an individual or combined adult and pediatric neurologist or epileptologist or with a pediatrician, pediatric and adult epilepsy nurse specialists, 


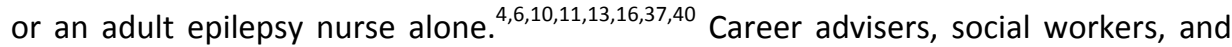
psychologists were available in pediatric and adult settings. ${ }^{10,11,19}$ Although different models have been described, Kuchenbuch et al. ${ }^{10}$ state the staffing was comparable in pediatric, adult, or joint transition clinics. ${ }^{10,40}$

Khan et al. ${ }^{5}$ and Camfield et al. ${ }^{16}$ stated that transition care should be initiated within the pediatric setting, with pediatric input continued for a time in concert with the adult health-care worker at the point of transition. The presence of a familiar pediatrician should provide continuity of care, and medical and mental issues can be revisited from both the pediatric and adult perspectives. ${ }^{4-6,13,16,18,40}$

Appleton et al. ${ }^{4}$ advised to involve a nurse specialist, as a nurse is often considered to be more approachable compared to a physician, and nurses have the ability to visit patients at different times and settings which might promote interaction.

The role of a social worker is also considered beneficial. The social worker has specific knowledge about psychosocial problems, environmental interactions, and required supportive interventions. A social worker can provide adequate information and guidance for financial support, family dynamics and system issues, and is of added value for patients and relatives who usually seek information in support groups. ${ }^{12,19}$ Except for the abovementioned health-care specialists, some patients require multidisciplinary medical examination or treatment by referral to physiotherapists, dieticians, occupational therapists, psychiatrists, and genetic counseling or neurologic subspecialties, such as behavioral specialists or sleep specialists. ${ }^{6,24}$

\section{Patient characteristics, timing of transition and follow-up}

Different opinions are found about the timing of transitioning. Appleton et al. ${ }^{4}$ conducted a data analysis of a transition clinic in a children's hospital and described a mean age of 16.3 years (12.8-21) at the time of referral to the clinic. In McRandal et al.'s ${ }^{39}$ Teenage Epilepsy Clinic, the age limit is a minimum of 12 years until the age they are ready to be transferred to adult care. In the Epilepsy Transition Program of Borlot et al. ${ }^{6}$, patients were transferred to adult care when they turned 18 years. Jurasek et al. ${ }^{13}$ and Khan et al. ${ }^{5}$ advise to transfer patients from pediatric to adult care at the maximum age of 17 , but keeping in mind that the transition process had no strict age limitations due to developmental disabilities of the child with epilepsy. $^{4,5,13,15,39}$

Camfield et al. ${ }^{16}$ advise that preparation for transition should begin as early as possible in children with severe and chronic epilepsy, e.g., Lennox-Gastaut syndrome, since transition and early arrangements for guardianship, for example, are inevitable. ${ }^{24}$ Kuchenbuch et al. ${ }^{10}$ state that the preparation for transition should begin at the age of 12 years in chronic disease. In addition, they found that children with high seizure frequency were more likely to make a delayed transition between healthcare providers, but statistical significance was not reached. 
Appleton et al. ${ }^{4}$ found that at the age of 18 years, $58 \%$ of the patients were transferred to an adult neurologist, whereas $27 \%$ were in follow-up in the transition clinic and $8 \%$ had been discharged to a general practitioner (GP).

Most children with epilepsy were either transferred to adult care with infrequent follow-up or remain under the care of a pediatrician, often with more frequent visits compared to adult health services. ${ }^{5,12}$ In the transition clinic of Appleton et al. ${ }^{4}$, patients were seen every two months in an adult neuroscience unit, whereas lyer and Appleton ${ }^{11}$ found that the frequency of visits ranged from monthly to every four months in tertiary paediatric centers. In contrast, Kuchenbuch et al. ${ }^{10}$ found no statistical difference in follow up in patients with Dravet syndrome, visiting the pediatrician every $4.8( \pm 2.5)$ months compared to $6.1( \pm 3.2)$ visits in an adult follow up setting in a special center for rare diseases.

\section{Revision of previously made diagnosis}

One of the characteristics of childhood-onset epilepsy is that it may remit, continue, or relapse during adolescence or adulthood. ${ }^{7,37}$ In some epilepsy syndromes, seizure presentation may change over time. ${ }^{8,30}$ Lately, advanced diagnostic imaging have developed, increasing genetic etiologies have been found, and new AED treatment may have become available since many patients had their last reassessment. For that reason, revision of previously made epilepsy diagnosis, underlying cause, and treatment is beneficial. ${ }^{22,24,46}$

Smith et al. ${ }^{37}$ collected retrospective clinical data from 207 referred patients with epilepsy or suspicion of epilepsy in a transition clinic of a university hospital and found that in the great majority (84\%) of patients, the previously made diagnosis of epilepsy or seizures was correct. Percentages of correctly classified epilepsy syndromes were not represented. In thirty patients (14\%), the previously made diagnosis was rejected, which equals the $10 \%$ found in Appleton's et al.'s ${ }^{4}$ transition clinic. Patients were either diagnosed with another epilepsy syndrome, or, in 10\%, diagnosed with nonepileptic disorders, and $4 \%$ were misdiagnosed with epilepsy. ${ }^{4}$ Misdiagnosis has major consequences for ones life, not only in the long term but also in restriction of daily activities. $^{34}$

\section{AED treatment}

Optimizing AED treatment during transition is highly recommendable. ${ }^{21}$ Smith et al. ${ }^{37}$ found that $80 \%$ of the patients were considered to be taking adequate antiepileptic medication at the time of referral. Smith et al. ${ }^{37}$ and Camfield et al. ${ }^{16}$ found that AED treatment was optimized in 20 and 35\%, respectively, either by adding medication, by withdrawing medication, or by replacing type or dose of the prescription.

Several retrospective studies have been conducted to evaluate AED treatment, with most focusing on a specific epilepsy syndrome and are therefore not comparable to more common and less severe epilepsies. ${ }^{21,23}$ 
For several reasons, medication compliance is one of the key issues during adolescence. ${ }^{29,31}$ Interactions with other prescribed drugs and cosmetic, cognitive, and behavioral adverse events of AEDs contribute to noncompliance., $318,21,29-31$ Noncompliance is associated with lower self-esteem and more restrictions on daily activities. $^{31}$

In Asato et al.'s ${ }^{3}$ survey, about a third of the adolescents (35\%) reported missing AEDs at least once last month, and $55 \%$ reported completely missing or even stopping an AED at some point in time. In 70\%, forgetfulness or not having the pills with them was the reason for not taking the prescription. Other reasons for noncompliance were as follows: caregiver-related issues (15\%), not considering themselves of having symptoms (15\%), adverse effects (9\%), and social issues (5\%). About $7 \%$ of the patients found it unimportant to take medication frequently. In the vast majority, the caregiver was responsible for compliance, with the adolescent mostly self-responsible in a lesser extent. Noncompliance in self-responsible adolescents might be underreported in trials, as epilepsy is significantly more often accompanied by comorbidities, e.g., intellectual disabilities or behavioral problems. ${ }^{3,18,30}$

Except from the abovementioned side effects, interaction with oral contraceptives and potential teratogenicity of AEDs must be discussed when girls approach the childbearing age. ${ }^{31}$ Secondly, because of weight gain, pharmacokinetic properties change during adolescence, leading to suboptimal therapy by relatively lower serum levels of AEDs. ${ }^{29,31}$

\section{Epilepsy surgery}

If applicable, the opportunity for epilepsy surgery, expectations for the future, and chances for success must be discussed..$^{16,35,37}$ Early epilepsy surgery can reduce AED prescription and seizure frequency and improve postoperative intellectual abilities, thereby increasing education and vocational achievement, independence, and quality of life. However, epilepsy surgery has a great impact during adolescence, and the most ideal timing and long-term consequences for behavioral and psychiatric disorders remain unknown. ${ }^{35}$

\section{Ketogenic diet}

Special attention should be paid to continuing the high-fat, low-carbohydrate ketogenic diet, or, alternatively, the modified Atkins diet. Even though many patients are weaned of the diet after a few years, guidance by dieticians is advisable during the years of transition. ${ }^{28,36}$ 


\section{Need for health information regarding epilepsy and associated challenges}

Revision of psychosocial and medical conditions is equally important compared to providing adequate information. ${ }^{2,4,5,16,29,33,37}$ The need for health information and communication barriers are probably the most addressed issues in the reviewed literature. ${ }^{1}$ Information can unblock barriers for independence of the adolescent. ${ }^{2}$ Many epilepsy syndromes develop during childhood and evolve during adolescence. ${ }^{30}$ As information about epilepsy is often only provided to the caregiver during childhood, adolescents often have a lack of knowledge about their own illness and comorbid conditions. ${ }^{1,2,16,23,30}$ This may lead to misconceptions about epilepsy and AEDs, increased stigma and poor psychosocial and educational outcomes, and negative influence on quality of life over the long term. ${ }^{1,2,13,41}$ To improve selfacceptance of the patient's disabilities, information should be provided to both the parent and patient. ${ }^{27}$ Information, for example on new treatment and innovations, is nowadays provided not only by health-care workers but also by other resources, e.g., relatives and friends, social media, or the Internet.

Lewis et al. ${ }^{2}$ conducted a mixed-method systematic review about the process of information exchange between young patients with epilepsy and health-care professionals. Informing caregivers reduced fear of both seizures and transition and stimulated positive coping patterns leading to supportiveness, whereas insufficient knowledge led to parental restrictions in daily life, increased stigma, low selfconfidence, and poor psychosocial participation. . $^{216,29,31,41}$

Communication skills should be adjusted to adolescents and focused on the patient's point of view on epilepsy. ${ }^{1}$ Patients and relatives understanding the importance of epilepsy management and its related concerns are more able to make adequate decisions, thereby improving independence. ${ }^{2,13}$

Another obstacle in providing information to adolescents with epilepsy is that seizures are associated with concentration problems and memory impairment resulting in poor understanding and remembering important information. Information exchange is only effective when it is given repeatedly, relevant and individualized. ${ }^{2}$

Although parents should definitely be involved in the transition process, the presence of parents during the consultation is ambiguous: it can either be supportive or negative, e.g., adolescents often feel embarrassed when asking delicate questions about substance use and sexuality. 2,16,31,37,39

If health-care workers provide insufficient information, parents find networking with other parents and support groups the most reliable way to allocate community and funding resources. ${ }^{12}$ However, it is up to health-care providers to discuss and assess this wide range of psychosocial, medical, and lifestyle issues including management of comorbidities. The most common domains and subjects to assess are shown in Table 2.2. 
Table 2.2 The most important domains for information and social intervention during transition $^{2-6,9,11,13,18,21,23,24,27,29,34,36,37,39,45-47}$

\begin{tabular}{|c|c|}
\hline \multirow[t]{5}{*}{ Education and employment } & Education \\
\hline & Employment (e.g., protected environments) \\
\hline & Career opportunities \\
\hline & Job applications \\
\hline & Scholarships \\
\hline \multirow[t]{3}{*}{ Health and lifestyle issues } & Seizure triggers (e.g., sleep deprivation) \\
\hline & Interaction of AED's with alcohol and recreational drugs and risk of seizure \\
\hline & Dressing, feeding, mobility \\
\hline \multirow[t]{2}{*}{ Hobbies } & Sports and exercise (e.g., diving) \\
\hline & Daily activities \\
\hline \multirow[t]{14}{*}{$\begin{array}{l}\text { Epilepsy and self- } \\
\text { management }\end{array}$} & $\begin{array}{l}\text { Education about epilepsy diagnosis, prognosis and comorbidities (e.g., } \\
\text { SUDEP) }\end{array}$ \\
\hline & AED and side effects (e.g., weight, bone health, behavioral problems) \\
\hline & Psychiatric disorders (e.g., anxiety or mood disorders) \\
\hline & Change, withdrawal and interactions of AEDs or other prescriptions \\
\hline & Management of seizures, emergency plan \\
\hline & Appointments with therapists and doctors \\
\hline & Health maintenance \\
\hline & Self-administration of medication \\
\hline & Epilepsy surgery \\
\hline & Ketogenic diets \\
\hline & Vagus nerve stimulation \\
\hline & Genetic counseling \\
\hline & Self-acceptance \\
\hline & Autonomy, independence \\
\hline \multirow[t]{4}{*}{ Social } & Social support network \\
\hline & Attitudes of peers \\
\hline & Friends \\
\hline & Family involvement \\
\hline \multirow[t]{3}{*}{ Specific problems } & Driving regulations, transportation \\
\hline & Life choices, decision-making \\
\hline & $\begin{array}{l}\text { Syndrome-specific comorbid conditions (e.g., migraine, esthetic appearance } \\
\text { in Sturge-Weber syndrome) }\end{array}$ \\
\hline \multirow[t]{4}{*}{ Sexual } & Relationships \\
\hline & (Oral) contraception \\
\hline & (Teratogenicity of AED's during) pregnancy \\
\hline & Heredity of condition \\
\hline \multirow[t]{4}{*}{ Finance } & Financial independence \\
\hline & Health insurance \\
\hline & Need to establish guardianship \\
\hline & Cost of medication \\
\hline Housing & Housing and living environment (e.g., residential living) \\
\hline
\end{tabular}

\section{Availability, quality, and cost-effectiveness of transitional services}

Camfield et al. ${ }^{18}$ conducted a survey among attendees of an epilepsy symposium and found that over $10 \%$ of respondents, mainly pediatricians, were still treating adults with epilepsy. While in $11 \%$ of the respondents' health-care centers a transition clinic was present, $13 \%$ of the participants had used a transition clinic for their patients. 
Almost all neurologists experienced problems with transition, and about $40 \%$ of the health-care workers were satisfied.

The presence of transition programs often depends upon a nation's cultural background and financial resources. Transition programs are better implemented in developed countries because of funding. ${ }^{40}$ Iyer and Appleton ${ }^{11}$ conducted a survey and found an epilepsy transition clinic was present in fifteen of the responding eighteen pediatric neurology centers in the UK. Kuchenbuch et al. ${ }^{10}$ evaluated transition in a specialized center in France among a population of children with Dravet syndrome and found 20/51 (39\%) patients without and 31/51 (61\%) with transition experience in this particular patient group. Still, these data are rough estimates at best and the exact number of transition clinics and its involvement in patient care remain largely unknown. ${ }^{5}$

Borlot et al. ${ }^{6}$ conducted a survey among adult and pediatric neurologists and epileptologists to measure the comfort level of treating adolescents with childhoodonset epilepsy and comorbid conditions. Adult neurologists' comfort level in treating patients with typical childhood epilepsy conditions, e.g., epileptic encephalopathies and genetic syndromes, was significantly lower than that of adult or pediatric epileptologists and pediatric neurologists. For idiopatic generalized epilepsy and temporal lobe epilepsy, no significant difference was found. Even in treating patients with intellectual disabilities and autistic features the adult neurologists felt less confident compared to adult epileptologists ( $15.4 \%$ vs. $53.5 \%$ and $15.4 \%$ vs. $40 \%$ ). Adult neurologist epileptologists mentioned the need for support of medical healthcare professionals, for example psychiatrists or psychologists, occupational therapists, and nurse practitioners, in the management of adolescents with epilepsy.

Jurasek et al. $^{13}$ found that adolescents and their parents are satisfied by the implementation of a transition clinic and agreed that it lessened their fears of moving to adult care and improving their knowledge of adult issues. Kuchenbuch et al. ${ }^{10}$ found that $60 \%$ of the families of patients with Dravet syndrome were satisfied with the quality of preparation for transition to adult care. Higher satisfaction was found among patients aged at least 18 years and in otherwise good health and after longer follow-up duration in the pediatric setting with accessible health-care workers.

Khan et al. ${ }^{5}$ state continuity of health care during transition will be cost-effective at least in the short and medium term, as it may prevent frequent hospital care and improve unnecessary prescriptions. Unfortunately, no qualitative data are available to evaluate the effectiveness and costs benefits of a transition clinic. ${ }^{1,5,18}$ 


\section{Barriers for transition from pediatric to adult care}

Several patient-related and clinician-related barriers can constrain the process of transition from pediatric to adult care.

\section{Patient-related factors}

One of the most common barriers for the medical transition is the mutual relationship between parents, patients, and the pediatrician they have become familiar with during years of health care. ${ }^{6,10,18,22,27,45}$ Parents frequently refuse to leave the pediatrician for an adult health-care worker, while adolescents might feel uncomfortable in continuing health-care from a pediatric perspective. ${ }^{4,5,12,18,22,27,45}$ In some cases, pediatricians and family even agreed to remain under pediatric follow-up because of their long-term relationship. ${ }^{27}$ The most common opinion among parents is that adult health-care workers are not accessible and supportive and have a lack of time, resulting in disappointing quality of adult health care compared to the pediatric setting. ${ }^{5,10,18,27}$ Secondly, adult health-care workers' communication skills may not meet with the intellectual capacity of adolescents with epilepsy and other associated conditions. As a result, communication about epilepsy is often centered around the parents. If adolescents are not involved in discussion of their needs, they can be restrained from their development to independence. ${ }^{1,18}$

\section{Health-care-related factors}

Pediatric and adult health-care providers themselves experience roadblocks during transition to adult care, mainly due to lack of preparation for transition care. ${ }^{12}$ First, transfer from pediatric to adult care should incorporate referrals with extensive information about the patient's medical and personal history. ${ }^{47}$

According to Kuchenbuch et al. ${ }^{10}$, pediatric health-care workers often presume that adult health-care providers have insufficient knowledge about the adolescent's specific condition. Indeed, not all adult neurologists feel familiar with childhood-onset epilepsies. ${ }^{45}$ Besides, adult neurologists often feel they have insufficient training in child neurology to communicate with and care for young adults with chronic neurological conditions and related cognitive impairment, whereas pediatricians lack knowledge of adult problems and concerns. ${ }^{6,18}$ There is a limited number of adult health-care workers who had specific training to deal with the needs of youth with epilepsy. $^{6,32,40}$ Insufficiently trained adult health-care workers and lack of multidisciplinary transition clinics result in long waiting lists. ${ }^{10,18}$

Insurance or financial support is mentioned as a barrier for transition, but the access to transitional care is dependent upon the national health-care system. ${ }^{12,40}$ 


\section{Discussion}

Transition in epilepsy is different from other childhood-onset chronic illnesses. ${ }^{5,12}$ Intellectual disabilities, behavioral disorders, and psychiatric disorders are more common among patients with epilepsy compared to patients with other childhoodonset chronic illnesses or healthy controls. ${ }^{5}$ In addition, epilepsy and its associated conditions may interfere with brain maturation and postpone cerebral development. ${ }^{9,48}$ The child with epilepsy may achieve independence and selfmanagement at a later age than their healthy peers. ${ }^{5,11,12}$ It is not the child's age but rather developmental maturity that determines the process of transition into adulthood. ${ }^{13,48,49}$ For these reasons, children with epilepsy should be treated differently by health-care professionals in order to meet their specific needs. ${ }^{5,11,12}$ Since transition is a gradual process, it can take many years to transfer a child from pediatric to adult care, instead of a one-time handing over. ${ }^{45,49}$

Transitional problems occur along all domains (medical, psychological, social, economic, and environmental), and nonmedical support during the years of transition is clearly insufficient for patients and their caregivers. ${ }^{1,22-24,26,49}$ Although the evidence is conflicting, in our opinion, transitional care is preferable for all patients with childhood-onset epilepsies, regardless of their pathophysiology or current medical state. We hypothesize that early intervention for epilepsy-related personal, psychosocial, and environmental issues during transition can improve long-term individual and societal outcome. Applied medical and nonmedical support, tailored interventions, and skills training can improve coping strategies, educational and vocational achievements, and thereby self-acceptance, independence, and peer acceptance. $^{23,27,49}$

Transition to adult health care is currently unorganized and inconsistent. ${ }^{12,33}$ The most desirable model and the exact number of transition clinics for children with epilepsy remain unknown. ${ }^{5,11,12,32,39,40,46}$ Childhood-onset epilepsy is a diverse and complex condition associated with several comorbidities, and multidisciplinary care involving both pediatric and adult professionals is advisable. ${ }^{24,29,46}$ The advice and applied interventions should be tailored to one's specific health needs and depend on the patient's epilepsy syndrome and management of associated medical, psychosocial, and mental health issues. ${ }^{27}$ However, despite the agreement about its benefits, the number of transition clinics seems clearly insufficient. $5,11,12,32,39,40,46$

Before implementation of transition care, several health-care-related barriers for transition have to be overcome. Communication and collaboration between pediatric and adult health-care workers have to be optimized to improve transfer and other aspects of transition. Thereafter, increasing the number of transitional services will change the organization of the health-care system, resulting in a shift of responsibility towards other health-care workers. Nowadays, most transition care is provided by 
tertiary epilepsy clinics, and to widely implement transition programs, secondary hospitals should be able to do so. ${ }^{40}$ The question is whether sufficient pediatric and adult resources are available to organize transition care in chronic epilepsy. ${ }^{6,11,18,37}$ The capacity of specialists should be optimized to overcome long waiting lists. ${ }^{18}$

In some countries, the GP plays an important coordinating role in the treatment of patients. Transition care can then rather easily refer patients back to the GP but only in those cases where continuity of specialized care is no longer necessary, since a GP cannot be expected to treat patients with epilepsy with complex conditions. On the other hand, patients and their family need to know when help is needed. ${ }^{40}$

An important aspect of health-care is health-care technology. Health-care technology has to be improved to ensure that the optimal transition care is reflected by the patient file management. Cloud computing technology is well suited for document and file sharing and even joint data file editing with all major stakeholders in the care process. However, this should be combined with secure data protection and rules for document ownership and access rights. The patient should become the owner of his data, and the care professional should access his data in a transparent and traceable way, so that the patient can observe who has accessed and used his records. This will allow the optimal distribution and coordination of care tasks for patients with epilepsy, while the patient himself is a center point in the data management.

Although we consider transition care as beneficial, no evaluations have been made so far. The effectiveness and cost benefits of joint clinics and applied interventions remain unknown. ${ }^{1,40,49}$ Risk factors for poor psychosocial and medical outcome, effectiveness of interventions, the most desirable model for transition care, and cost benefits in the long-term have to be evaluated. More longitudinal research is necessary to develop a protocol for transitional care.

\section{Appendix A}

(((epilepsy[MeSH] OR epilepsy[TW] OR epileps*[TW] OR epilept*[TW] OR seizure[MeSH] OR seizure[TW] OR convulsion[MeSH] OR convulsion[TW] OR convulsion*[TW]) AND (("Transition to Adult Care"[Mesh] OR transition[TW] OR transition*[TW]) OR (((paediatric[TW] OR pediatric[TW]) OR (adolescen*[TW] OR teenage*[TW] OR teen[TW] OR teens[TW] OR youth[TW] OR youths[TW] OR underage*[TW] OR junior school*[TW] OR junior high*[TW] OR middle school*[TW] OR high school*[TW] OR highschool*[TW] OR senior high[TW] OR boy*[TW] OR girl*[TW] OR puberty[MeSH] OR pube*[TW] OR young people*[TW] OR minors[TW])) AND ("adult care"[TW] OR adult service*[TW])))) AND (English[Language] OR Dutch[Language] OR German[Language])) NOT ((animal*[TW] OR animals[MeSH]) NOT (human*[TW] OR humans[MeSH])) 


\section{References}

1. Lewis SA, Noyes J. Effective process or dangerous precipice: qualitative comparative embedded case study with young people with epilepsy and their parents during transition from children's to adult services. BMC Pediatr 2013; 13:169.

2. Lewis SA, Noyes J, Mackereth S. Knowledge and information needs of young people with epilepsy and their parents: Mixed-method systematic review. BMC Pediatr 2010; 10:103.

3. Asato MR, Manjunath R, Sheth RD et al. Adolescent and caregiver experiences with epilepsy. J Child Neurol 2009; 24:562-71.

4. Appleton RE, Chadwick D, Sweeney A. Managing the teenager with epilepsy: paediatric to adult care. Seizure 1997; 6:27-30.

5. Khan A, Baheerathan A, Hussain N, et al. Transition of children with epilepsies to adult care. Acta Paediatr 2013; 102:216-21.

6. Borlot F, Tellez-Zenteno JF, Allen A, et al. Epilepsy transition: Challenges of caring for adults with childhood-onset seizures. Epilepsia 2014; 55:1659-66.

7. Camfield PR, Camfield CS. What Happens to Children With Epilepsy When They Become Adults? Some Facts and Opinions. Pediatr Neurol 2014; 51:17-23.

8. Beghi E, Camfield PR, Camfield CS. Epidemiologic aspects: Lost in transition. Epilepsia 2014; 55 Suppl 3:3-7.

9. Thomson L, Fayed N, Sedarous F, et al. Life quality and health in adolescents and emerging adults with epilepsy during the years of transition: a scoping review. Dev Med Child Neurol 2014; 56:421-33.

10. Kuchenbuch $\mathrm{M}$, Chemaly N, Chiron $\mathrm{C}$, et al. Transition and transfer from pediatric to adult health care in epilepsy: a families' survey on Dravet syndrome. Epilepsy Behav 2013; 29:161-5.

11. Iyer A, Appleton R. Transitional services for adolescents with epilepsy in the U.K.: a survey. Seizure 2013; 22:433-7.

12. Schultz RJ. Parental experiences transitioning their adolescent with epilepsy and cognitive impairments to adult health care. J Pediatr Health Care 2013; 27:359-66.

13. Jurasek L, Ray L, Quigley D. Development and implementation of an adolescent epilepsy transition clinic. J Neurosci Nurs 2010; 42:181-9.

14. Reeve DK, Lincoln NB. Coping with the challenge of transition in older adolescents with epilepsy. Seizure 2002; 11:33-9.

15. Warnell P. The transition experience of epilepsy patients/families: results of a telephone survey. Axone 1998; 20:31-3.

16. Camfield P, Camfield C, Pohlmann-Eden B. Transition from pediatric to adult epilepsy care: a difficult process marked by medical and social crisis. Epilepsy Curr 2012; 12:13-21.

17. Wu DY, Ding D, Wang Y, et al. Quality of life and related factors in Chinese adolescents with active epilepsy. Epilepsy Res 2010; 90:16-20.

18. Camfield PR, Gibson PA, Douglass LM. Strategies for transitioning to adult care for youth with LennoxGastaut syndrome and related disorders. Epilepsia 2011; 52 Suppl 5:21-7.

19. Shanske S, Arnold J, Carvalho M, et al. Social workers as transition brokers: facilitating the transition from pediatric to adult medical care. Soc Work Health Care 2012; 51:279-95.

20. Parachuri V, Inglese C. Neurological problems in the adolescent population. Adolesc Med State Art Rev 2013; 24:1-28, $x$.

21. Chiron C, An I. Pharmacology aspects during transition and at transfer in patients with epilepsy. Epilepsia 2014; 55 Suppl 3:8-11.

22. Scheffer IE, Dravet C. Transition to adult life in the monogenic epilepsies. Epilepsia 2014; 55 Suppl 3:12-5.

23. Camfield CS, Berg A, Stephani U, et al. Transition issues for benign epilepsy with centrotemporal spikes, nonlesional focal epilepsy in otherwise normal children, childhood absence epilepsy, and juvenile myoclonic epilepsy. Epilepsia 2014; 55 Suppl 3:16-20.

24. Camfield PR, Bahi-Buisson N, Trinka E. Transition issues for children with diffuse cortical malformations, multifocal postnatal lesions, (infectious and traumatic) and Lennox-Gastaut and similar syndromes. Epilepsia 2014; 55 Suppl 3:24-8. 
25. Camfield P, Camfield C, Nolan K. Helping families cope with the devastation of Dravet syndrome. Eur J Paediatr Neurol 2012; 16 Suppl 1:S9-12.

26. De Saint-Martin A, Rudolf G, Seegmuller C, et al. Epileptic encephalopathy with continuous spikewaves during sleep: The need for transition from childhood to adulthood medical care appears to be related to etiology. Epilepsia 2014; 55 Suppl 3:21-3.

27. Thiele EA, Granata T, Matricardi S, et al. Transition into adulthood: Tuberous sclerosis complex, Sturge-Weber syndrome, and Rasmussen encephalitis. Epilepsia 2014; 55 Suppl 3:29-33.

28. Kossoff EH, Veggiotti $P$, Genton $P$, et al. Transition for patients with epilepsy due to metabolic and mitochondrial disorders. Epilepsia 2014; 55 Suppl 3:37-40.

29. Kerr M, Kluger G, Philip S. Evolution and management of Lennox-Gastaut syndrome through adolescence and into adulthood: are seizures always the primary issue? Epileptic Disord 2011; 13 Suppl 1:S15-26.

30. Glauser TA. Following catastrophic epilepsy patients from childhood to adulthood. Epilepsia 2004; 45 Suppl 5:23-6.

31. Nordli DR, Jr. Special needs of the adolescent with epilepsy. Epilepsia 2001; 42 Suppl 8:10-7.

32. Schor NF. Life at the interface: adults with "pediatric" disorders of the nervous system. Annals of neurology 2013; 74:158-163.

33. Rodenburg R, Wagner JL, Austin JK, et al. Psychosocial issues for children with epilepsy. Epilepsy Behav 2011; 22:47-54.

34. Nashef L, Capovilla G, Camfield C, et al. Transition: Driving and exercise. Epilepsia 2014; 55 Suppl 3: 41-5.

35. Cross JH, Duchowny M. Transition in lesional focal epilepsy, and following epilepsy surgery. Epilepsia 2014; 55 Suppl 3:34-6.

36. Kossoff EH, Henry BJ, Cervenka MC. Transitioning pediatric patients receiving ketogenic diets for epilepsy into adulthood. Seizure 2013; 22:487-9.

37. Smith PE, Myson V, Gibbon F. A teenager epilepsy clinic: observational study. Eur J Neurol 2002; 9:373-6.

38. Ellingford C. Short report: refocusing transition clinics. Paediatr Nurs 2006; 18:37.

39. McRandal M, Arthur A, Whitehouse WP. Young person's epilepsy transition clinic. Child Care Health Dev 2012; 38:604.

40. Carrizosa J, An I, Appleton R, et al. Models for transition clinics. Epilepsia 2014; 55 Suppl 3:46-51.

41. Mu PF. Transition experience of parents caring of children with epilepsy: a phenomenological study. Int J Nurs Stud 2008; 45:543-51.

42. Austin JK, Dunn DW, Huster GA. Childhood epilepsy and asthma: changes in behavior problems related to gender and change in condition severity. Epilepsia 2000; 41:615-23.

43. Ferro MA. Adolescents and young adults with physical illness: a comparative study of psychological distress. Acta Paediatr 2014; 103:e32-7.

44. Camfield P, Camfield C. Help youth with epilepsy to become competent and happy adults: Transition care. Seizure 2013; 22:414-415.

45. Nabbout R, Camfield P. Transition in adulthood: The challenge of epilepsies. Epilepsia 2014; 55 Suppl 3:1-2.

46. Nabbout R, Camfield P. Bringing the transition of epilepsy care from children to adults out of the shadows. Epilepsia 2014; 55 Suppl 3:52-3.

47. Devinsky O. Transition to adult care for children with epilepsy-A call for action. Epilepsia 2014; 55 Suppl 3:54-5.

48. Colver A, Longwell S. New understanding of adolescent brain development: relevance to transitional health-care for young people with long term conditions. Archives of disease in childhood 2013; 98:902-7.

49. Watson R, Parr JR, Joyce C, et al. Models of transitional care for young people with complex health needs: a scoping review. Child Care Health Dev 2011; 37:780-91.

50. Douglass LM. Introduction: Transitioning care for adults with Lennox-Gastaut syndrome: challenges and promises. Epilepsia 2011; 52 Suppl 5:1-2.

51. Appleton RE. Transition from paediatric clinic to the adult service. J R Soc Med 2001; 94:554. 


\section{Chapter 3}

The evaluation of a multidisciplinary epilepsy transition clinic for adolescents

RPJ Geerlings, AP Aldenkamp, LMC Gottmer-Welschen, PHN de With, S Zinger, AL van Staa, AJA de Louw

Eur J Paediatr Neurol 2016;20:385-92 


\section{Abstract}

\section{Introduction}

The main goal of the transition clinic is to explore and optimize medical issues during transition from adolescence to adulthood, and to ease the transition into adult care. However, only limited data on the process and outcomes of transitional care in clinical practice are available.

\section{Objective}

To describe the process and outcomes of an Epilepsy Transition Clinic in a tertiary referral center in The Netherlands.

\section{Methods}

Data were collected from patients with epilepsy (aged 15-25 years), who visited the transition clinic between March 2012 and September 2014.

\section{Results}

The Epilepsy Transition Clinic is staffed with a multidisciplinary team including a neurologist/ epileptologist, clinical neuropsychologist, a social worker and an educationalist/occupational counselor, all with knowledge of paediatric and adult medical and developmental issues. In total, 117 patients with epilepsy were included in the analysis. After consultation, 89 patients received a diagnostic work-up (76.1\%), change in AED prescription $(n=64,54.7 \%)$, or consultation/tailored advice ( $n=73,62.4 \%)$. In fourteen patients $(12.0 \%)$ the epilepsy diagnosis was changed. Nineteen patients $(16.2 \%)$ had complete epilepsy remission for over one year. Forty-three patients (36.8\%) were referred to adult care.

\section{Conclusion}

This study describes a multidisciplinary epilepsy transition clinic staffed by a neurologist/ epileptologist, neuropsychologist, a social worker and an educationalist/occupational counselor. Diagnostic work-up and evaluation of psychosocial and educational/vocational status during adolescence are strongly recommended. 


\section{Introduction}

Transition is defined as the process of moving from one state to another. ${ }^{1}$ In this manuscript we describe two types of transition, namely the transition from childhood to adulthood, and the transition from paediatric to adult care.

Adolescence can be seen as a phase during transition from childhood to adulthood. Adolescence is characterized by the development of autonomy and independence, by increasing social interaction with peers, and future choices in education, employment, and living arrangements. ${ }^{2-5}$ Adolescents with epilepsy have to deal with additional lifestyle implications, e.g., driving regulations, occupational restrictions and medication adherence. ${ }^{2-6}$ Furthermore, epilepsy and comorbid conditions can substantially delay physical, cognitive and social development during childhood, affecting the transition to adulthood, and thereby risking lowered psychosocial outcome. $^{3,4,6,7}$ Previous studies found indeed that patients with (childhood-onset) epilepsy, with or without comorbid intellectual disabilities, had a lower educational and vocational outcome and subsequently a lower socioeconomic status. In addition, these patients experienced more social isolation and higher depression rates, and had more problems with self-care and daily activities compared with healthy controls. ${ }^{5,8-11}$ Epilepsy and comorbid conditions can either persist or remit in adolescence and emerging adulthood, with major consequences for the patient's life, e.g., for choice of treatment, career opportunities, daily activities, or living arrangements. ${ }^{3}$ Therefore, re-evaluation of medical and psychosocial problems during adolescence and early adulthood is essential. ${ }^{12}$ At a certain point, the adolescent with ongoing seizures has to transition from a family-centered paediatric care to the individual-centered adult care. ${ }^{13}$ Epilepsy transition clinics have been set up to optimize seizure control, to initiate early interventions for psychosocial problems, and to lessen the fear of moving to adult care. ${ }^{3,14}$

To evaluate medical, familial, educational/occupational and psychosocial developmental issues during transition from adolescence to adulthood, and to guide the transition into adult care, a multidisciplinary Epilepsy Transition Clinic was set up at our tertiary Epilepsy Center in 2012.

\section{Objectives}

The objectives of this study are to describe the process and outcomes of our multidisciplinary Epilepsy Transition Clinic at the tertiary Epilepsy Center Kempenhaeghe. 


\section{Methods}

\section{The Epilepsy Transition Clinic}

The Epilepsy Transition Clinic was set up in March 2012 as part of outpatient care of a tertiary epilepsy center. The transition clinic is staffed by a neurologist/epileptologist, clinical neuropsychologist, an educationalist/occupational counselor and a social worker, all with knowledge of and experience in paediatric and adult medical and developmental issues in patients with epilepsy.

Patients (and their caregiver(s)) are seen in three consecutive thirty minute consultations ('the carousel') planned in one morning with the above mentioned health care professionals, as is shown in Figure 3.1. The neurologist and clinical neuropsychologist work together in a combined consultation because of the interaction between the two fields of expertise. All three consultations focus on exploring the adolescent's developmental stage (e.g., individualization and schooling/work), as well as obtaining information on relevant age-related issues such as driving, the use of antiepileptic drugs (AEDs) with potential teratogenic effects, and the use of alcohol/drugs. The potential risk of inheritance of epilepsy was discussed with young women in child bearing age. If applicable, the interactions between AEDs and oral contraceptives was discussed by the neurologist. Also the future perspectives of the adolescent and his/her parents are assessed. In a consecutive multidisciplinary meeting, functioning and development in he four transitional domains (medical, neuropsychological, social, educational/vocational) is reviewed, after which a tailored advice is provided to the patient. This advice can cover one or several of the domains and is discussed with the patient (and caregiver(s)) directly after the multidisciplinary meeting. Most importantly, the advice is focused on autonomy, with the patient actively involved and in charge of his own decisions. All health professionals incorporate empowerment in their communication during the consultations.

Following this consultation carousel, a diagnostic work-up can be provided, including magnetic resonance imaging (MRI), neuropsychological assessment, electroencephalography (EEG), or collection of blood samples. Treatment changes in the current AEDs can be advised or the patient can be offered alternative treatment options, such as a ketogenic diet (KD), vagus nerve stimulator (VNS), or epilepsy surgery. Tailored advices from the health care professionals can include for example a vocational training, or support from a (neuro)psychologist or from a social worker (e.g., in organizing living arrangements or financial guidance). Preferably, after two to three visits, the patient is referred to an adult neurologist (if preferred by the patient, the transition clinic's neurologist or another adult neurologist working at our tertiary referral center can provide long-term medical epilepsy care with regular visits at the transition clinic's neurologist after transition to adult care), or, in case of seizure remission without AEDs, to a general practitioner. The procedure of the Epilepsy Transition Clinic is shown in Figure 3.1. 


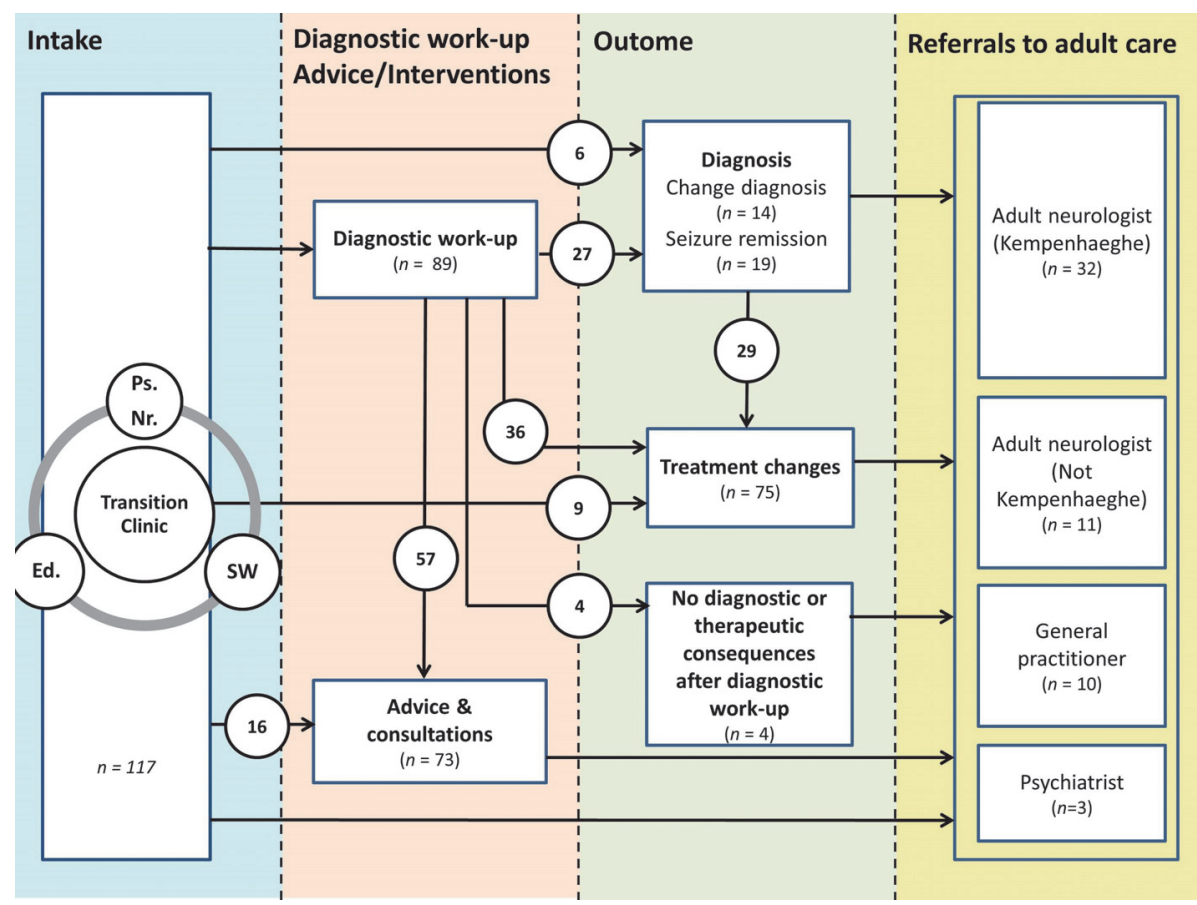

Figure 3.1 Evaluation of the epilepsy transition clinic, showing the number of diagnostic work-ups, advice and consultations, outcome and referrals after a visit at the epilepsy transition clinic. Some patients had both a diagnostic work-up and a consultation by the social worker, educationalist or clinical neuropsychologist. Ed: Educationalist; Ps: Psychologist; Nr: Neurologist; SW: Social worker.

\section{Inclusion and exclusion criteria}

Adolescents and young adults who visited the transition clinic between March 2012 and September 2014, with a confirmed diagnosis or highly probable diagnosis of (childhood-onset) epilepsy were included in the study. The age limits for referral to the transition clinic were 15 to 25 years. Patients diagnosed with non-epileptic seizures only, or those with severe mental retardation $(I Q<35)$ were excluded.

\section{Data collection}

The following medical, demographic and psychosocial data were collected from all patients who visited the Epilepsy Transition Clinic: age, gender, epilepsy syndromes classified according to International League Against Epilepsy (ILAE) 1989 classification, seizure frequency and duration of epilepsy in years, use of AEDs and self-reported medication adherence, other epilepsy treatments (KD, VNS, or epilepsy surgery), full scale intelligence quotient (FS IQ) by neuropsychological testing using the Wechsler 
Intelligence Scale for Children, educational and vocational status, living arrangements. Special education was defined as an educational setting (school) for patients with special needs, e.g., developmental delays, mental disabilities, learning disorders, or comorbid emotional and behavioral conditions e.g. ADHD or autism spectrum disorders. Patients were asked if they had ever been in a special education setting, either now or in the past. Having a social network was defined as having a support network of friends, or adequate social interaction with peers. Independence was evaluated by the social worker and clinical neuropsychologist and defined as patients who were in charge of making their own decisions and take care of themselves in terms of household chores and personal hygiene. The amount of family support was evaluated by the neuropsychologist and/or social worker.

To evaluate diagnostic procedures and outcomes, data about diagnostic work-up (EEG, clinical neuropsychological assessment, MRI, blood laboratory tests, and $24 \mathrm{~h}$ admittance to ease the diagnostic work-up) were collected. Change in AED prescriptions and change of diagnosis, applied interventions and consultations and number of referrals (to adult care) were collected. All data were recorded in an IBM SPSS database.

\section{Statistical analysis}

Statistical analysis was performed by IBM SPSS Version 21. We used descriptive statistics to compute percentages (\%) and frequencies $(n)$ of categorical variables. In case of a normal distribution pattern of continuous variables, the mean and standard deviation (SD) are shown, whereas in case of a non-normal distribution pattern the mean and interquartile range (IQR) are represented.

\section{Results}

\section{Patient characteristics}

Table 3.1 shows that 117 patients were included in our study (65 boys, 52 girls), with a median age of 18.3 years (IQR 3). Mean full intelligence score was 82.5 (SD 15.4), and forty-two patients had a below average IQ (36.2\%) or had a mild mental retardation (19.8\%). Forty-eight patients (43.6\%) of the total population ever had special education, of which 12 patients with a normal intelligence. Fifty-two patients (48.1\%) showed independence. Fourteen out of sixteen adult patients (aged 21-25 years) were still living at home with their parents. Three out of these sixteen adult patients were currently unemployed and not studying. Eighty-five patients (78.7\%) were considered having sufficient social participation and social support from peers. Thirty-three patients (30.0\%) were considered having unsupportive family conditions. 
Table 3.1 Demographic and psychosocial variables of adolescents visiting the Epilepsy Transition Clinic.

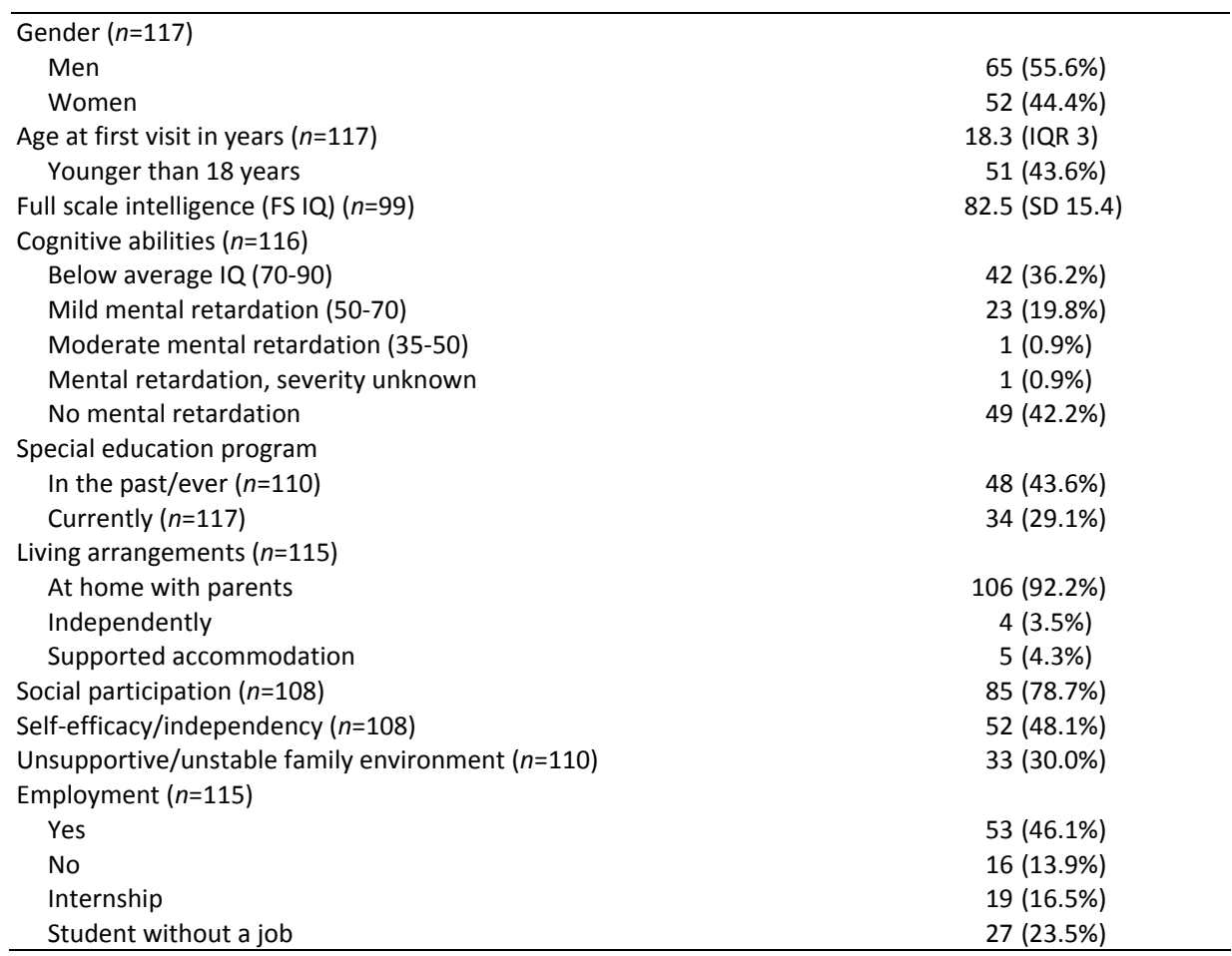

Data are presented as means (SD; standard deviation), $n$ (\%) or median (interquartile range (IQR)), in case of a skewed distribution.

Epilepsy-related variables are shown in Table 3.2. Mean duration of epilepsy was about 10.4 years (SD 5.0), and 59 patients (54.1\%) had a seizure frequency of less than one seizure per year. Ninety-four patients $(80.3 \%)$ were diagnosed with localizationrelated epilepsy. Fifty-eight (69.0\%) were self-reported compliant to AEDs. Nine patients (7.6\%) were not using any AEDs anymore at time of referral to the transition clinic, mostly because of seizure remission. 
Table 3.2 Adolescent's epilepsy-related variables at their first visit at the Epilepsy Transition Clinic.

\begin{tabular}{lc}
\hline Age at diagnosis epilepsy in years $(n=112)$ & $7.6($ IQR 7.8$)$ \\
Duration of epilepsy (years) $(n=112)$ & 10.4 (SD 5.0) \\
Type of epilepsy $(n=117)$ & $94(80.3 \%)$ \\
Localization-related epilepsy & $5(4.3 \%)$ \\
$\quad$ Idiopathic & $26(22.2 \%)$ \\
Symptomatic & $63(53.8 \%)$ \\
Cryptogenic & $19(16.2 \%)$ \\
Generalized epilepsy & $14(12.0 \%)$ \\
Idiopathic & $5(4.3 \%)$ \\
Symptomatic & $0(0 \%)$ \\
Cryptogenic & $4(3.5 \%)$ \\
Not classified yet & \\
Seizure frequency ( $n=109)$ & $10(9.2 \%)$ \\
Daily & $13(11.9 \%)$ \\
Weekly & $19(17.4 \%)$ \\
Monthly & $8(7.3 \%)$ \\
Yearly & $59(54.1 \%)$ \\
Less than 1/year & \\
Number of AEDs ( $n=117)$ & $9(7.6 \%)$ \\
No current AED treatment & $54(46.2 \%)$ \\
Monotherapy & $54(46.2 \%)$ \\
Polytherapy (2-4 AEDs) & $58(69.0 \%)$ \\
AED adherence $(n=84)$ & \\
Previous therapies $(n=117)$ & $5(4.3 \%)$ \\
Epilepsy surgery & $2(1.7 \%)$ \\
Vagal nerve stimulator & $2(1.7 \%)$ \\
Ketogenic diet &
\end{tabular}

\section{Diagnostic procedures and outcome}

The number of diagnostic work-ups is shown in Figure 3.1 and Table 3.3. In 89 patients (76.1\%), a diagnostic work-up was provided. Twenty-eight patients further a diagnostic work-up was already done in the past, or a diagnostic work-up was not considered necessary during their visit at the transition clinic.

Clinical neuropsychological assessment was conducted in 61 patients (52.1\%). In thirty-four patients (29.1\%) also the intellectual abilities were tested. Seven patients (6.0\%) were tested for autism spectrum disorder, and this diagnosis was confirmed in two patients $(1.7 \%)$. In eleven patients $(9.4 \%)$ the test was focused specifically on AED's potential cognitive adverse effects (such as reduced central processing speed) which were found in 4 patients (3.4\%). A second clinical neuropsychological assessment was conducted in four patients to evaluate the effects of AED withdrawal; 3 out of 4 patients showed substantial improvement of their processing speed after AED switch or withdrawal; in one patient the side effects increased after switch of AED. 
Table 3.3 Results of the Epilepsy Transition Clinic: referrals, diagnostic procedures and outcomes.

\begin{tabular}{|c|c|}
\hline \multicolumn{2}{|l|}{ Referral by $(n=117)$} \\
\hline Neurologist of the Epilepsy Transition Clinic & $54(54.5 \%)$ \\
\hline Other neurologist within the epilepsy center & $45(45.5 \%)$ \\
\hline Referral from external neurologists & $10(8.5 \%)$ \\
\hline General practitioner & $4(3.4 \%)$ \\
\hline Paediatrician & $4(3.4 \%)$ \\
\hline \multicolumn{2}{|l|}{ Diagnostic work-up ( $n=117)$} \\
\hline EEG & 89 (76.1\%) \\
\hline $24 \mathrm{~h}$ ambulatory EEG registration & $61(52.1 \%)$ \\
\hline $1 \mathrm{~h}$ EEG registration & $39(33.3 \%)$ \\
\hline MRI & $22(18.8 \%)$ \\
\hline Laboratory & $28(23.9 \%)$ \\
\hline Admittance for diagnostic work-up & $31(26.5 \%)$ \\
\hline Clinical neuropsychological assessment & $41(35.0 \%)$ \\
\hline Specific reason clinical neuropsychological assessment & $61(52.1 \%)$ \\
\hline Intellectual abilities & $34(29.1 \%)$ \\
\hline Mental slowing as a side effect of AED treatment & $11(9.4 \%)$ \\
\hline Personality and coping strategies & $7(6.0 \%)$ \\
\hline Autism spectrum disorder & $7(6.0 \%)$ \\
\hline Attention and concentration & $2(1.7 \%)$ \\
\hline \multicolumn{2}{|l|}{ Outcome initial/first clinical neuropsychological assessment } \\
\hline Growing into deficit & $28(23.9 \%)$ \\
\hline Diagnosis other than epilepsy & $2(1.7 \%)$ \\
\hline Negative effects of epilepsy on central processing speed & $3(2.6 \%)$ \\
\hline Mental slowing as a side effect of AED treatment & $8(6.8 \%)$ \\
\hline Autism spectrum disorder & $4(3.4 \%)$ \\
\hline Behavioral disorder & $2(1.7 \%)$ \\
\hline Negative coping strategies & $1(0.9 \%)$ \\
\hline Outcome follow-up/second clinical neuropsychological assessment & $4(3.4 \%)$ \\
\hline Increase central processing speed after optimizing epilepsy treatment & $8(6.8 \%)$ \\
\hline Negative effects of epilepsy on central processing speed & $2(1.7 \%)$ \\
\hline Improvement central processing speed after AED withdrawal/switch & $3(2.6 \%)$ \\
\hline Increase side effects after switch AED & $1(0.9 \%)$ \\
\hline No obvious difference & $4(3.4 \%)$ \\
\hline AED change $(n=117)$ & $64(54.7 \%)$ \\
\hline Withdrawal of AED & $20(17.1 \%)$ \\
\hline Start additional AED & $9(7.7 \%)$ \\
\hline Switch AED & $11(9.4 \%)$ \\
\hline Increase dose AED & $8(6.8 \%)$ \\
\hline Decrease dose AED & $16(13.7 \%)$ \\
\hline \multicolumn{2}{|l|}{ Main reasons AED change } \\
\hline Complete epilepsy remission $>1$ year & $19(16.2 \%)$ \\
\hline Side effects & $16(13.7 \%)$ \\
\hline Women in child bearing age (Withdrawal of Valproate) & $9(7.7 \%)$ \\
\hline Change diagnosis ( $n=117)$ & $14(12.0 \%)$ \\
\hline Other type of epilepsy syndrome & $11(9.4 \%)$ \\
\hline No epilepsy & $3(2.6 \%)$ \\
\hline Epilepsy surgery ( $n=117)$ & $8(6.8 \%)$ \\
\hline Ketogenic diet $(n=117)$ & $1(0.9 \%)$ \\
\hline Vagus nerve stimulator $(n=117)$ & $2(1.7 \%)$ \\
\hline
\end{tabular}


In 16 patients (13.7\%) seizures negatively influenced the central processing speed. In 8 of the 16 patients improvement was observed after adequate reduction of seizure frequency. In 2 patients the negative effects of epilepsy persisted, even after adjustment of AEDs. Seven patients (6.0\%) were specifically tested for their personality and coping strategies.

Twenty-eight MRIs (23.9\%) were conducted, of which 5 were abnormal and had consequences for further treatment options: 3 patients were referred for epilepsy surgery and one patient received a VNS.

Sixty-one EEG (52.1\%) registrations included 22 one-hour EEG registrations (18.8\%) and 39 24-h ambulatory EEG registrations (33.3\%). Thirty-three EEGs were abnormal. Forty-one patients (35.0\%) were shortly admitted (approximately $24 \mathrm{~h}$ ) to facilitate the diagnostic work-up.

Following diagnostic work-up, epilepsy diagnoses were changed in 14 patients (12.0\%), out of which 3 patients (2.6\%) were diagnosed with non-epileptic seizures.

Nineteen patients (16.2\%) had complete seizure remission (for at least one year).

Antiepileptic drugs were changed in 64 patients (54.7\%). In 20 patients (17.1\%) AEDs were completely withdrawn, and dosage was adjusted (either increased or decreased) in 24 patients $(20.5 \%)$. The main reason for changing AED treatment was seizure remission, or side effects in 16 patients (13.7\%). Valproate was completely withdrawn in 9 out of 10 girls, because of potential teratogenic effects in women in the child bearing age.

After a diagnostic work-up, eight patients (6.8\%) were referred for a pre-surgical assessment for epilepsy surgery. One patient started a ketogenic diet, and two patients were referred for a vagus nerve stimulator.

\section{Consultations and interventions}

Consultations and interventions are shown in Figure 3.1 and Table 3.4. Thirty-one patients $(26.5 \%)$ required assistance by the social worker to apply for suitable housing or supported living accommodations. Improving separation from parents, financial assistance or guardianship, or help to improve the adolescent's social interaction with peers were provided in 9 patients $(7.7 \%), 12$ patients $(10.3 \%)$, and 4 patients $(3.4 \%)$, respectively. In nine patients $(7.7 \%)$, a social worker was involved to improve family interactions and support.

Educational ( $n=25,21.4 \%$ ) or vocational assistance or Vocational Training (both $n=11$; 9.4\%), appropriate for the individual's capacity, were provided by the educationalist/occupational counselor. In 17 patients (14.5\%) psychological consultations and follow-up for psychosocial problems was provided. 
Table 3.4 Results of the Epilepsy Transition Clinic: interventions and consultations.

\begin{tabular}{lc}
\hline Advice/interventions (some patients had $>1$ intervention/advice) $(n=117)$ & $73(62.4 \%)$ \\
Social worker & $54(46.2 \%)$ \\
Housing assistance & $31(26.5 \%)$ \\
Reason financial advice & $12(10.3 \%)$ \\
Reason improving family support & $9(7.7 \%)$ \\
Reason improving separation/individualization & $9(7.7 \%)$ \\
Reason increasing social interaction and support & $4(3.4 \%)$ \\
Reason planning daily activities & $2(1.7 \%)$ \\
Reason addiction & $1(0.9 \%)$ \\
Educationalist/vocational counselor & $39(33.3 \%)$ \\
Educational assistance & $25(21.4 \%)$ \\
Vocational assistance & $11(9.4 \%)$ \\
Vocational training & $11(9.4 \%)$ \\
Psychological treatment & $17(14.5 \%)$ \\
\hline
\end{tabular}

\section{Transition from paediatric to adult care}

As shown in Table 3.3, 99 patients were referred by a neurologist of our epilepsy center, of which 54 (54.5\%) by the transition clinic's neurologist. Ten patients (8.5\%) were referred by an external neurologist, 4 (3.4\%) by their general practitioner, and $3(3.4 \%)$ by a paediatrician.

At time of referral to the transition clinic, 66 patients (56.4\%) were 18 years or older. In total, 43 patients (36.8\%) were referred from a paediatrician or paediatric neurologist to an adult neurologist. Three patients $(2.6 \%)$ were referred to a psychiatrist for further follow-up because of the impact of their psychiatric comorbid conditions. At the time of analysis, 57 patients (48.7\%) were still in follow-up at the transition clinic's neurologist for the following reasons: sixteen patients (13.7\%) preferred to remain under long-term medical epilepsy care with regular visits at the transition clinic's neurologist after transition to adult care ('transition to adult medical care'), or under temporary follow-up because of recent changes in epilepsy treatment ( $n=34,29.1 \%)$, or awaiting the results of a diagnostic work-up $(n=7,6.0 \%)$. However, not all epilepsy patients are in need of epilepsy care at a specialized tertiary referral hospital, and 11 patients (9.4\%) were referred to an external neurologist at a general hospital for further epilepsy care. Ten patients (8.5\%) no longer required follow-up of specialized epilepsy care because of complete seizure remission ( 8 out of 10 ) or adequate seizure control for at least one year, and were referred back to their general practitioner. The number of referrals are shown in Figure 3.1 and Table 3.5. 
Table 3.5 Results of the Epilepsy Transition Clinic: referrals and main reasons to remain under (temporary) follow-up.

\begin{tabular}{lr}
\hline Referral to ( $n=117)$ & $32(27.4 \%)$ \\
Adult neurologist within the epilepsy center & $11(9.4 \%)$ \\
External referral to adult neurologists & $10(8.5 \%)$ \\
General practitioner & $3(2.6 \%)$ \\
Psychiatrist & $6(5.1 \%)$ \\
Lost-to-follow-up & \\
Main reasons for follow-up at the transition clinic's neurologist $(n=57)$ & $16(13.7 \%)$ \\
Long-term epilepsy care ('Transition to adult care') & $34(29.1 \%)$ \\
After recent treatment changes (e.g. AED prescription) & $7(6.0 \%)$ \\
Awaiting the results of a diagnostic work-up &
\end{tabular}

\section{Discussion}

Our epilepsy transition clinic uses a combined approach of a neurologist/ epileptologist, neuropsychologist, an educationalist/occupational counselor and a social worker. This multidisciplinary approach allows us to re-evaluate specific medical and psychosocial developmental issues that arise during transition from adolescence to adult and provide both fine-tuned diagnostic work-up and treatment interventions. Several transition clinics for adolescents with epilepsy have been described, but only limited data on the process and outcomes of transitional care in clinical practice are available. There is no consensus for its setting, staffing or the necessary procedures, and there is still no proof which model is the best. ${ }^{4,14-17}$ Transition clinics are held within the paediatric or adult setting. ${ }^{15}$ Joint consultation of adult and paediatric neurologists with or without support of epilepsy nurses is the most reported organization form. This staffing is sometimes complemented with career advisers, social workers and psychologists. ${ }^{15,16,18-20}$ The presence of a familiar (paediatric) health care worker can provide continuity of care. ${ }^{3,4,7,13-15}$ A collaboration between paediatric and adult health care workers is sometimes recommended, as medical and psychosocial issues can be evaluated from both perspectives. ${ }^{3,13}$ However, Lewis et al. ${ }^{21}$ state that adolescents with epilepsy still experience insufficient psychosocial care during transition to adult health care.

A neuropsychologic revaluation of cognitive, behavioral and attention problems during transition to adulthood is highly recommendable, because behavioral problems and cognitive impairments and even cognitive deterioration require medical or psychoeducational interventions. ${ }^{2,12}$ In addition, unrecognized conditions with major consequences for adolescents with epilepsy must be diagnosed. Moreover, a clinical neuropsychologic assessment can provide specific data about the patient's intellectual abilities, or cognitive adverse events of the AED's (e.g., central processing speed). These data can be useful for further follow-up, e.g., to monitor treatment effects or for an educationalist to determine the patient's academic expectations. ${ }^{12}$ 
The collaboration with the educationalist/occupational counselor is especially important, as learning disorders, underemployment and unemployment are common in adolescents with epilepsy. ${ }^{22}$ Even patients with epilepsy with a normal intelligence suffer academic underachievement, and frequently fail to complete higher education. $^{12}$

Sixty percent of the patients with epilepsy worry about future education and employment. ${ }^{4}$ An educationalist/occupational counselor helps patients to make appropriate future career choices in line with the characteristics of their epilepsy and their individual capacities, based on the outcome of a clinical neuropsychological assessment. Furthermore, the educationalist/occupational counselor has the ability to contact the patient's teacher or school staff members to provide further information about the individual's wishes and capacities with an individual education plan.

Among our population, we found that $13.7 \%$ of the patients $(n=16)$ were unemployed and currently not studying, compared to $20.5 \%$ of the youth aged $15-27$ years in the Dutch population (Statistics Netherlands). However, the mean age at first visit was just above 18 years old in our transition clinic, and $77.8 \%(n=91)$ of our population was still in school, which might be a reasonable explanation for the differences found with the Dutch reference population which has supposedly a higher average age. Causes for unemployment among adolescents with epilepsy include seizure frequency and severity, transportation or driving restrictions, and stigma by employers and society. Predictors for employment are seizure control, level of intelligence, adaptive coping styles and vocational training. ${ }^{22}$

One of the most important contributions from the social worker was to optimize and arrange future living arrangements for adult patients without seizure remission. Ninety-two percent of the adolescent study population was still living at home with their parents, of which $88.2 \%$ (15 out of 17 ) of the adolescents aged $21-25$ years. This percentage is extremely high, compared to the normal population in which $50 \%$ of the girls and $65 \%$ of the boys at age 21 , and $15 \%$ and $30 \%$ at the age of 25 live with their parents (Statistics Netherlands).

A social worker has extensive knowledge about resource facilitations, community support, and the consequences of the child's illness on complex family relations and family support. ${ }^{12,20}$ Literature suggests one of the most important reasons for relatives to seek help from a social worker is to increase the patient's independence and selfresponsibility. ${ }^{12}$ In our study, we found that 9 patients needed support from a social worker to increase their independence and self-efficacy. Although we have no comparative numbers, the clinical experience in our patient group shows many adolescents develop a passive role in daily functioning and gaining independence, leading to so called 'learned helplessness'. ${ }^{23}$

Independence and social participation were evaluated by the social worker and clinical neuropsychologist, but it would be better to use standardized measures for these variables. One example of a validated tool to measure social participation during transition to adulthood (validated for youth with cerebral palsy and normal 
intelligence) is the Rotterdam Transition Profile. ${ }^{24}$ This tool distinguishes three developmental phases of transition to adulthood, namely the dependent childhood phase, the transition phase, and the independent adulthood phase. In total, six domains of social participation and three healthcare domains are evaluated in order to determine the adolescent's level of functioning. ${ }^{24}$

Based on the outcomes of our epilepsy transition clinic, re-evaluation of medical and psychosocial issues during the years of transition to adulthood is of utmost importance. After a diagnostic work-up, the diagnosis was changed in 14 patients (12.0\%), compared to $15 \%$ found by Appleton et al. ${ }^{4}$ In the study of Smith et al. ${ }^{17}$, 30 out of 207 patients (14.5\%) were diagnosed with a non-epileptic diagnosis, and 4 out of these 207 patients (1.9\%) with a single seizure. Most of the patients consulted by Smith et al. ${ }^{17}$ were referred by general practitioners, paediatric neurologist, general paediatricians, namely 94 patients, 59 patients and 41 patients respectively.

The relatively low number of altered diagnosis in our study compared to Appleton et al. ${ }^{4}$ and Smith et al. ${ }^{17}$ is not surprising, since most of the patients were referred by a specialized neurologists/epileptologist from our specialized epilepsy hospital, and a probable diagnosis of epilepsy had been made before.

In nineteen patients with seizure remission for at least one year, AEDs were reduced and finally withdrawn. Eight patients with seizure remission were referred to their general practitioner, one patient was referred to adult care for further follow-up, and six remained temporarily under the care of a neurologist in our centre pending withdrawal of their AED. In 16 patients AEDs were causing side effects (e.g., mental slowing), and in 9 women in the child bearing age Valproate was withdrawn. In total, an AED change was applied in 64 patients (54.7\%). Furthermore, a total of eleven referrals for epilepsy surgery, a VNS or a ketogenic diet were made. These numbers indicate that many patients were on an inappropriate antiepileptic drug treatment, or had suboptimal antiepileptic therapy and therefore side effects or inadequate seizure control.

In Appleton's clinic ${ }^{4}, 22 \%$ of the patients underwent a change in AED prescription, but dose alterations were excluded from their analysis. Prescriptions were changed in $20 \%$ of the teenagers in the clinic of Smith et al. ${ }^{17}$ Remarkably, patients with a diagnosis of 'epilepsy or probable epilepsy' were referred to the transition clinic of Smith et al. ${ }^{17}$, and $14 \%$ finally obtained a diagnosis of non-epileptic disorders.

Forty-three patients with ongoing seizures were referred to adult care, after a multidisciplinary evaluation of their medical, educational/vocational, and psychosocial status in order to optimize not only seizure control but also their independence, and future perspective for a suitable job and living arrangements.

Transition from child to adulthood is a process, and development to independence is not captured within strict age limits. ${ }^{3}$ The age limitation of our transition clinic had a 
minimum of 15 years, but had an upper limit of 25 years, since developmental milestones are often delayed in patients with epilepsy. ${ }^{14,25}$ This explains why patients in our transition clinic were approximately two years older compared to other studies. ${ }^{14,16,17}$ Although the optimal age for transition to adult care remains unknown, experts advise to prepare patients with a chronic disease for the medical transition process at a young age (e.g., 12 years old). ${ }^{13-15,18}$ We recommend to start the preparation for transition to adult medical care as early as possible, preferably at the pretransitional age when children are still in paediatric care. The Transition Readiness Assessment Questionnaire (TRAQ) can be used to assess the adolescent's readiness for transition to adult care. The TRAQ is a validated tool for adolescents with special health care needs to objective the adolescent's readiness for transition from paediatric to adult care by measuring their self-management skills and selfadvocacy. ${ }^{26}$ Furthermore, this tool can be used to determine the need for additional educational support and interventions.

To further improve transition from paediatric to adult care, multidisciplinary transitional services should be integrated within the traditional paediatric and adult epilepsy health care services. The number of transition clinics for adolescents and young adults with epilepsy should be increased, and their setting should finally be extended to local referral hospitals too, instead of tertiary referral epilepsy centers only. $^{15}$

\section{Conclusion}

This study describes a transition clinic in a tertiary epilepsy center, staffed by a neurologist/epileptologist, neuropsychologist, a social worker and an educationalist/ occupational counselor. A diagnostic work-up and evaluation of medical, psychosocial and educational/vocational status during adolescence and early adulthood are strongly recommended in order to optimize seizure control and long-term psychosocial outcome for patients with persistent seizures, before transition from paediatric to adult care. 


\section{References}

1. Mu PF. Transition experience of parents caring of children with epilepsy: a phenomenological study. Int J Nurs Stud 2008;45:543-51.

2. Lewis SA, Noyes J. Effective process or dangerous precipice: qualitative comparative embedded case study with young people with epilepsy and their parents during transition from children's to adult services. BMC Pediatr 2013;13:169.

3. Khan A, Baheerathan A, Hussain N, et al. Transition of children with epilepsies to adult care. Acta Paediatr 2013;102:216-21.

4. Appleton RE, Chadwick D, Sweeney A. Managing the teenager with epilepsy: paediatric to adult care. Seizure 1997;6:27-30.

5. Baker GA, Spector S, McGrath Y, et al. Impact of epilepsy in adolescence: a UK controlled study. Epilepsy Behav 2005;6:556-62.

6. Asato MR, Manjunath R, Sheth RD, et al. Adolescent and caregiver experiences with epilepsy. J Child Neurol 2009;24:562-71.

7. Camfield P, Camfield C, Pohlmann-Eden B. Transition from pediatric to adult epilepsy care: a difficult process marked by medical and social crisis. Epilepsy Curr 2012;12:13-21.

8. Sillanpaa M, Helen Cross J. The psychosocial impact of epilepsy in childhood. Epilepsy Behav 2009;15 Suppl 1:S5-10.

9. Chin RF, Cumberland PM, Pujar SS, et al. Outcomes of childhood epilepsy at age 33 years: a population-based birth-cohort study. Epilepsia 2011;52:1513-21.

10. Jalava M, Sillanpaa M, Camfield C, et al. Social adjustment and competence 35 years after onset of childhood epilepsy: a prospective controlled study. Epilepsia 1997;38:708-15.

11. Geerts A, Brouwer O, van Donselaar C, et al. Health perception and socioeconomic status following childhood-onset epilepsy: the Dutch study of epilepsy in childhood. Epilepsia 2011;52:2192-202.

12. Goldstein J, Plioplys S, Zelko F, et al. Multidisciplinary approach to childhood epilepsy: exploring the scientific rationale and practical aspects of implementation. J Child Neurol 2004;19:362-78.

13. Camfield PR, Gibson PA, Douglass LM. Strategies for transitioning to adult care for youth with LennoxGastaut syndrome and related disorders. Epilepsia 2011;52 Suppl 5:21-7.

14. Jurasek L, Ray L, Quigley D. Development and implementation of an adolescent epilepsy transition clinic. J Neurosci Nurs 2010;42:181-189.

15. Carrizosa J, An I, Appleton R, Camfield P, Von Moers A. Models for transition clinics. Epilepsia 2014;55 Suppl 3:46-51.

16. Iyer A, Appleton R. Transitional services for adolescents with epilepsy in the U.K.: a survey. Seizure 2013;22:433-7.

17. Smith PE, Myson V, Gibbon F. A teenager epilepsy clinic: observational study. Eur J Neurol 2002; 9:373-6.

18. Kuchenbuch $\mathrm{M}$, Chemaly N, Chiron C, et al. Transition and transfer from pediatric to adult health care in epilepsy: a families' survey on Dravet syndrome. Epilepsy Behav 2013;29:161-5.

19. Reeve DK, Lincoln NB. Coping with the challenge of transition in older adolescents with epilepsy. Seizure 2002;11:33-9.

20. Shanske S, Arnold J, Carvalho M, et al. Social workers as transition brokers: facilitating the transition from pediatric to adult medical care. Soc Work Health Care 2012;51:279-95.

21. Lewis SA, Noyes J, Mackereth S. Knowledge and information needs of young people with epilepsy and their parents: Mixed-method systematic review. BMC Pediatr 2010;10:103.

22. Bautista RE, Shapovalov D, Saada F, et al. The societal integration of individuals with epilepsy: perspectives for the 21st century. Epilepsy Behav 2014;35:42-9.

23. Seligman ME. Learned helplessness. Ann Rev Med 1972;23:407-12.

24. Donkervoort M, Wiegerink DJ, van Meeteren J, et al. Transition to adulthood: validation of the Rotterdam Transition Profile for young adults with cerebral palsy and normal intelligence. Dev Med Child Neurol 2009;51:53-62.

25. Colver A, Longwell S. New understanding of adolescent brain development: relevance to transitional healthcare for young people with long term conditions. Arch Dis Child 2013;98:902-7. 
26. Sawicki GS, Lukens-Bull K, Yin X, et al. Measuring the transition readiness of youth with special healthcare needs: validation of the TRAQ--Transition Readiness Assessment Questionnaire. J Pediatr Psychol 2011;36:160-71. 


\section{Chapter 4}

Developing from child to adult: risk factors for poor psychosocial outcome in adolescents and young adults

with epilepsy

RPJ Geerlings, AP Aldenkamp, LMC Gottmer-Welschen, PHN de With, S Zinger, AL van Staa, AJA de Louw

Epilepsy Behav 2015;51:182-90 


\section{Abstract}

\section{Introduction}

Childhood-onset epilepsy during the years of transition to adulthood may affect normal social, physical, and mental development, frequently leading to psychosocial and health-related problems in the long-term.

\section{Objective}

This study aimed to describe the main characteristics of patients in transition, and to identify risk factors for poor psychosocial outcome in adolescents and young adults with epilepsy.

\section{Methods}

Patients with epilepsy, 15-25 years of age, who visited the Kempenhaeghe Epilepsy Transition Clinic from March 2012 to December 2014 were included $(n=138)$. Predefined risk scores for medical, educational/occupational status, and independence/separation/identity were obtained, along with individual risk profile scores for poor psychosocial outcome. Multivariate linear regression analysis and discriminant analysis were used to identify variables associated with an increased risk of poor long-term psychosocial outcome.

\section{Results}

Demographic, epilepsy-related, and psychosocial variables associated with a high risk of poor long-term outcome were lower intelligence, higher seizure frequency, ongoing seizures, and an unsupportive and unstable family environment. Using the aforementioned factors in combination, we were able to correctly classify the majority $(55.1 \%)$ of the patients regarding their risk of poor psychosocial outcome.

\section{Conclusion}

Our analysis may allow early identification of patients at high risk of prevention, preferably at pretransitional age. The combination of a chronic refractory epilepsy and an unstable family environment constitutes a higher risk of transition problems and poor outcome in adulthood. As a consequence, early interventions should be put into place to protect youth at risk of poor transition outcome. 


\section{Introduction}

Transition from adolescence to adulthood is a challenging period in life, especially for youth with epilepsy and for their caregivers. ${ }^{1}$ Epilepsy and comorbidities, their treatment, and persistent social stigma have a substantial impact on the child's and their relatives' lives. ${ }^{1,2}$ Furthermore, childhood-onset epilepsy and comorbid conditions may interfere with normal brain maturation and delay age-appropriate social, physical, and cognitive development, leading to poor psychosocial outcome and societal integration in the long term. ${ }^{3}$

Adolescents are vulnerable to negative psychosocial consequences. ${ }^{4}$ Sillanpää and Cross $^{1}$ and Camfield and Camfield ${ }^{5}$ evaluated long-term psychosocial outcome of childhood-onset epilepsy among patients without obvious cognitive impairment. Adults with childhood-onset epilepsy had lower educational levels, less social interaction, and more problems in self-care and daily activities compared with healthy controls. Chin et al. ${ }^{6}$ examined psychosocial, medical, and mental health outcomes in adults with childhood-onset epilepsy. Patients with epilepsy without intellectual disabilities or other comorbid conditions showed outcomes equal to those in healthy controls regarding medical, educational, and vocational status but experienced significantly more problems with social interaction and relationships. Furthermore, patients with epilepsy and concomitant cognitive impairment had worse psychosocial outcome compared with controls with cognitive impairment in absence of epilepsy. Moreover, Baker et al. ${ }^{7}$ found that adolescents with epilepsy had an increased risk of psychopathology (e.g., depression and anxiety disorders). In a prospective cohort study by Jalava et al. ${ }^{8}$, a statistically significantly decreased social outcome in patients with epilepsy compared with controls thirty-five years after onset of childhood epilepsy was shown. In particular those on antiepileptic polypharmacy or having ongoing seizures reported lower health status. Again, patients had lower educational and vocational rates and lower marital status. These findings are in accordance with Geerts et al. ${ }^{9}$, who found that self-perception of health, educational achievement, living arrangements, and socioeconomic status were less among patients with epilepsy than in the healthy population. Furthermore, remission inpatients with epilepsy had a worse outcome than expected. ${ }^{5,9}$ Therefore, seizure remission is no guarantee for better psychosocial outcome. ${ }^{5,6,9}$

Wakamoto et al. ${ }^{10}$ and Reeve and Lincoln ${ }^{11}$ found more nonproductive coping strategies in adolescents with epilepsy compared with controls, especially during the process of transition, indicating inability to deal with adolescent transitional problems. $^{10,11}$

Continuity of psychosocial and medical care is required to prevent these adolescents and young adults from having negative long-term consequences of epilepsy and to improve societal integration. ${ }^{6}$ On approaching adulthood, adolescents should, at some point, transition from the family-centered pediatric care to the individual-centered adult care. However, recent literature often describes the outcome of this transition, 
which is often a direct transfer to adult care instead of a comprehensive transition process, as problematic. ${ }^{12-14}$ Suddenly, the adolescent is expected to manage his own medical condition along with arising challenging life situations such as their career and relationships. Several transition clinics for adolescents with epilepsy have been set up to cope with this problem. ${ }^{15-18}$ Up to now different designs of transition clinics have been used. Joint consultation of an adult and a pediatric neurologist with or without support of epilepsy nurse specialists is mentioned most. ${ }^{15-18}$

Transition to adulthood is a gradual process starting in early adolescence and continuing into young adulthood. The objective of specialized transition clinics is to identify and intervene in current issues and concerns of adolescents and mark the start of transition from pediatric to adult care. Recognition of patients at risk of poor psychosocial outcome can lead to detection of problems and application of interventions. ${ }^{1}$

The main objective of this study was to analyze risk factors for poor psychosocial outcome in adolescents and young adults with epilepsy who visited a newly set up transition clinic at the tertiary Epilepsy Centre Kempenhaeghe, The Netherlands.

\section{Methods}

\section{Transition clinic}

A transition clinic for adolescents and young adults with epilepsy was set up at Epilepsy Centre Kempenhaeghe in March 2012. Patients were referred to the transition clinic in case at least one medical, psychological or psychosocial issue was present at the moment of referral, e.g., problems with transition from pediatric to adult care, revision of epilepsy diagnosis, optimization of treatment options, learning problems or career advice. Not all patients had had a neuropsychological assessment to measure their intelligence level before their first visit to the transition clinic, but patients with probable severe mental disabilities (presumed $1 Q<50$ ) were not accepted at the transition clinic, since mental retardation might interfere with normal transitional issues and developmental opportunities. These patients were referred to a specific outpatient clinic for patients with both epilepsy and mental retardation at our tertiary referral center.

The epilepsy transition clinic resides in a tertiary referral center for children and adults with epilepsy. It is staffed by a multidisciplinary team consisting of an adult neurologist with adequate knowledge of both pediatric and adult care, a psychologist, a social worker, and an educationalist/occupational counselor. 
Every patient (and caregiver) is scheduled for three consecutive consultations during one morning, in which they are seen by all four abovementioned health-care professionals. The procedure of the transition clinic is shown in Figure 4.1.

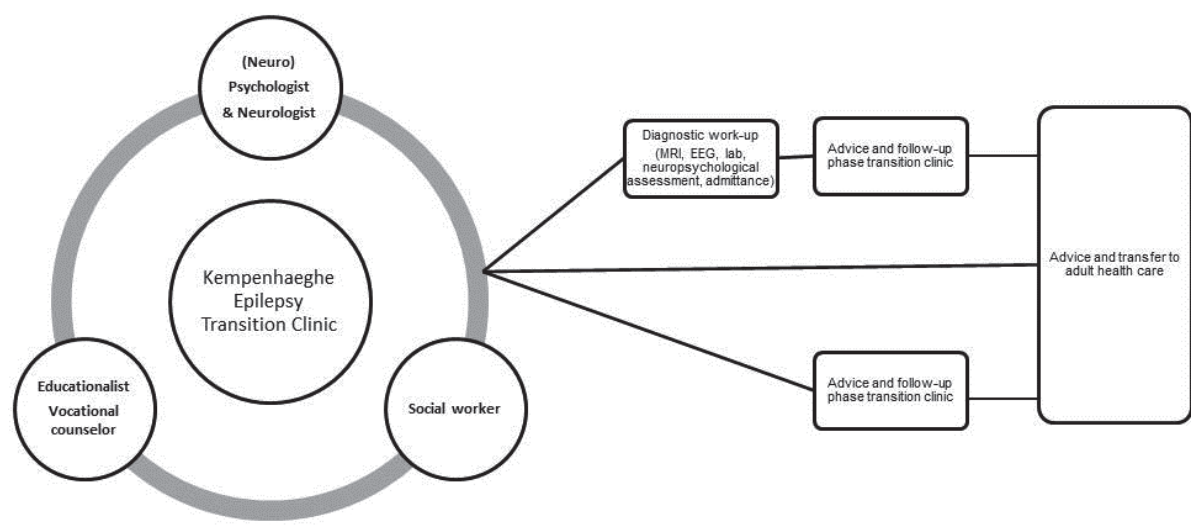

Figure 4.1 Flowchart transition clinic.

All consultations focus on independence and empowerment of the adolescent. Subsequently, the health-care professionals discuss four domains of transition (medical, psychological, social, and educational/vocational) in a multidisciplinary meeting in which tailored advice is formulated. This advice is then discussed with the adolescent (and caregiver) directly afterwards, with the adolescent being in charge of his own decisions.

This advice can be focused on one or several of the four domains leading to a new diagnostic work-up, interventions, or further follow-up by a psychologist, an educationalist/vocational counselor, or a social worker. A diagnostic work-up, including magnetic resonance imaging (MRI), electroencephalography (EEG), a neuropsychologic test, and/or laboratory tests (serum antiepileptic drug (AED) levels, monitoring, for example, renal and/or liver failure, or genetic counseling), provides a new 'snapshot' of the current medical and psychosocial status before the final intervention or advice is provided. The final intervention or advice depends on the individual's problems and may consist of antiepileptic drug alterations, job training or coaching, help with finding suitable housing, support from social work or psychological support. There may be a follow-up period of appointments with the neurologist, psychologist, social worker, or educationist. The goal of the transition clinic is finding tailor-made solutions for transition problems before transferring the patient to adult care. The number of total visits depends on the medical, vocational/educational, or psychosocial problems of the individual patient. Some patients visited the transition clinic only once before they were referred to adult 
medical care. Others, for example, patients who underwent a diagnostic work-up or a change in AED prescription, were followed by the transition clinic's neurologist for a time until they were ready for transition to adult medical care.

No relevant validated scoring systems for adolescents or young adults with epilepsy exist. There is a validated scoring system for patients with traumatic brain injury, namely, the Sydney Psychosocial Reintegration Scale Version 2 (SPRS-2). ${ }^{19}$ The SPRS-2 scores the level of functioning on three different domains: occupational activity for work and leisure, independent living, and relationships. The SPRS-2 is also used in other neurologic conditions, e.g., stroke, primary brain tumor, and spinal cord injury, and is reported in multiple studies. Our scoring system is roughly based on the SPRS-2 for patients with traumatic brain injury, but with respect to specific transitional problems. Scores for the current level of functioning on the medical domain, educational/occupational domain, and independence/separation/identity domain were allocated by the transition clinic's neurologist and psychologist. Scores range from 0 (normal), -1 (suboptimal), to -2 (poor) in our scoring system, compared with scores of 0 ('extreme') to 4 ('not at all') in the SPRS-2. To cope with the wide range of intellectual abilities of the included patients, we individually allocated scores with respect to the optimal level of functioning which can be achieved by an individual. An overview of the classification of our scoring system is provided in Table 4.1.

Another score, namely the risk profile score, was individually determined by the transition clinic's neurologist and psychologist according to the patient's risk of future decline in psychosocial outcome. Risk profile scores for good, moderate, or poor social outcome ranged from 1 to 3 , as previously defined by Camfield and Camfield ${ }^{20}$, and were also allocated with respect to the patient's intellectual capacity and related maximum level of functioning. A score of 3 indicated that the patient already had poor perspectives for transitional outcome, a score of 2 indicated that the patient had a substantial risk of negative outcome (moderate), and a score of 1 indicated a low risk (no obvious risk) for poor psychosocial outcome. Scores for the current level of functioning on the medical domain, educational/occupational domain, and independence/separation/identity domain were allocated by the transition clinic's neurologist and psychologist in a consensus model. If no agreement occurred, discussions were required until consensus. Therefore, a kappa to express the correlation of these scores by the neurologist and psychologist cannot be provided. 


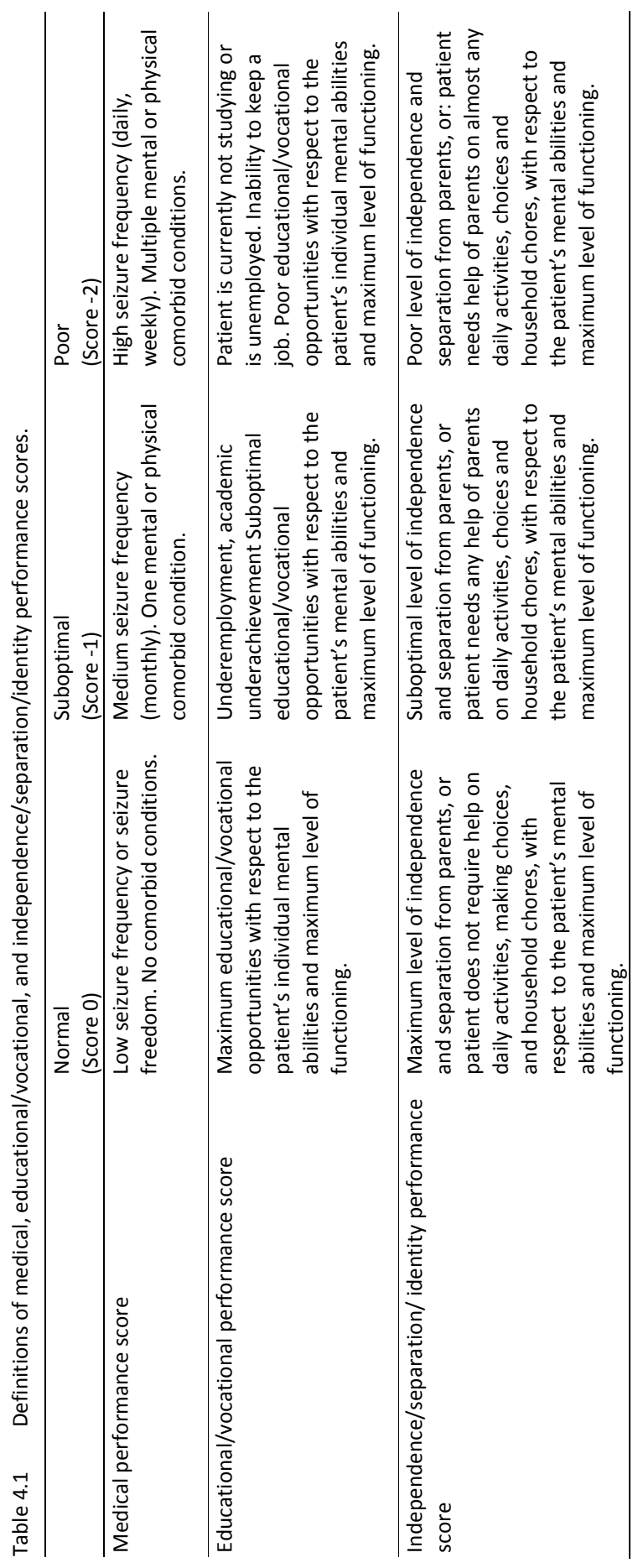




\section{Inclusion and exclusion criteria}

Patients who visited the transition clinic from the start in March 2012 until December 2014 to participate in the study. The criteria for an appointment at the transition clinic (mentioned above in the Methods section) were the same as the inclusion criteria for this study. Adolescents and young adults, 15-25 years of age, with confirmed (childhood-onset) epilepsy were eligible for a visit to the transition clinic. This upper age limit was chosen because developmental milestones are often delayed in patients with epilepsy. ${ }^{3,16}$ Patients were excluded from our analysis if they had nonepileptic seizures only or if they were diagnosed with an $I Q<50$.

\section{Data collection}

Data of all patients who visited the transition clinic and met the inclusion criteria for this study were entered in an IBM SPSS database. Demographic, medical, and psychosocial data were collected, specifically gender, age at first appointment the transition clinic, epilepsy syndromes classified according to International League Against Epilepsy (ILAE) 1989 classification, duration of epilepsy in years, frequency of seizures, use of concomitant antiepileptic drugs, and correct ingestion of the AEDs as reported by the patients themselves or other treatments (e.g., vagus nerve stimulation (VNS), ketogenic diet (KD), or epilepsy surgery), full scale intelligence quotient (IQ) by neuropsychological testing using the Wechsler Intelligence Scale for Children, substance use, psychiatric disorder diagnosed by health-care professionals (mood disorder, attention-deficit/hyperactivity disorder (ADHD), autism spectrum disorder (ASD), or anxiety disorder), all DSM-IV diagnosed by a psychologist or psychiatrist, physical comorbidities (diabetes, arthritis, or other chronic diseases with childhood-onset continuing into adolescence), educational and vocational status, housing, and family history of epilepsy. Having a social network was defined as having several friends or having a romantic relationship. ${ }^{21,22}$ Age-appropriate social independence, evaluated by the social worker, was defined as patients who were able to independently make their own decisions or take care of their own personal hygiene including minor household chores appropriate to the individual's intellectual (dis)abilities. ${ }^{23}$ The level of family support was evaluated by the social worker and clinical neuropsychologist as 'sufficient' or 'insufficient' and was based on the information gathered during the consecutive consultations at the first visit to the transition clinic. A medical work-up was only conducted when considered necessary by the health-care workers and of added value for revision of the diagnosis or for further interventions and consultations. Subsequently, we evaluated the diagnostic work-up conducted after the first visit to the transition clinic, the interventions, consultations, and follow-up by the psychologist, educationalist/vocational counselor, or social worker, and data on referral to adult health-care providers. 


\section{Statistical analysis}

Statistical analysis was performed by using IBM SPSS Version 21. We used descriptive statistics to compute frequencies $(n)$ and percentages (\%) of categorical variables. Means are presented with median, standard deviation (SD), and range.

Nonparametric correlation analysis was used to compute the correlation between the three different performance scores (independent variables) and the individual risk profile score (dependent variable) represented by the Pearson's correlation coefficient $(r)$. The threshold for significance was $p<0.05$.

Data were categorized as demographic (age, gender, IQ, and ever having special education), medical (duration of epilepsy, IQ, number of AEDs, and seizure frequency), or social independence variables (self-reported AED adherence, seizure-free over one year, living arrangements, social participation, and unsupportive/unstable family environments and interactions). Backward multiple linear regression analysis was applied to determine demographic, medical, and social variables as independent risk factors associated with the risk profile score. The proportion of explained variance $\left(R^{2}\right)$, unstandardized coefficient B, standard error B (SE B), 95\% Confidence Interval $(\mathrm{Cl})$, and standardized coefficients $(\beta)$ are shown. The threshold for significance was $p<0.05$.

Because the level of intelligence was used in both demographic and medical regression models, the level of significance from this variable differs between these models. To create a uniform set of outcome variables, the correlation between variables and risk profile scores is represented the Pearson's correlation coefficient $(r)$, and the level of significance $(p)$ in regression analysis. All variables which were significant in the regression analysis were included in a discriminant function analysis to determine the predictive value of these variables.

\section{Ethics}

The Medical Ethics Committee of Kempenhaeghe considered this as a medical audit for which general approval of patients was already provided. Patients could withdraw consent for participation upon request.

\section{Results}

\section{Outcome of the epilepsy transition clinic}

Between March 2012 and December 2014, a total of 148 patients visited the transition clinic at Epilepsy Centre Kempenhaeghe, a tertiary center for patients with epilepsy in The Netherlands. Ten patients were excluded from our analysis: two patients did not give consent to use their medical data for research purposes, three patients exceeded the age limitation for inclusion, three patients were not diagnosed 
with epilepsy at the time of their first visit (two suffering from psychogenic nonepileptic seizures and one having learning disabilities without epilepsy), and wo patients were excluded because severe posttraumatic stress disorder initiated their social problems, not epilepsy. A total of 138 patients were finally included in this study.

\section{Patient characteristics}

Demographic, epilepsy-related, and psychosocial characteristics at the initial visit to the transition clinic are shown in Table 4.2. A total of 78 (56.5\%) men and 60 (43.5\%) women visited the transition clinic, with a mean age of 18.7 years (median=18.2, $\mathrm{SD}=2.1$ ). The mean IQ was 82.6 (median=82, SD=15.3). Sixty (43.5\%) patients had ever been involved in a special education program. Seventy-three $(52.9 \%)$ patients had at least one mental or psychiatric comorbidity, of which autism spectrum disorder (ASD) (14.5\%) was the most common (men $n=15$, women $n=5)$. Twenty-one (15.2\%) had physical comorbidity, e.g., hearing problems $(n=6,4.3 \%)$ or cerebral palsy $(n=5,3.6 \%)$. The mean age at diagnosis of epilepsy was 8.1 years (median=8.0, SD=4.9) with a mean duration of epilepsy of 10.5 years (median=9.7, SD=5.1). The most common type of epilepsy syndrome was localization-related epilepsy ( $n=109,79.0 \%)$. On average, patients were seizure-free for 1.5 years (median=0.3, SD=2.9). Sixty-four (46.4\%) patients were seizure-free for more than one year. One hundred and twentyseven (92.0\%) patients were currently using AEDs, of which 67 (48.6\%) patients were on monotherapy. One hundred and nine (79.0\%) patients showed self-reported AED adherence. Three patients had a VNS (2.2\%), two were on a KD (1.4\%) and six had had epilepsy surgery in the past (4.3\%).

In the total study population, 127 (92.0\%) patients were still living at home with their parents compared with 15 (88.2\%) out of 17 patients $21-25$ years of age. Four (23.5\%) out of seventeen patients 21-25 years of age were unemployed and not studying. Forty (29.0\%) patients were living in an unsupportive and unstable family environment. Ninety-eight (71.0\%) patients were considered to have their own sufficient social network. Based on the data collection, $63(45.7 \%)$ patients were considered independent. 
Table 4.2 Demographic, epilepsy-related, and psychosocial variables.

\begin{tabular}{|c|c|c|c|c|}
\hline & & Median & SD & Range \\
\hline \multicolumn{5}{|l|}{ Gender } \\
\hline Men & $78(56.5 \%)$ & & & \\
\hline Women & 60 (43.5\%) & & & \\
\hline Mean age at first visit & 18.7 & 18.2 & 2.1 & $15-25$ \\
\hline Younger than 18 years of age & $62(44.9 \%)$ & & & \\
\hline Mean Full scale Intelligence Quotient (FSIQ) & 82.6 & 82 & 15.3 & $51-113$ \\
\hline $\mathrm{I} Q>100$ & $15(10.9 \%)$ & & & \\
\hline IQ 90-100 & $23(16.7 \%)$ & & & \\
\hline IQ 70-90 & $49(35.5 \%)$ & & & \\
\hline IQ 50-70 & $25(18.1 \%)$ & & & \\
\hline Not assessed & $26(18.8 \%)$ & & & \\
\hline Mean age at diagnosis of epilepsy & 8.1 & 8.0 & 4.9 & $0.1-21.5$ \\
\hline Mean duration of epilepsy (years) & 10.5 & 9.7 & 5.1 & $0.33-21.32$ \\
\hline \multicolumn{5}{|l|}{ Type of epilepsy } \\
\hline Localization-related epilepsy & $109(79.0 \%)$ & & & \\
\hline Idiopathic & $6(4.3 \%)$ & & & \\
\hline Symptomatic & 27 (19.6\%) & & & \\
\hline Cryptogenic & $76(55.1 \%)$ & & & \\
\hline Generalized epilepsy & $24(17.4 \%)$ & & & \\
\hline Idiopathic & $19(13.8 \%)$ & & & \\
\hline Symptomatic & $5(3.6 \%)$ & & & \\
\hline Cryptogenic & $0(0 \%)$ & & & \\
\hline Landau-Kleffner syndrome & $1(0.7 \%)$ & & & \\
\hline Not classified yet & $4(2.9 \%)$ & & & \\
\hline \multicolumn{5}{|l|}{ Seizure frequency } \\
\hline Daily & $16(11.6 \%)$ & & & \\
\hline Last week & $16(11.6 \%)$ & & & \\
\hline Last month & $26(18.8 \%)$ & & & \\
\hline Last year & $8(5.8 \%)$ & & & \\
\hline Seizure-free $>1$ year & $64(46.4 \%)$ & & & \\
\hline Unknown & $8(5.8 \%)$ & & & \\
\hline Mean number of seizure-free years & 1.5 & 0.3 & 2.9 & $0-21.3$ \\
\hline \multicolumn{5}{|l|}{ Number of AEDs } \\
\hline No current AED treatment & $11(8.0 \%)$ & & & \\
\hline Monotherapy & $67(48.6 \%)$ & & & \\
\hline Polytherapy ( 2 to 4 AEDs) & $60(43.5 \%)$ & & & \\
\hline \multicolumn{5}{|l|}{ Self-reported AED adherence } \\
\hline Yes/most likely yes & $109(79.0 \%)$ & & & \\
\hline No & $18(13.0 \%)$ & & & \\
\hline No current AED treatment & $11(8.0 \%)$ & & & \\
\hline \multicolumn{5}{|l|}{ Previous therapies } \\
\hline Epileptic surgery & $6(4.3 \%)$ & & & \\
\hline Vagal Nerve Stimulator & $3(2.2 \%)$ & & & \\
\hline Ketogenic diet & $2(1.4 \%)$ & & & \\
\hline \multicolumn{5}{|l|}{ Special education program } \\
\hline In the past/ever & $60(43.5 \%)$ & & & \\
\hline Current & $42(30.4 \%)$ & & & \\
\hline \multicolumn{5}{|l|}{ Living arrangements } \\
\hline At home with parents & 127 (92.0\%) & & & \\
\hline Independent & $4(2.9 \%)$ & & & \\
\hline Supported accommodation & $5(3.6 \%)$ & & & \\
\hline Unknown & $2(1.4 \%)$ & & & \\
\hline
\end{tabular}


Table 4.2 (continued)

\begin{tabular}{|c|c|c|c|c|}
\hline & & Median & SD & Range \\
\hline Social participation & $98(71.0 \%)$ & & & \\
\hline Independence & $63(45.7 \%)$ & & & \\
\hline Unsupportive/unstable family environment & $40(29.0 \%)$ & & & \\
\hline \multicolumn{5}{|l|}{ Employment } \\
\hline Yes & $59(42.8 \%)$ & & & \\
\hline No & $18(13.0 \%)$ & & & \\
\hline Internship & $21(15.2 \%)$ & & & \\
\hline Student without a job & $38(27.5 \%)$ & & & \\
\hline Unknown & $2(1.4 \%)$ & & & \\
\hline
\end{tabular}

Data are presented as number $(n, \%)$. Means are presented with median, standard deviation (SD), and range.

\section{Transitional care}

A supplementary diagnostic work-up was considered necessary in 100 (72.5\%) patients and involved a neuropsychologic test ( $n=73,52.9 \%)$, an EEG ( $n=70,50.7 \%)$, $\operatorname{MRI}(n=29,21.0 \%)$, or laboratory tests $(n=48,34.8 \%)$. Forty-five $(32.6 \%)$ patients were briefly (for a maximum of $24 \mathrm{~h}$ ) admitted to facilitate the diagnostic work-up.

The epilepsy diagnosis was changed in 16 (11.6\%) patients following their diagnostic work-up, from which thirteen were diagnosed with a different epilepsy syndrome, and three were diagnosed with a nonepileptic disorder (e.g., nonepileptic seizures). To be more specific, in eight patients, the diagnosis of cryptogenic localization-related epilepsy was changed: four patients were diagnosed with either idiopathic generalized epilepsy or cryptogenic generalized epilepsy; in one patient, the diagnosis was specified as juvenile absence epilepsy (JAE); one patient was diagnosed with idiopathic localization-related epilepsy; in one patient, the diagnosis was not yet specified but certainly not cryptogenic localization-related epilepsy; and one patient was diagnosed with nonepileptic seizures.

In four patients, the diagnosis of idiopathic generalized epilepsy was changed: in two patients, the diagnosis was specified as juvenile myoclonic epilepsy; one patient was diagnosed with cryptogenic localization-related epilepsy; and one patient was diagnosed with nonepileptic seizures.

Two patients with symptomatic localization-related epilepsy were diagnosed with another major cause than epilepsy for their transition problems, namely, a visual agnosia due to a developmental malformation of the occipital lobes or another cause of their symptomatic localization-related seizures than previously diagnosed.

One patient with idiopathic localization-related seizures was diagnosed with symptomatic localization-related seizures.

One patient with symptomatic generalized seizures was diagnosed with idiopathic generalized seizures.

Antiepileptic drugs were changed in 75 (54.3\%) patients, for example, because of remission of epilepsy $(n=22,15.9 \%)$ or side effects $(n=16,11.6 \%)$. In ten $(90,9 \%)$ out of 
eleven women using valproate, this AED was withdrawn because of reaching the childbearing age. In addition, eleven (8.0\%) patients were referred to an assessment team to explore epilepsy surgery as a treatment option. Two (1.4\%) patients were referred for a VNS, and one patient was referred to start with a KD.

A social worker was involved in guidance and follow-up of $63(45.7 \%)$ patients, and exploration of living arrangements was carried out in $36(26.1 \%)$ patients. The educationalist/vocational counselor provided 47 (34.1\%) patients with advice and follow-up. Some patients had more than one follow-up consultation or intervention. Follow-up and interventions are shown in Table 4.3. Because transition is a gradual process instead of a single handing over, the number of visits to the transition clinic ranged from 1 to 9 (average=2.95, median=2), with a maximum total duration of 30.95 months (average=8.6 months, median=4.4) from the time of referral to the transition clinic until the time of referral to adult care. At the time of statistical analysis of this manuscript, 71 (51.4\%) patients were still in follow-up of epilepsy care by the neurologist of the transition clinic. The main reasons for remaining under temporary follow-up are as follows: (1) changes in AED prescription ( $n=36,50.7 \%)$ and (2) waiting for the results of a diagnostic work-up ( $n=16,22.5 \%)$. Nineteen (36.8\%) out of these 71 patients in follow-up decided to continue their long-term epilepsy care with regular visits to the transition clinic's adult neurologist, and, thus, were 'referred to adult care'.

Table 4.3 Transition clinic variables.

\begin{tabular}{|c|c|c|c|}
\hline & & Median & Range \\
\hline Visits to the transition clinic & 2.95 & 2 & $1-9$ \\
\hline Duration of follow-up at the transition clinic (months) & 8.6 & 4.4 & 0-30.95 \\
\hline Diagnostic work-up after first visit to the transition clinic & $100(72.5 \%)$ & & \\
\hline Clinical neuropsychological assessment & $73(52.9 \%)$ & & \\
\hline EEG & $70(50.7 \%)$ & & \\
\hline MRI & $29(21.0 \%)$ & & \\
\hline Admittance for diagnostic work-up & $45(32.6 \%)$ & & \\
\hline Laboratory & $48(34.8 \%)$ & & \\
\hline Serum blood levels & $47(34.1 \%)$ & & \\
\hline AED levels & $37(26.8 \%)$ & & \\
\hline Genetic counseling & $9(6.5 \%)$ & & \\
\hline AED change & $75(54.3 \%)$ & & \\
\hline \multicolumn{4}{|l|}{ Reason for AED change } \\
\hline Epilepsy remission & $22(15.9 \%)$ & & \\
\hline Side effects & $16(11.6 \%)$ & & \\
\hline Switch of AED & $8(5.8 \%)$ & & \\
\hline Addition of AED & $8(5.8 \%)$ & & \\
\hline Increase dose of AED & $7(5.1 \%)$ & & \\
\hline Decrease dose of AED & $4(2.9 \%)$ & & \\
\hline Woman in child-bearing age & $10(7.2 \%)$ & & \\
\hline Change of diagnosis & $16(11.6 \%)$ & & \\
\hline Other types of epilepsy syndrome & $13(9.4 \%)$ & & \\
\hline No epilepsy diagnosis & $3(2.2 \%)$ & & \\
\hline
\end{tabular}




\begin{tabular}{|c|c|c|c|}
\hline & & Median & Range \\
\hline \multicolumn{4}{|l|}{$\begin{array}{l}\text { Consultation transition clinic (some patients had }>1 \\
\text { intervention/consultation) }\end{array}$} \\
\hline Social worker & $63(45.7 \%)$ & & \\
\hline Housing assistance & $36(26.1 \%)$ & & \\
\hline Reason - improving family support & $10(7.2 \%)$ & & \\
\hline Reason - improving separation/individualization & $13(9.4 \%)$ & & \\
\hline Reason - financial advice & $14(10.1 \%)$ & & \\
\hline Reason - increasing social interaction and support & $5(3.6 \%)$ & & \\
\hline Reason - addiction & $1(0.7 \%)$ & & \\
\hline Reason - planning daily activities & $2(1.4 \%)$ & & \\
\hline Educationalist/vocational counselor & $47(34.1 \%)$ & & \\
\hline Educational assistance & $30(21.7 \%)$ & & \\
\hline Vocational assistance & $14(10.1 \%)$ & & \\
\hline Vocational training & $11(8.0 \%)$ & & \\
\hline Psychological assistance & $19(13.8 \%)$ & & \\
\hline Epilepsy surgery & $11(8.0 \%)$ & & \\
\hline Vagal Nerve Stimulator & $2(1.4 \%)$ & & \\
\hline Ketogenic diet & $1(0.7 \%)$ & & \\
\hline \multicolumn{4}{|l|}{ Referral to } \\
\hline Transition clinic's neurologist (see below) & $71(51.4 \%)$ & & \\
\hline Adult neurologist within the epilepsy center & $35(25.4 \%)$ & & \\
\hline External referral to adult neurologist & $11(8.0 \%)$ & & \\
\hline General practitioner & $11(8.0 \%)$ & & \\
\hline Psychiatrist & $3(2.2 \%)$ & & \\
\hline Pediatric neurologist (patient $<18$ years of age) & $1(0.7 \%)$ & & \\
\hline Lost to follow-up & $6(4.3 \%)$ & & \\
\hline \multicolumn{4}{|l|}{$\begin{array}{l}\text { Main reasons for follow-up with the transition } \\
\text { clinic's neurologist }\end{array}$} \\
\hline Long-term epilepsy care ('Transition to adult care') & $19(26.8 \%)$ & & \\
\hline After recent changes in AED prescription & $36(50.7 \%)$ & & \\
\hline Awaiting the results of a diagnostic work-up & $16(22.5 \%)$ & & \\
\hline
\end{tabular}

Data are presented as number $(n, \%)$. Means are presented with median and range.

Eventually, 46 (33.3\%) patients were transferred to an adult neurologist, of which 35 were sent to a neurologist in a tertiary referral center and 11 to a neurologist in a general hospital. Eleven (8.0\%) patients were referred to a general practitioner, and three $(2.2 \%)$ to a psychiatrist for further follow-up. Fourteen (10.1\%) patients had seizure remission. Three out of these 14 patients had a low total performance score over the three domains, indicating current poor level of functioning, combined with a high risk profile score. These three patients were referred to the social worker and/or psychologist for further care and follow-up of their psychosocial problems, but medical care was no longer required because of their seizure freedom. 


\section{Correlations of performance scores with risk profile scores}

According to the risk profile scores, $47.8 \%$ were scored as high-risk patients, and about $31.9 \%$ were at mild risk of poor outcome in the long term.

Performance scores for medical, educational/occupational status, and independence/separation/identity showed a significant correlation with the risk profile scores. Scores for independence/separation/identity were strongly related $(r=0.823, p<0.001)$, followed by educational/occupational scores $(r=0.731, p<0.001)$, and medical status $(r=0.575, p<0.001)$ (Table 4.4).

Table 4.4 Medical, educational/vocational and independence performance scores and personal risk profile scores. Nonparametric correlations between performance scores and risk profile scores are shown.

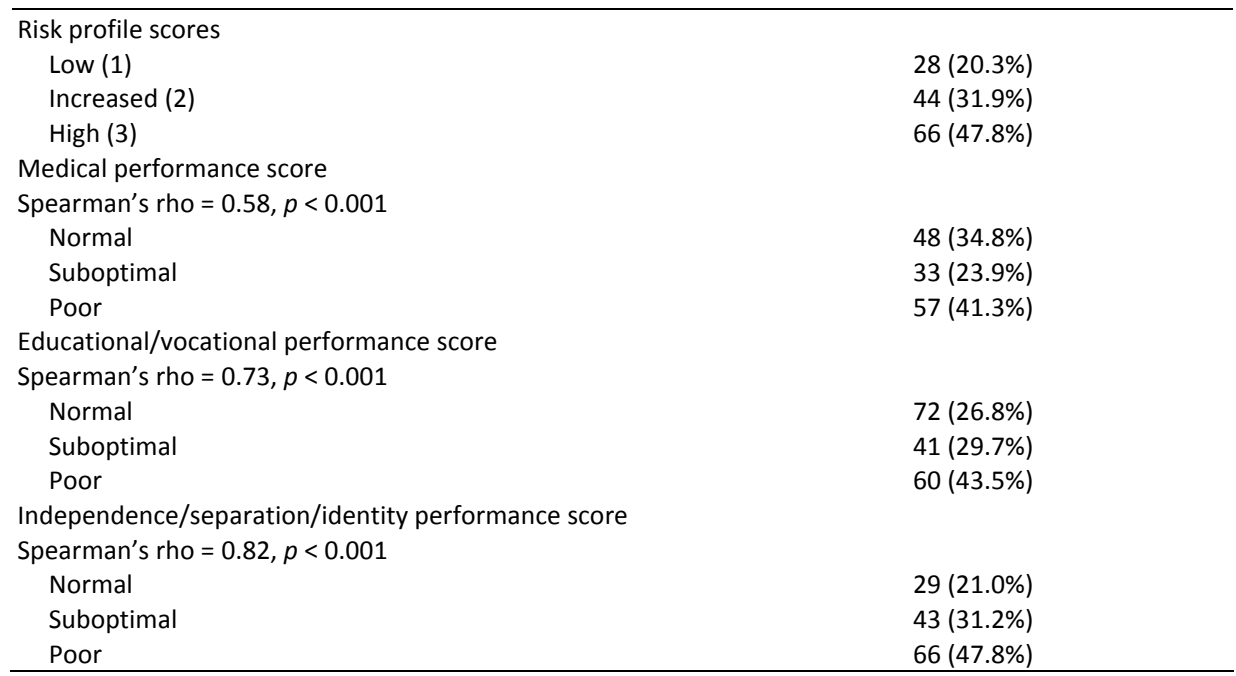

Data are presented as number $(n, \%)$.

\section{Multivariate linear regression analysis of demographic, medical, and psychosocial variables with risk profile scores}

Demographic, medical (epilepsy related), and psychosocial variables were entered in three separate multivariate linear regression analyses to predict risk profile scores. The prediction models for all three individual linear regression analyses were statistically significant for demographic variables $F(4,133)=5.648, p<0.001$, explaining $14.5 \%$ of the variance $\left(R^{2}=0.145\right)$, for epilepsy-related variables $F(4,133)=8.735$, $p<0.001$, accounting for $20.8 \%$ of the variance $\left(R^{2}=0.208\right)$, and for psychosocial variables $F(5,132)=7.127, p<0.001$ explaining approximately $21.3 \%$ of the variance $\left(R^{2}=0.213\right)$ of risk profile scores. There were no signs of multicollinearity in all of the three models, with a VIF-value ranging between 1.013 and 1.198. 
Significant variables in predicting risk profile scores were unsupportive family environment $(r=0.363, p<0.001)$, lower intelligence (in both demographic and medical analyses, $r=-0.334$ and $p<0.000$ and $p=0.005$, respectively), higher seizure frequency $(r=0.311, p=0.001)$, and ongoing seizures (seizure remission was negatively correlated with a high risk) ( $r=-0.257, p=0.045)$. The strongest weight belonged to unsupportive family environment $(\beta=0.315)$, followed by IQ (in the demographic analysis, $\beta=-0.310$, and $\beta=-0.224$ in the medical analysis), seizure frequency $(\beta=0.273)$, and, to a lesser extent, to ongoing seizures $(\beta=0.166)$. An overview of the results of the regression analyses is shown in Table 4.5 and in Figure 4.2.

Table 4.5 Correlations of risk profile scores and demographic, epilepsy-related, and psychosocial variables.

\begin{tabular}{lccccc}
\hline & $r$ & $\mathrm{~B}(\mathrm{Cl})$ & $\mathrm{SE} \mathrm{B}$ & $\beta$ & $p$ \\
\hline Demographic variables $\mathrm{R}^{2}=0.145$ & & & & & \\
$\quad$ Age at first visit & 0.087 & $0.046(-0.015-0.107)$ & 0.031 & 0.121 & 0.137 \\
Gender & 0.028 & $0.084(-0.171-0.339)$ & 0.129 & 0.054 & 0.515 \\
IQ & -0.344 & $-0.018(-0.027$ to -0.008$)$ & 0.005 & -0.310 & $<0.001$ \\
Special education & 0.210 & $0.203(-0.073-0.479)$ & 0.139 & 0.127 & 0.148 \\
Epilepsy-related variables $\mathrm{R}^{2}=0.208$ & & & & & \\
Duration of epilepsy & 0.247 & $0.025(-0.001-0.050)$ & 0.013 & 0.159 & 0.058 \\
IQ & -0.344 & $-0.014(-0.023$ to -0.004) & 0.005 & -0.224 & 0.005 \\
Number of AEDs & 0.088 & $-0.002(-0.148-0.145)$ & 0.074 & -0.002 & 0.981 \\
Seizure frequency & 0.311 & $0.148(0.064-0.232)$ & 0.043 & 0.273 & 0.001 \\
Psychosocial variables $\mathrm{R}^{2}=0.213$ & & & & & \\
Adherence & -0.209 & $-0.237(-0.511-0.037)$ & 0.139 & -0.138 & 0.090 \\
Seizure-free >1 year & -0.257 & $-0.274(-0.542$ to -0.006) & 0.136 & -0.166 & 0.045 \\
Living arrangements & 0.034 & $0.076(-0.242-0.395)$ & 0.161 & 0.037 & 0.637 \\
$\quad$ Social participation & -0.181 & $-0.270(-0.566-0.026)$ & 0.150 & -0.141 & 0.073 \\
$\quad$ Unsupportive family environment & 0.363 & $0.550(0.277-0.823)$ & 0.149 & 0.315 & $<0.001$ \\
\hline
\end{tabular}

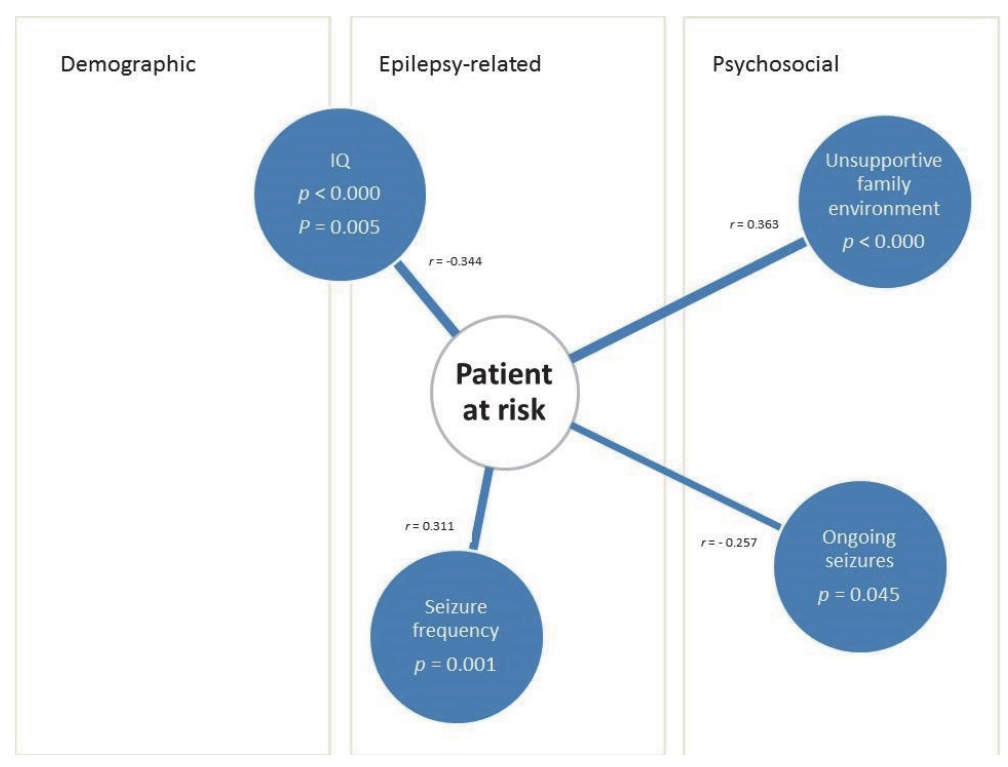


Figure 4.2 Significant demographic, epilepsy-related, and psychosocial variables and their correlation coefficient $(r)$.

\section{Discriminant analysis}

The results of the regression analysis were tested in a discriminant function analysis to control for the predictive power of the identified risk factors for poor transitional outcome. Intelligence, frequency of seizures and seizure freedom over one year, and unsupportive family interactions were used as predictor variables. The discriminant analysis significantly differentiated groups (Wilks' Lambda $=0.718, \mathrm{Chi}^{2}(4)=30.612$, $p<0.001)$. Studying the Structure Matrix Table revealed that unsupportive family interactions $(0.708)$, and low intelligence $(-0.657)$ were strong predictors, whereas seizure frequency $(0.093)$ and ongoing seizures $(0.050)$ were poor predictors. The cross-validated classification showed that with the predictors in combination $55.1 \%$ of the patients were correctly classified. Patients at high risk were better classified (positive predictive value of $57.6 \%$ ) compared with patients without obvious risk (negative predictive value $46.4 \%$ ) for poor transitional outcome.

\section{Discussion}

In our study, we described four risk factors for poor psychosocial outcome in adolescents and young adults with epilepsy. In both regression and discriminant analyses, impaired, unsupportive, and unstable family dynamics was the strongest predictor for long-term poor psychosocial outcome in adolescents and young adults with epilepsy. Intelligence level and seizure remission were negatively correlated variables for poor transitional outcome in the long term. Furthermore, a high seizure frequency was found to be significant (Table 4.5, Figure 4.2).

This study identified risk factors during the years of transition and took into account multidomain specific transitional problems. Previous studies have focused on risk factors in either children or adults, while adolescence and approaching adulthood are characterized by a specific developmental period not comparable with other age groups. $^{24-28}$ Specific age-related developmental milestones, e.g., medication adherence, and living arrangements as a part of developing independence are not yet relevant for a cared-for childhood population. However, most childhood studies are based on parent-reported instead of patient-reported quality-of-life or psychosocial outcome measures. ${ }^{25-29}$ Outcomes reported by parents or health-care workers do not necessarily correlate with patient-reported outcomes. ${ }^{30}$ Studies including adolescents and young adults were not conducted in an epilepsy transition clinic and 
predominantly measured health-related quality-of-life (HRQOL), without examining age-specific transition-related psychosocial and medical issues, e.g., development of independence and living arrangements. ${ }^{26}$ Because designs and population of these studies differ substantially from our study, it is difficult to compare the results.

Only a few studies mentioned the detrimental effects of unsupportive family environments and lack of social and societal support as profound risk factors for poor psychosocial outcome in patients with epilepsy. ${ }^{2,28,31-33}$ Fastenau et al. $^{32}$ found that children (8-15 years) with epilepsy and intellectual disabilities were at risk of poor academic outcome, especially those with a disruptive or unstable family environment. Jayalakshmi et al. ${ }^{34}$, found that patients with juvenile myoclonic epilepsy (15-40 years of age) without proper family support had lower AED adherence, resulting in reduced seizure control, a higher incidence of psychiatric disorders, and lower educational and vocational levels. Furthermore, patients experiencing societal or family support have improved coping mechanisms, higher socioeconomic status, and, thus, an increased self-reported quality of life $(\mathrm{QoL}){ }^{2,33}$ Further, higher $\mathrm{QoL}$ is associated with fewer outpatient or hospital visits and admissions. ${ }^{2}$

In our study, a lower intelligence level was the second strongest risk factor for longterm poor psychosocial outcome. Intellectual disabilities and associated learning disorders affect approximately $26 \%$ to $33 \%$ of the patients with epilepsy, respectively. ${ }^{1,2,35-37}$ Several studies identified intelligence or education level as predictors of psychosocial problems during adolescence and early adulthood. ${ }^{10,20,25-}$ ${ }^{28,38,39}$ However, these results have some limitations, as some psychosocial items in the HRQOL outcome measurement are irrelevant to children with an intellectual disability. ${ }^{25}$ In our current study, scores on the three different domains were allocated with respect to the patient's maximum intellectual abilities (See Table 4.1 for further details).

Evidence is conflicting, as one study ${ }^{40}$ and a meta-analysis ${ }^{29}$ found that intelligence and level of education were not significantly associated with poor outcome. Remarkably, most of the studies evaluated in the meta-analysis excluded children with a cognitive disability.

Epilepsy-specific factors are among the most commonly analyzed predictors for longterm psychosocial outcome in patients with epilepsy. ${ }^{25,26,29,31,39-45}$ Seizure frequency and the consequences of ongoing seizures are the most predominant epilepsy-related determinants of physical and mental well-being and social participation. ${ }^{26,29,40,42-47}$ However, Eom et al. ${ }^{41}$ and Miller et al. ${ }^{25}$ found seizure frequency to not significantly influence any aspect of psychosocial function, and according to Kokkonen et al. ${ }^{39}$, having epilepsy itself did not significantly influence the psychosocial outcome. The aforementioned heterogeneity among study populations and designs might be a reasonable explanation for the contradictory evidence. Poor psychosocial outcome is predicted not only by seizure frequency alone but also by seizure type and seizure severity. ${ }^{46}$ Unfortunately, both variables were not studied separately in our study. 
Several studies indicated that patients with seizure remission have a persistent increased risk of adverse social outcome in the long-term. Sillanpää et al. ${ }^{48}$ showed that patients with normal intelligence and epilepsy in remission were less often in a relationship and less often employed compared with controls after long-term followup. Geerts et al. ${ }^{9}$ found that both patients with ongoing seizures and patients with seizure remission had a worse outcome than expected compared with the Dutch control group after 15 years of follow-up. Camfield and Camfield ${ }^{20}$ found that adults with childhood Rolandic epilepsy had a better psychosocial outcome compared with patients with juvenile myoclonic epilepsy, epilepsy with generalized tonic-clonic seizures only, epilepsies characterized by complex partial seizures, and epilepsies characterized by only focal seizures with secondary generalization. However, even in patients with seizure remission, adverse psychosocial outcomes were found. ${ }^{20}$ In another study, Camfield et al. ${ }^{22}$ stated that patients with benign epilepsy with centrotemporal spikes (BECTSs) do not need any care or further follow-up because psychosocial outcomes are similar to those in the population in contrast to patients with nonlesional focal epilepsy in otherwise normal children (NLFN), childhood absence epilepsy (CAE), and juvenile myoclonic epilepsy (JME).

Ideally, early identification of patients at risk of poor psychosocial outcome could lead to preventive measures. Besides, it would be beneficial to prepare youth with chronic epilepsy for transition to adulthood, for example by increasing and supporting their independence. Furthermore, preparation for transition to adult care can be improved at an early stage, although the optimum age limit for preparation and transition remains unknown. ${ }^{49-51}$

\section{Strengths and limitations}

This study has several limitations. Firstly, demographic, epilepsy-related, and psychosocial characteristics account for $14.5 \%, 20.8 \%$, and $21.3 \%$ of the explained variance, respectively. With the predictors in combination, $55.1 \%$ of the patients were correctly classified, indicating that the outcome score is determined by more variables than we included in the current analysis. In general, $55.1 \%$ is a high score, though as in clinical practice, many factors cannot be controlled.

Secondly, children with other comorbid physical conditions were entered in the analysis. This could introduce confounders, as other chronic childhood-onset diseases might also affect psychosocial and medical outcomes.

Thirdly, several social variables in our analysis were ('objectively') scored by the health-care professionals of the transition clinic, e.g., age-appropriate social independence was scored by the social worker. It remains unclear whether these scores correspond with the patient's ('subjective') perception. A study by van Hedel et al. $^{30}$ showed only moderate correlations between patient-reported and investigator- 
reported scores for independency up to one year after patients' spinal cord injury. Different physical, psychological, and cultural factors can influence patient-reported outcome, and differences exist between physical and emotional scores reported by patients and investigators. ${ }^{30,52}$ Hence, it would be of added value to measure patientreported outcomes on physical and emotional domains as well, along with their preferences for transitional care. ${ }^{25,29,50}$

Unfortunately, we were unable to collect a valid group of matched control patients within our hospital because, in our tertiary referral epilepsy center, only patients with epilepsy are treated.

Fourth, Borlot et al. ${ }^{53}$ recently found that patients primary referred to a tertiary center like Kempenhaeghe might have more severe epileptic syndromes.

It was unfortunately impossible to prove the efficacy of interventions within this study. In order to identify positive interventions and therapies, we suggest that future studies should focus on positive or negative psychosocial outcome as a result of previous interventions.

\section{Conclusion}

We identified four risk factors for poor psychosocial outcome in the long-term in adolescents and young adults with epilepsy, namely poor family support, ongoing seizures (chronic refractory epilepsy), a high seizure frequency, and a low intelligence level. Identification of risk factors can lead to early recognition of those at risk and thereby to an early adequate therapeutic approach and tailored interventions. This study stressed the importance of revision of epilepsy diagnosis and its treatment, psychosocial issues that arise during adolescence and early adulthood, and transitional care. 


\section{References}

1. Sillanpää M, Helen Cross J. The psychosocial impact of epilepsy in childhood. Epilepsy Behav 2009;15 Suppl 1:S5-10.

2. Bautista RE, Shapovalov D, Saada F, et al. The societal integration of individuals with epilepsy: perspectives for the 21st century. Epilepsy Behav 2014;35:42-9.

3. Colver A, Longwell S. New understanding of adolescent brain development: relevance to transitional healthcare for young people with long term conditions. Arch Dis Child 2013;98:902-7.

4. Valizadeh L, Barzegar M, Akbarbegloo M, et al. The relationship between psychosocial care and attitudes toward illness in adolescents with epilepsy. Epilepsy Behav 2013;27:267-71.

5. Camfield PR, Camfield CS. What Happens to Children With Epilepsy When They Become Adults? Some Facts and Opinions. Pediatr Neurol 2014;51:17-23.

6. Chin RF, Cumberland PM, Pujar SS, et al. Outcomes of childhood epilepsy at age 33 years: a population-based birth-cohort study. Epilepsia 2011;52:1513-21.

7. Baker GA, Spector S, McGrath Y, et al. Impact of epilepsy in adolescence: a UK controlled study. Epilepsy Behav 2005;6:556-62.

8. Jalava $M$, Sillanpää $M$, Camfield $C$, et al. Social adjustment and competence 35 years after onset of childhood epilepsy: a prospective controlled study. Epilepsia 1997;38:708-15.

9. Geerts A, Brouwer O, van Donselaar C, et al. Health perception and socioeconomic status following childhood-onset epilepsy: the Dutch study of epilepsy in childhood. Epilepsia 2011;52:2192-202.

10. Wakamoto $\mathrm{H}$, Nagao $\mathrm{H}$, Hayashi $\mathrm{M}$, et al. Long-term medical, educational, and social prognoses of childhood-onset epilepsy: a population-based study in a rural district of Japan. Brain Dev 2000; 22:246-55.

11. Reeve DK, Lincoln NB. Coping with the challenge of transition in older adolescents with epilepsy. Seizure 2002;11:33-9.

12. Khan A, Baheerathan A, Hussain N, et al. Transition of children with epilepsies to adult care. Acta Paediatr 2013;102:216-21.

13. Schultz RJ. Parental experiences transitioning their adolescent with epilepsy and cognitive impairments to adult health care. J Pediatr Health Care 2013;27:359-66.

14. Camfield P, Camfield C, Pohlmann-Eden B. Transition from pediatric to adult epilepsy care: a difficult process marked by medical and social crisis. Epilepsy Curr 2012;12:13-21.

15. Iyer A, Appleton R. Transitional services for adolescents with epilepsy in the U.K.: a survey. Seizure 2013;22:433-7.

16. Jurasek L, Ray L, Quigley D. Development and implementation of an adolescent epilepsy transition clinic. J Neurosci Nurs 2010;42:181-9.

17. Smith PE, Myson V, Gibbon F. A teenager epilepsy clinic: observational study. Eur J Neurol 2002; 9:373-6.

18. Appleton RE, Chadwick D, Sweeney A. Managing the teenager with epilepsy: pediatric to adult care. Seizure 1997;6:27-30.

19. Tate R, Hodgkinson A, Veerabangsa A, et al. Measuring psychosocial recovery after traumatic brain injury: psychometric properties of a new scale. J Head Trauma Rehabil 1999;14:543-57.

20. Camfield C, Camfield P. Twenty years after childhood-onset symptomatic generalized epilepsy the social outcome is usually dependency or death: a population-based study. Dev Med Child Neurol 2008;50:859-63.

21. Camfield P, Camfield C, Nolan K. Helping families cope with the devastation of Dravet syndrome. Eur J Paediatr Neurol 2012;16 Suppl 1:S9-12.

22. Camfield CS, Berg A, Stephani U, et al. Transition issues for benign epilepsy with centrotemporal spikes, nonlesional focal epilepsy in otherwise normal children, childhood absence epilepsy, and juvenile myoclonic epilepsy. Epilepsia 2014;55 Suppl 3:16-20.

23. Miller SM, Chan F. Predictors of life satisfaction in individuals with intellectual disabilities. J Intellect Disabil Res 2008;52:1039-47.

24. Devinsky O. Transition to adult care for children with epilepsy--a call for action. Epilepsia 2014;55 Suppl 3:54-5. 
25. Miller V, Palermo TM, Grewe SD. Quality of life in pediatric epilepsy: demographic and diseaserelated predictors and comparison with healthy controls. Epilepsy Behav 2003;4:36-42.

26. Devinsky O, Westbrook L, Cramer J, et al. Risk factors for poor health-related quality of life in adolescents with epilepsy. Epilepsia 1999;40:1715-20.

27. Sillanpää M. Children with epilepsy as adults: outcome after 30 years of follow-up. Acta Paediatr Scand. Supplement 1990;368:1-78.

28. Sillanpää M. Epilepsy in children: prevalence, disability, and handicap. Epilepsia 1992;33:444-9.

29. Ferro MA. Risk factors for health-related quality of life in children with epilepsy: a meta-analysis. Epilepsia 2014;55:1722-31.

30. van Hedel HJ, Dokladal P, Hotz-Boendermaker S. Mismatch between investigator-determined and patient-reported independence after spinal cord injury: consequences for rehabilitation and trials. Neurorehabil Neural Repair 2011;25:855-64.

31. Wu DY, Ding D, Wang Y, et al. Quality of life and related factors in Chinese adolescents with active epilepsy. Epilepsy Res 2010;90:16-20.

32. Fastenau PS, Shen J, Dunn DW, et al. Neuropsychological predictors of academic underachievement in pediatric epilepsy: moderating roles of demographic, seizure, and psychosocial variables. Epilepsia 2004;45:1261-72.

33. Charyton C, Elliott JO, Lu B, et al. The impact of social support on health related quality of life in persons with epilepsy. Epilepsy Behav 2009;16:640-5.

34. Jayalakshmi S, Padmaja G, Vooturi S, et al. Impact of family support on psychiatric disorders and seizure control in patients with juvenile myoclonic epilepsy. Epilepsy Behav 2014;37:7-10.

35. de Boer HM, Mula M, Sander JW. The global burden and stigma of epilepsy. Epilepsy Behav 2008; 12:540-6.

36. Aldenkamp AP, Weber B, Overweg-Plandsoen WC, et al. Educational underachievement in children with epilepsy: a model to predict the effects of epilepsy on educational achievement. J Child Neurol 2005;20:175-80.

37. Berg AT, Langfitt JT, Testa FM, et al. Global cognitive function in children with epilepsy: a communitybased study. Epilepsia 2008;49:608-14.

38. Bompori E, Niakas D, Nakou I,et al. Comparative study of the health-related quality of life of children with epilepsy and their parents. Epilepsy Behav 2014;41:11-7.

39. Kokkonen J, Kokkonen ER, Saukkonen AL, et al. Psychosocial outcome of young adults with epilepsy in childhood. J Neurol Neurosurg Psychiatry 1997;62:265-8.

40. Mitchell WG, Scheier LM, Baker SA. Psychosocial, behavioral, and medical outcomes in children with epilepsy: a developmental risk factor model using longitudinal data. Pediatrics 1994;94:471-7.

41. Eom S, Eun SH, Kang HC, et al. Epilepsy-related clinical factors and psychosocial functions in pediatric epilepsy. Epilepsy Behav 2014;37:43-8.

42. Melikyan E, Guekht A, Milchakova L, et al. Health-related quality of life in Russian adults with epilepsy: the effect of socio-demographic and clinical factors. Epilepsy Behav 2012;25:670-5.

43. Zhao Y, Wu H, Li J, et al. Quality of life and related factors in adult patients with epilepsy in China. Epilepsy Behav 2011;22:376-9.

44. Djibuti M, Shakarishvili R. Influence of clinical, demographic, and socioeconomic variables on quality of life in patients with epilepsy: findings from Georgian study. J Neurol Neurosurg Psychiatry 2003; 74:570-3.

45. Guekht AB, Mitrokhina TV, Lebedeva AV, et al. Factors influencing on quality of life in people with epilepsy. Seizure 2007;16:128-33.

46. Baker GA, Gagnon D, McNulty P. The relationship between seizure frequency, seizure type and quality of life: findings from three European countries. Epilepsy Res 1998;30:231-40.

47. Wirrell EC, Camfield CS, Camfield PR, et al. Long-term psychosocial outcome in typical absence epilepsy. Sometimes a wolf in sheeps' clothing. Arch Pediatr Adolesc Med. 1997;151:152-8.

48. Sillanpää $\mathrm{M}$, Jalava $\mathrm{M}$, Kaleva $\mathrm{O}$, et al. Long-term prognosis of seizures with onset in childhood. $\mathrm{N}$ Engl J Med 1998;338:1715-22.

49. Camfield $\mathrm{P}$, Camfield C. Help youth with epilepsy to become competent and happy adults: Transition care. Seizure 2013;22:414-5. 
50. van Staa $\mathrm{AL}$, Jedeloo S, van Meeteren J, et al. Crossing the transition chasm: experiences and recommendations for improving transitional care of young adults, parents and providers. Child Care Health Dev 2011;37:821-32.

51. Kuchenbuch $\mathrm{M}$, Chemaly N, Chiron C, et al. Transition and transfer from pediatric to adult health care in epilepsy: a families' survey on Dravet syndrome. Epilepsy Behav 2013;29:161-5.

52. Curhan KB, Levine CS, Markus HR, et al. Subjective and Objective Hierarchies and Their Relations to Psychological Well-Being: A U.S/Japan Comparison. Soc Psychol Personal Sci 2014;5:855-64.

53. Borlot F, Tellez-Zenteno JF, Allen A, et al. Epilepsy transition: Challenges of caring for adults with childhood-onset seizures. Epilepsia 2014;55:1659-66. 


\section{Chapter 5}

\section{Long-term effects of a multidisciplinary transition}

intervention from paediatric to adult care in patients

with epilepsy

RPJ Geerlings, AP Aldenkamp, LMC Gottmer-Welschen, AL van Staa, AJA de Louw 


\section{Abstract}

\section{Purpose}

To evaluate the long-term effects of a multidisciplinary transition intervention compared to the impact of patient-related intrinsic factors on the improvement in medical and psychosocial outcome.

\section{Methods}

All patients who visited our multidisciplinary Epilepsy Transition Clinic between March 2012 and September 2014 were invited to participate $(n=114)$. Patients were sent one questionnaire and informed consent was obtained. Questions included the patient's level of functioning on three transitional domains and a list with medical health care workers. Previously defined scores on three transitional domains and the risk profile score were re-evaluated. Past and current patient characteristics were compared using descriptive statistics. Discriminant analyses were used to determine the influence of patient-related intrinsic factors (defined as the risk factors from our previous study) and a multidisciplinary transition intervention on the improvement of medical and psychosocial outcome.

\section{Results}

Sixty-six out of 114 invited participants (57.9\%) completed the questionnaire. Discriminant analyses showed that the patient-related intrinsic factors combined proved a strong predictor for improvement in medical outcome (72.7\%) and relatively strong for educational/vocational outcome (51.5\%). The transition interventions are a relative strong predictor of improvement in medical outcome $(56.1 \%)$, educational/vocational outcome $(53.0 \%)$ and improvement in the overall risk score (54.5\%).

\section{Conclusion}

Based on the overall improvement of psychosocial outcome in most patients, and the influence of a transition intervention on medical, educational/vocational outcome and the overall risk score, it is likely that adolescents with epilepsy benefit from visiting a multidisciplinary epilepsy transition clinic. 


\section{Introduction}

Adolescence is a critical and vulnerable period in life because adolescents have to develop their own identity, autonomy, peer relationships and their own social network. ${ }^{1-3}$ Having a chronic illness transferring into adulthood, such as epilepsy, makes adolescence even more complex. Several studies indicated that patients with epilepsy are at risk of persistent long-term poor psychosocial outcome on several transitional domains, e.g., education and employment. ${ }^{1,4-7}$ Therefore, age-specific issues often deserve special attention in adolescents with epilepsy. Further, adolescents with (chronic) epilepsy have to transfer from paediatric to adult medical care at a certain point in life. ${ }^{3,4}$ If insufficient attention is given to this transition, adolescents and young adults with epilepsy may withdraw from necessary medical and psychosocial health care, and end up in a troublesome situation. To cope with these problems, epilepsy transition clinics have been set up for adolescents. ${ }^{8,9} \mathrm{~A}$ transition clinic can provide help for medical, psychosocial and developmental issues during adolescence. ${ }^{8,10}$ Although the main objective of an epilepsy transition clinic is to revise the previously made epilepsy diagnosis and treatment options, and to transfer the adolescent to an adult health care system, most transition clinics also provide special attention for the above mentioned developmental age-specific issues of patients with epilepsy. ${ }^{4,8,9,11}$

Several different models of epilepsy transition clinic staffing have been reported, including both paediatricians and adult neurologists, or nurse specialist. Sometimes referral to a psychologist, a social worker or a career adviser is made. ${ }^{8,9,11-15}$ Only little evidence is published about the attempts that have been made to evaluate the effectiveness of transition interventions in chronic disease. ${ }^{16}$ Prior et al. ${ }^{16}$ reviewed studies that described health care transition interventions in for example diabetes, kidney disease and juvenile idiopathic arthritis. However, to the best of our knowledge, no information is available about the true, i.e. long-term effects of transition interventions in patients with epilepsy. Therefore the objective of this study was to evaluate the long-term effects of a multidisciplinary transition intervention compared to patient-related intrinsic factors on the improvement in medical and psychosocial outcome.

\section{Methods}

\section{Epilepsy Transition Clinic}

An Epilepsy Transition Clinic was set up in March 2012 in Epilepsy Center Kempenhaeghe, a tertiary referral center for patients with epilepsy. Our transition clinic is staffed with a neurologist, a clinical neuropsychologist, a social worker and an 
educationalist/vocational counselor, all with adequate knowledge of paediatric and adolescent developmental issues, paediatric and adult medical care and of epileptology.

All patients who had an appointment for a visit at the transition clinic were between 15 to 25 years of age. As described in our previous study ${ }^{11}$, this age limit was chosen because developmental milestones are often delayed in patients with epilepsy. ${ }^{11,17}$ In our opinion, transition is a gradual process, and should not be limited by only reaching the adult age. To get an appointment at the multidisciplinary Epilepsy Transition Clinic, patients had to have a diagnosis of epilepsy and at least one medical issue (e.g., problems with transition from paediatric to adult care), psychological issue (e.g., in the development of self-management and independence) or psychosocial issue (e.g., career advice) related to the transition phase. Not all patients had had an assessment of their Full Scale Intelligence Quotient (FS IQ) to measure their intelligence level in the past, before their first visit to the transition clinic. Patients with severe mental disabilities (FS IQ<50) were not accepted at the transition clinic but referred to a special outpatient clinic for patients with epilepsy and mental disabilities at our epilepsy center. All patients were given appointments with the above mentioned health care workers in three consecutive consultations on the same morning (the 'carousel'). ${ }^{11}$ The neurologist and clinical neuropsychologist work together in one consultation, after which all patients had appointments with the social worker, and the educationalist/vocational counselor. All professionals stimulate independence and empowerment of the adolescent. After all three consecutive appointments, the four health care professionals discuss the progress of transition on the medical, psychological, social and educational/vocational domain, in a short multidisciplinary case-meeting. Consequently a personalized advice is discussed with the patient.

The transition clinic's advice may include a new 'snap-shot' for a diagnostic work-up, such as a magnetic resonance imaging (MRI), electroencephalography (EEG), a neuropsychological test and/or laboratory tests or genetic counseling. Not all patients had a strict medical indication for a full diagnostic work-up. One or more diagnostic procedures (e.g., MRI, EEG, neuropsychological tests) were only conducted when considered necessary for revision of the medical diagnosis (e.g., EEG) or in optimizing the multidisciplinary advice during the transition process (e.g., measurements of the Full Scale Intelligence Quotient to provide adequate career advice). Other advices included support by health care workers, e.g., in finding housing, financial support, vocational training or psychosocial support. All patients visited the whole 'carousel' at least once. Some patients were followed by the transition clinic's neurologist for a short period (for example because of a diagnostic work-up or after a recent change in AED prescription), others had a few follow-up visits for further support by the psychologist, social worker or educationalist/vocational counselor. Transition is a gradual process, and there was no set number of maximum visits to the transition 
clinic. The total number of visits at the transition clinic varied, depending on the medical or psychosocial problems of the individual, but finished after two or three visits preferably. After completing the transition clinic, the medical transition, i.e. the transfer from paediatric to adult medical care was facilitated. Patients were either referred to an adult neurologist at the tertiary referral epilepsy center, to an external adult neurologist, or, in case of seizure remission after withdrawal of AEDs, to a general practitioner.

In our previous study ${ }^{11}$, we scored patients who visited the transition clinic on three transitional domains, namely their medical performance, educational/vocational performance and the development of their own independence/separation/identity. Scores are further defined in Table 5.1. As mentioned ${ }^{11}$, no validated scoring system to assess the level of functioning on transitional domains in adolescents or young adults with epilepsy existed. Therefore, we developed our own scoring system, based on the Sydney Psychosocial Reintegration Scale Version 2 (SPRS-2), a validated scoring system for patients with traumatic brain injury. In our scoring system, scores ranged from 0 (normal), -1 (suboptimal), to -2 (poor). To cope with the wide range of intellectual abilities and the maximum levels of functioning of the individual patients, and the comorbid conditions, scores were individually allocated by the transition clinic's neurologist and psychologist with respect to the optimal level of functioning which can be achieved by the individual.

We also developed a risk profile scoring system. ${ }^{11}$ This risk profile score too was individually allocated by the transition clinic's neurologist and psychologist and represented the patient's risk for future adverse psychosocial outcome. A risk profile score of 3 indicated that the patient had poor perspectives for long-term psychosocial outcome, a score of 2 indicated a substantial increased ('moderate') risk for adverse psychosocial outcome, and a score of 1 indicated a low risk ('no obvious risk') for longterm psychosocial outcome. ${ }^{11}$

All scores were allocated by the transition clinic's neurologist and psychologist. If no agreement occurred, discussions were required until consensus.

Last, the interventions that took place during the transition clinic were recorded and categorized in three groups according to the interventions, namely: a) transition clinic only; b) transition clinic in combination with a single intervention (either medical, or social (by the social worker or educationalist/vocational counselor); c) transition clinic in combination with a multidisciplinary approach (both medical and the social worker or educationalist). 


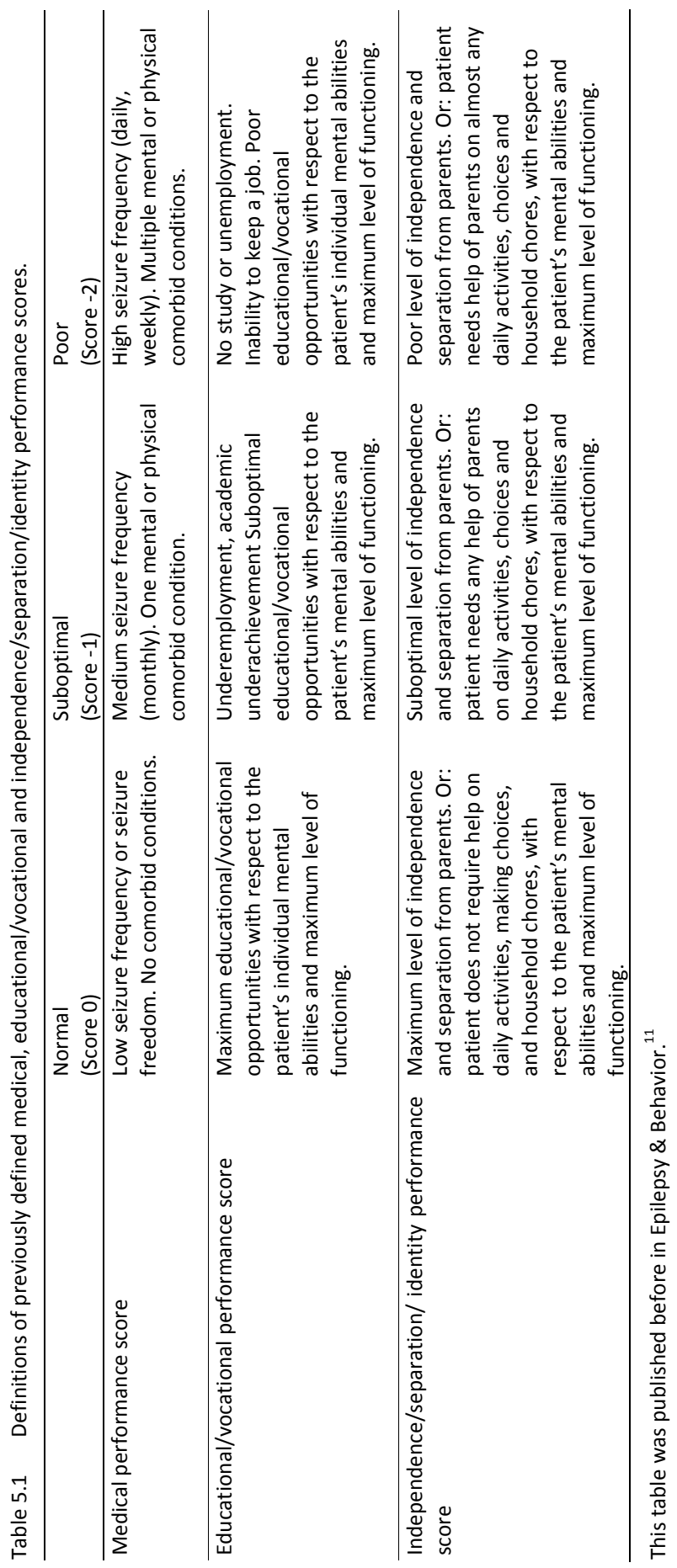




\section{Study population and study procedure}

All patients in this follow-up study were recruited from the study population of our previous study. ${ }^{11}$ The minimum duration between the initial visit at the transition clinic and the invitation for the study was six months, the maximum duration was three years. Because patients were transitioned from paediatric to adult medical care, and were no longer in follow-up at the transition clinic or at our tertiary referral center, a questionnaire was sent to every patient who visited our epilepsy transition clinic from March 2012 until September 2014. The questionnaires contained questions regarding the patient's medical, educational/vocational status, and independence. To be more specific: we asked patients to report their seizure frequency by filling out a number and additionally choosing the option daily/weekly/monthy/yearly. Data about their current and past treatment options, their neurologist and number of visits per year, and the number of hospital admittances due to epilepsy were collected with the questionnaire. Furthermore, we asked to report their current education or employment status, their financial income and, if applicable, financial guardianship, relationships, housing, level of independence by completing several household tasks. Finally, a list of medical and societal healt care workers, e.g., the number and frequency of different (health) care providers the patient was in contact with at the moment, was assessed.

Based on the patient reported outcome, previously collected baseline statistics were compared to the current outcome. The above mentioned performance sores and the risk profile score were re-evaluated and re-allocated (Table 5.2) according to the definitions in Table 5.1.

Data of all patients who gave written informed consent, and fully completed the questionnaire, were entered in an IBM SPSS database.

Table 5.2 Grouping and distribution pattern of patients' past and current risk profile scores.

\begin{tabular}{lc}
\hline Group 1: Improvement of risk profile score or & $\begin{array}{c}\text { Total number of patients } \\
(n=66)\end{array}$ \\
persistent low risk profile score & 2 \\
Past score: $3 \rightarrow$ current score: $1(-2)$ & 7 \\
Past score: $3 \rightarrow$ current score: $2(-1)$ & 14 \\
Past score: $2 \rightarrow$ current score: $1(-1)$ & 11 \\
$1=1$ & $34(52 \%)$ \\
Total & \\
Group 2: Stable moderate risk profile score & $6(9 \%)$ \\
2=2 & \\
Group 3: Deterioration of risk profile score or & \\
persistent high risk profile score & 1 \\
Past score: $1 \rightarrow$ current score: $2(+1)$ & 3 \\
Past score: $1 \rightarrow$ current score: $3(+2)$ & 7 \\
Past score: $2 \rightarrow$ current score: $3(+1)$ & 15 \\
$3=3$ & $26(39 \%)$ \\
Total & \\
\hline
\end{tabular}




\section{Statistical analysis}

All statistical analyses were performed by IBM SPSS Version 21. We used descriptive statistics to compute frequencies ( $n$ ) and percentages (\%) of categorical variables and to give an overview of baseline and current statistics. Means are presented with standard deviation (SD) and range.

First, patients were grouped according to their past and current risk profile scores. Patients with improvement of their risk profile score, or patients with a persistent low risk profile score, were grouped in group 1; patients with a moderate risk profile score were grouped in group 2; patients with a deterioration of risk profile score or persistent high risk profile score were grouped in group 3. Further information about the grouping of patients is provided in Table 5.2. After grouping of patients, patient's demographic, medical and social characteristics were compared using the aforementioned criteria for continuous or dichotomous variables. The involved medical and societal health care workers were classified in two ways. In our first analysis they were classified as dichotomous variables (yes/no) and compared between groups using the Chi-Square Test. In our second analysis, the frequency of the involved health care workers was classified as a continuous variable and compared using the Independent-Samples T Test. The threshold for significance was $p<0.05$ in both analyses.

Second, we performed a two-tailed Paired-Samples T Test to evaluate the difference in patient characteristics (the continuous variables), the performance scores and risk profile score over time between baseline and at follow-up. A $p$-value $<0.05$ was considered statistically significant.

Third, we conducted descriptive discriminant analyses to determine the predictive values of patient-related intrinsic factors (defined as the risk factors found in our previous study ${ }^{11}$ ) and transition interventions for final outcome. We used the difference (delta) in the three transitional performance scores and the difference in risk profile scores as dependent variables. We used two types of independent variables: first, the characteristics of the transition intervention (interventions during transition (as categorized in the Methods section above), duration of time since first visit at the transition clinic, and age at first visit at the transition clinic); second, the risk factors we found in our previous study ${ }^{11}$ (intelligence level, seizure frequency and an unstable and unsupportive family environment). However, to compare the impact of transition interventions to the impact of patient-related factors, and to avoid any confusion in the analyses, we chose to name the previously found risk factors as 'patient-related intrinsic factors' throughout this manuscript. The patient-related intrinsic factors and the interventions were entered in two separate discriminant analyses for each dependent variable. 


\section{Ethics}

This study was approved by the Medical Ethics Committee of Kempenhaeghe. Patients could participate voluntarily. Written informed consent was obtained from all participants.

\section{Results}

\section{Responder characteristics}

\section{Responder versus non-responder analysis}

A total of 114 patients were assessed at baseline and were invited to participate in this study. In total, completed questionnaires were obtained from 66 patients (57.9\%); 48 patients (42.1\%) were non-responding. The presence of an unsupportive/unstable family environment was significantly different between responders and nonresponders $(21.2 \%$ vs. $39.6 \%, p=0.04)$. Non-responders also had a significantly lower (=worse) performance score in the past for their level of independence/ separation/identity (-1.12 vs. $-1.48, p=0.02)$, and a significantly higher (=worse) risk profile score $(2.14$ vs. $2.44, p=0.04)$. In the other characteristics no statistically significant differences were found between responders and non-responders.

\section{Patient characteristics}

Patient characteristics at baseline and at follow-up are shown in Table 5.3. In total, 35 men (53.0\%) and 31 women (47.0\%) participated in this study. Their mean age was 18.9 years at baseline (median=18.6, SD=2.2) and 20.8 years at follow-up (median=20.7, SD=2.3). The mean Full Scale Intelligence Quotient was 83 (median=81, $\mathrm{SD}=16.9$ ). The mean age at diagnosis of epilepsy was 8.1 years (median=8.1, $S D=5.0$ ), with a mean duration of epilepsy of 10.6 years at baseline (median=9.5, SD=5.3) and 12.6 years at follow-up (median=11.9, SD=5.4). Fifty-two patients $(78.8 \%$ ) had a localization-related epilepsy, of which the cryptogenic type was most common (35 patients, 53.0\%). At baseline, 39 out of 66 patients (59.1\%) were seizure-free for one year, compared to 38 out of 66 patients (57.6\%) at follow-up. (The difference in seizure frequency over time had a $p$-vale of 0.81 ). Less patients were using polytherapy at follow-up ( 29 patients $(43.9 \%)$ vs. 32 previously $(48.5 \%), p=0.27)$, and nine patients (13.6\%) were not using AEDs anymore, compared to 7 patients (10.6\%) at baseline. Their self-reported AED adherence was higher at follow-up $(80.3 \%$ vs. $57.6 \%)$. 


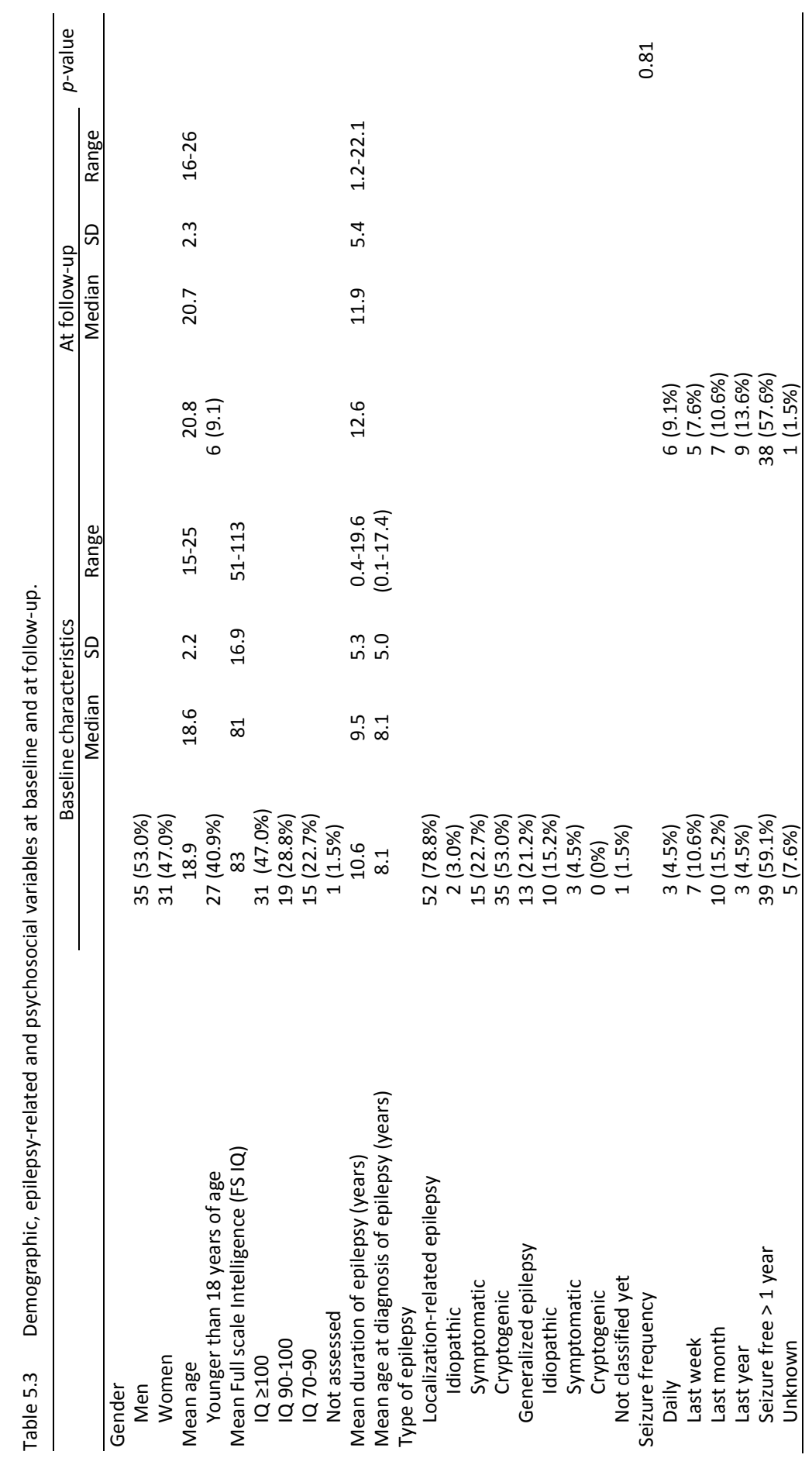




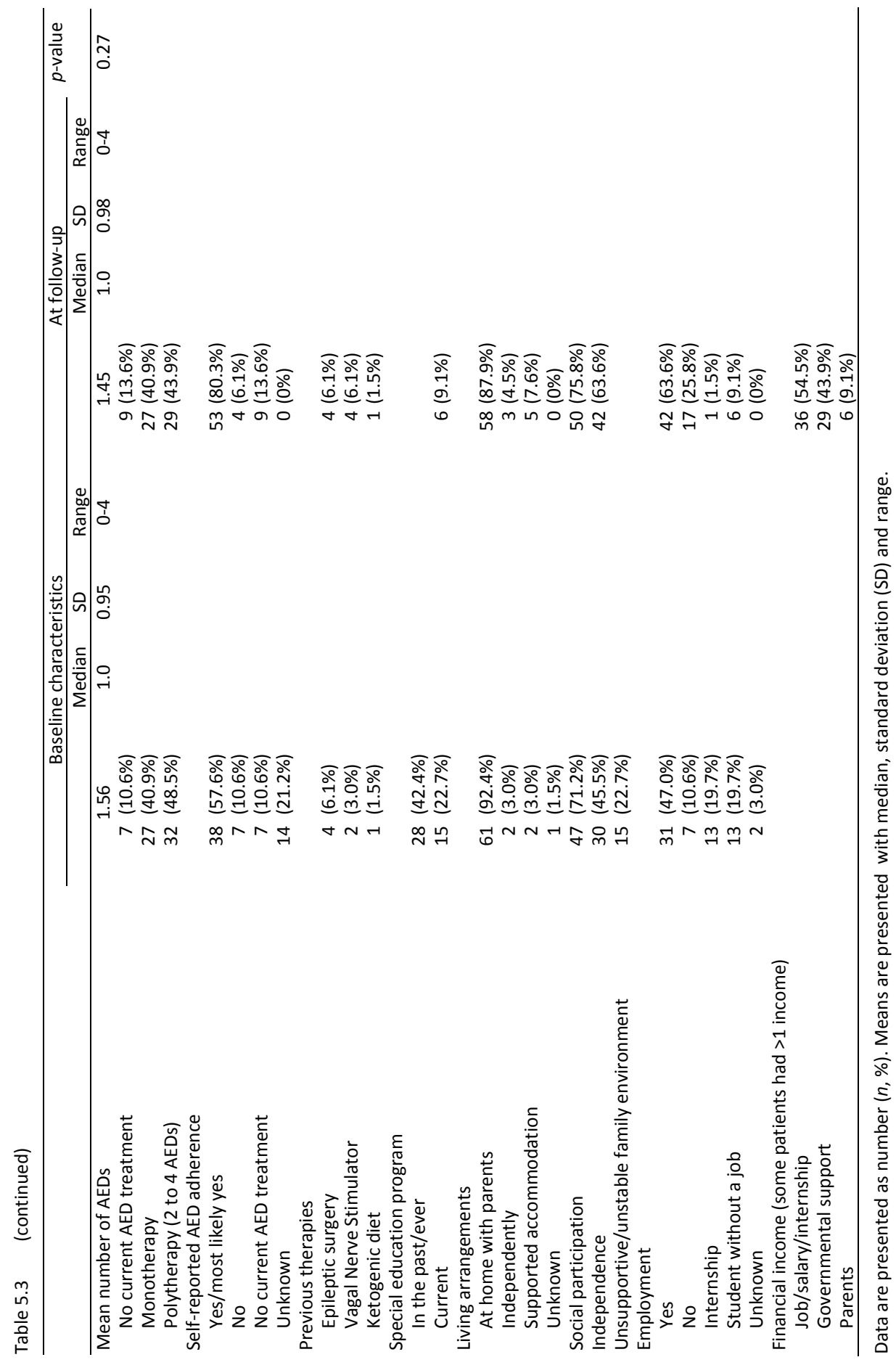


Compared to the baseline characteristics, more patients were independent from their parents at follow-up (42 vs. $3063.6 \%$ vs. $45.5 \%$ respectively), and more patients were socially participating at follow-up (50 vs. $47,75.8 \%$ vs.71.2\% respectively). Eight patients (12.1\%) were living either independently or in a supported accommodation compared to 4 patients (6.1\%) at baseline. More patients were employed at follow-up (31 vs. $42,47.0 \%$ vs. $63.6 \%$ ), and less patients were studying (13 vs. $6,19.7 \%$ vs. $9.1 \%$ ) or in an internship during their study (13 vs. 1, 19.7\% vs $1.5 \%$ ). Finally, more patients were not studying anymore and had not found a job afterwards compared to baseline (unemployment 7 vs. $17,10.6 \%$ vs. $25.8 \%$ ). Thirty-six patients (54.5\%) had a salary out of a job or internship, whereas 29 patients (43.9\%) were on some kind of governmental financial support.

Transition clinic interventions are shown in Table 5.4. The mean duration of follow-up between the transition interventions and the current study was 23.7 months (median=24.1, SD=10.4). After their first visit at the epilepsy transition clinic, a diagnostic work-up was done in 56 patients (84.8\%), involving 35 (53.0\%) clinical neuropsychological assessments and EEG recording. Furthermore, $17 \mathrm{MRIs}$ (25.8\%) and 22 laboratory tests (33.3\%) were performed. Twenty-two patients (33.3\%) were briefly admitted ( $<24$ hours) to complete the diagnostic work-up. Forty-two patients (63.6\%) underwent a change in AED prescription based on the evaluations of the multidisciplinary transition clinic, of which 3 patients $(4.5 \%)$ were women in childbearing age using valproate. After visiting the transition clinic, two patients (3.0\%) were referred for the implantation of a vagal nerve stimulator.

The social worker was consulted in 26 patients (39.4\%), e.g., to provide help with housing assistance (15 patients, 22.7\%), for advice about financial guardianship (6 patients, 9.1\%) or to assist in the separation from parents (4 patients, $6.1 \%$ ). The educationalist/vocational counselor provided educational assistance in 18 patients (27.3\%), vocational assistance (6 patients, 9.1\%) or vocational training (4 patients, $6.1 \%)$. Psychosocial assistance was indicated in 10 patients (15.2\%).

In 43 patients $(65.2 \%)$ a medical transition was facilitated to an adult neurologist at our tertiary referral epilepsy center, and sixteen patients $(24.2 \%)$ were referred to an external adult neurologist for further epilepsy care. Seven patients (10.6\%) with seizure remission after AED withdrawal no longer needed specialized epilepsy care and were referred to their general practitioner.

Summarized, 12 patients $(18.2 \%)$ had only one visit at the transition clinic without further consultation, diagnostic procedure or follow-up in the transition outpatient clinic; 20 patients (30.3\%) visited the transition clinic and had either a diagnostic follow-up or a follow-up consultation with the psychologist or the social worker and educationalist; 34 patients (51.5\%) visited the transition clinic and had a multidisciplinary follow-up including a medical intervention (either diagnostic work-up or change in AED prescription) in combination with a consultation at the psychologist, social worker or educationalist. 
Table 5.4 Transition clinic interventions.

\begin{tabular}{|c|c|c|c|c|}
\hline & & Median & SD & Range \\
\hline Duration of follow-up at the transition clinic (months) & 23.7 & 24.1 & 10.4 & $6.6-40.3$ \\
\hline \multicolumn{5}{|l|}{ Diagnostic work-up after first visit at the transition clinic } \\
\hline (some patients had >1 type of diagnostic intervention) & $56(84.8 \%)$ & & & \\
\hline Clinical neuropsychological assessment & $35(53.0 \%)$ & & & \\
\hline EEG & $35(53.0 \%)$ & & & \\
\hline MRI & $17(25.8 \%)$ & & & \\
\hline Admittance for diagnostic work-up & $22(33.3 \%)$ & & & \\
\hline Laboratory & $22(33.3 \%)$ & & & \\
\hline AED change after evaluation at the transition clinic & $42(63.6 \%)$ & & & \\
\hline \multicolumn{5}{|l|}{ Reason AED change } \\
\hline Epilepsy remission & $12(18.2 \%)$ & & & \\
\hline Side effects & $10(15.2 \%)$ & & & \\
\hline Switch AED & $5(7.6 \%)$ & & & \\
\hline Adding AED & $5(7.6 \%)$ & & & \\
\hline Increase dose AED & $4(6.1 \%)$ & & & \\
\hline Decrease dose AED & $3(4.5 \%)$ & & & \\
\hline Women in child bearing age & $3(4.5 \%)$ & & & \\
\hline \multicolumn{5}{|l|}{$\begin{array}{l}\text { Consultations transition clinic (some patients had >1 } \\
\text { intervention/consultation) }\end{array}$} \\
\hline Social worker & $26(39.4 \%)$ & & & \\
\hline Housing assistance & $15(22.7 \%)$ & & & \\
\hline Reason improving family support & $5(7.6 \%)$ & & & \\
\hline Reason improving separation/individualization & $4(6.1 \%)$ & & & \\
\hline Reason financial advice & $6(9.1 \%)$ & & & \\
\hline Reason increasing social interaction and support & $1(1.5 \%)$ & & & \\
\hline Reason planning daily activities & $1(1.5 \%)$ & & & \\
\hline Educationalist/vocational counselor & $25(37.9 \%)$ & & & \\
\hline Educational assistance & $18(27.3 \%)$ & & & \\
\hline Vocational assistance & $6(9.1 \%)$ & & & \\
\hline Vocational training & $4(6.1 \%)$ & & & \\
\hline Psychological assistance & $10(15.2 \%)$ & & & \\
\hline \multicolumn{5}{|l|}{ Referral to } \\
\hline Adult neurologist within the epilepsy center & $43(65.2 \%)$ & & & \\
\hline External referral to adult neurologist & $16(24.2 \%)$ & & & \\
\hline General practitioner & $7(10.6 \%)$ & & & \\
\hline \multicolumn{5}{|l|}{ Type of interventions summarized } \\
\hline Transition clinic only & $12(18.2 \%)$ & & & \\
\hline Transition clinic + monodisciplinary & $20(30.3 \%)$ & & & \\
\hline Transition clinic + multidisciplinary & $34(51.5 \%)$ & & & \\
\hline
\end{tabular}

Data are presented as number $(n, \%)$. Means are presented with median and range.

As shown in Table 5.5, the risk profile score improved, but not statistically significant (2.14 at baseline vs. 1.97 at follow-up, $p=0.12$ ). The medical performance score improved from baseline mean $-1.09, \mathrm{SD}=0.87$ to a mean $-0.60, \mathrm{SD}=0.90(p<0.001)$, the educational/vocational performance score improved from $-1.06, S D=0.86$ to mean 0.82 , SD $0.89(p=0.01)$; the independence/separation/identity performance score improved from $-1.12, \mathrm{SD}=0.80$ to $-0.94, \mathrm{SD}=0.88(p=0.04)$. 
Table 5.5 Medical, educational/vocational and independence/separation/identity performance scores and risk profile score at baseline and at follow-up.

\begin{tabular}{lccc}
\hline & Baseline & Follow-up & $p$ \\
\hline Medical performance score & $-1.09(0.87)$ & $-0.60(0.90)$ & $<0.001$ \\
Educational/vocational performance score & $-1.06(0.86)$ & $-0.82(0.89)$ & 0.01 \\
Independence/separation/identity performance score & $-1.12(0.80)$ & $-0.94(0.88)$ & 0.04 \\
Risk profile scores & $2.14(0.76)$ & $1.97(0.89)$ & 0.12 \\
\hline
\end{tabular}

Data are presented as mean scores with standard deviation (SD).

\section{Medical and societal health care workers}

A beneficial outcome was not significantly correlated with the involvement of medical and societal health care workers both in terms of type of health care worker and quantity of support, except for the intervention by a psychologist $(23.5 \%$ compared to $3.1 \%, p=0.02)$.

\section{Descriptive discriminant analyses}

We used the interventions and the patient-related intrinsic factors ${ }^{11}$ as predictive variables in a discriminant analyses to evaluate the relative impact of the variables on the delta in risk profile score and performance scores. As mentioned above in the Results section, all scores improved at follow-up. The results of the discriminant analysis are shown in Table 5.6.

Table 5.6 Sensitivity and specificity of interventions and patient-related intrinsic factors in relation to improvement of psychosocial or medical outcome.

\begin{tabular}{|c|c|c|c|c|}
\hline Delta score & & Sensitivity & Specificity & Correctly classified \\
\hline \multirow[t]{2}{*}{ Medical performance score } & Intervention & $56.5 \%$ & $52.6 \%$ & $56.1 \%$ \\
\hline & $\begin{array}{l}\text { Patient-related } \\
\text { intrinsic factors }\end{array}$ & $80.4 \%$ & $52.6 \%$ & $72.7 \%$ \\
\hline \multirow{2}{*}{$\begin{array}{l}\text { Independence/separation/identity } \\
\text { performance score }\end{array}$} & Intervention & $38.7 \%$ & $54.2 \%$ & $43.9 \%$ \\
\hline & $\begin{array}{l}\text { Patient-related } \\
\text { intrinsic factors }\end{array}$ & $41.9 \%$ & $29.2 \%$ & $42.4 \%$ \\
\hline \multirow{2}{*}{$\begin{array}{l}\text { Educational/vocational } \\
\text { performance score }\end{array}$} & Intervention & $57.5 \%$ & $45.5 \%$ & $53.0 \%$ \\
\hline & $\begin{array}{l}\text { Patient-related } \\
\text { intrinsic factors }\end{array}$ & $45.0 \%$ & $59.1 \%$ & $51.5 \%$ \\
\hline \multirow[t]{2}{*}{ Risk profile score } & Intervention & $46.2 \%$ & $58.8 \%$ & $54.5 \%$ \\
\hline & $\begin{array}{l}\text { Patient-related } \\
\text { intrinsic factors }\end{array}$ & $23.1 \%$ & $61.8 \%$ & $45.5 \%$ \\
\hline
\end{tabular}




\section{Improvement in medical outcome}

The interventions combined showed a sensitivity of $56.5 \%$ and a specificity of $52.6 \%$ on improvement of medical outcome. The interventions combined could predict $56.1 \%$ of the classification of medical improvement.

The patient-related intrinsic factors showed a sensitivity of $80.4 \%$ and a specificity of $52.6 \%$. In total $72.7 \%$ of the improvement in medical outcome can be predicted when combining the patient-related intrinsic factors.

\section{Improvement in independence/separation/identity}

The interventions combined showed a sensitivity of $38.7 \%$ and a specificity of $54.2 \%$ on the improvement of independence/separation/identity outcome. In combination the intervention could predict $43.9 \%$ of the improvement of independence outcome. The patient-related intrinsic factors showed a sensitivity of $41.9 \%$ and a specificity of $29.2 \%$. In total $42.4 \%$ of the improvement in independence can be predicted when combining the patient-related intrinsic factors.

\section{Improvement in educational/vocational outcome}

The interventions combined showed a sensitivity of $57.5 \%$ and a specificity of $45.5 \%$ on the improvement of education/vocational outcome. In combination the intervention could predict $53.0 \%$ of the improvement of educational outcome.

The patient-related intrinsic factors showed a sensitivity of $45.0 \%$ and a specificity of $59.1 \%$. In total $51.5 \%$ of the improvement in educational/vocation outcome can be predicted when combining the patient-related intrinsic factors.

\section{Improvement in risk profile score}

The interventions combined showed a relative modest sensitivity of $46.2 \%$ and specificity of $58.8 \%$ in classifying the groups. In total the type of intervention could predict classification of risk improvement in $54.5 \%$.

The patient-related intrinsic factors combined had a sensitivity of $23.1 \%$ on an improvement on the risk profile score, with a specificity of $61.8 \%$. The patient-related intrinsic factors combined could predict correct classification of risk improvement in $45.5 \%$ of the patients.

\section{Discussion}

This study compared changes in transition characteristics from baseline to a follow-up on average two years later in 66 patients with a mean age of 18.9 years and a mean Full Scale Intelligence Quotient of 83. On average they had a mean duration of epilepsy of 12.6 years at follow-up. This is therefore a group with chronic (mostly 
cryptogenic localization-related) epilepsy that transits with epilepsy from childhood to adulthood. No relevant changes were found for seizure frequency, but with respect to treatment, less patients were on polytherapy, in more patients all AEDs were withdrawn and AED adherence had improved. In terms of transition outcomes, more patients were living independently from their parents, more were socially participating, and more patients were employed at follow-up.

The results of the performance scores improved, which is in line with the aforementioned descriptive results: the risk profile score improved, but this was not statistically significant.

The main objective of this study was to evaluate the long-term effects of a multidisciplinary transition intervention compared to the impact of patient-related factors on the improvement in medical and psychosocial outcome. Thus, the contribution of transition interventions on the positive delta (difference) in performance scores. The discriminant analyses combined indicated that the patientrelated intrinsic factors combined are a strong predictor of improvement in medical outcome $(72.7 \%)$. Our interpretation is that the patient-related intrinsic factors are inherent characteristics of the patients, e.g., the fact that the majority of the patients had a chronic epilepsy, and define a relatively stable situation.

The transition interventions on the other hand are an equally strong predictor as patient-related factors for improvement in educational/vocational outcome, independence and the improvement in the overall risk score. Here transition interventions can have more influence than the patient-related intrinsic factors on improvement of the educational/vocational outcome.

In predicting a favorable overall risk, the sensitivity of type of intervention is much higher than the patient-related intrinsic factors, with equal specificity. This again illustrates the impact of transition interventions for the overall positive result. Thus, the type of transition intervention contributed more to an improvement of the risk profile than the patient-related factors, which is understandable given the type of patient-related intrinsic factors (i.e., relative stable factors that all will have a similar influence at follow-up compared to baseline).

The improvement in psychosocial outcome cannot be explained by the involvement of individual health care workers or the frequency of appointments with health care workers.

No comparative studies can be found in literature, since this is the first study showing the effects of a multidisciplinary transition intervention after long-term follow-up. 


\section{Strengths and limitations}

This study has some methodological limitations. The first limitation is the use of questionnaires to obtain more information at follow-up. Since we are following patients through the transition process, most patients were no longer in follow-up at our transition clinic or at our tertiary referral hospital. In the pilot-phase of our study, many patients indicated that they would not participate in the study when they had to come over to our center for an interview because of the long distance to our tertiary epilepsy center. Therefore, we have to rely on the self-reported data.

Also, we were unable to re-evaluate the most significant variable in our previous study, namely an unsupportive family environment. This variable was significantly worse among non-responders. Further, non-responders had a significantly worse psychosocial outcome at baseline, indicating that the responders to our questionnaires probably have a better chance for a beneficial long-term psychosocial outcome at baseline. Therefore, results of this study might not be generalizable to the adolescent and young adult population with epilepsy.

Last, the 'patient-related intrinsic factor' is based on the results of previously found risk factors. Multiple variables were not tested.

\section{Conclusion}

Based on the overall improvement of psychosocial outcome in most patients, and the influence of a transition intervention on medical, educational/vocational outcome and the overall risk score, it is likely that adolescents with epilepsy benefit from visiting a multidisciplinary epilepsy transition clinic. 


\section{References}

1. Baker GA, Spector S, McGrath Y, et al. Impact of epilepsy in adolescence: a UK controlled study. Epilepsy Behav 2005;6:556-62.

2. Nordli DR, Jr. Special needs of the adolescent with epilepsy. Epilepsia 2001;42 Suppl 8:10-7.

3. Khan A, Baheerathan A, Hussain N, et al. Transition of children with epilepsies to adult care. Acta Paediatr 2013;102:216-21.

4. Camfield PR, Camfield CS. What Happens to Children With Epilepsy When They Become Adults? Some Facts and Opinions. Pediatr Neurol 2014;51:17-23.

5. Camfield P, Camfield C, Pohlmann-Eden B. Transition from pediatric to adult epilepsy care: a difficult process marked by medical and social crisis. Epilepsy Curr 2012;12:13-21.

6. Beghi E, Camfield PR, Camfield CS. Epidemiologic aspects: Lost in transition. Epilepsia 2014;55 Suppl 3:3-7.

7. Geerts A, Arts WF, Stroink H, et al. Course and outcome of childhood epilepsy: a 15-year follow-up of the Dutch Study of Epilepsy in Childhood. Epilepsia 2010;51:1189-97.

8. Iyer A, Appleton R. Transitional services for adolescents with epilepsy in the U.K.: a survey. Seizure 2013;22:433-7.

9. Smith PE, Myson V, Gibbon F. A teenager epilepsy clinic: observational study. Eur J Neurol 2002; 9:373-6.

10. Jurasek L, Ray L, Quigley D. Development and implementation of an adolescent epilepsy transition clinic. J Neurosci Nurs 2010;42:181-9.

11. Geerlings RP, Aldenkamp AP, Gottmer-Welschen LM, et al. Developing from child to adult: Risk factors for poor psychosocial outcome in adolescents and young adults with epilepsy. Epilepsy Behav 2015;51:182-90.

12. Shanske S, Arnold J, Carvalho M, et al. Social workers as transition brokers: facilitating the transition from pediatric to adult medical care. Soc Work Health Care 2012;51:279-95.

13. Appleton RE, Chadwick D, Sweeney A. Managing the teenager with epilepsy: paediatric to adult care. Seizure 1997;6:27-30.

14. Carrizosa J, An I, Appleton R, et al. Models for transition clinics. Epilepsia 2014;55 Suppl 3:46-51.

15. Camfield PR, Gibson PA, Douglass LM. Strategies for transitioning to adult care for youth with LennoxGastaut syndrome and related disorders. Epilepsia 2011;52 Suppl 5:21-7.

16. Prior $M$, McManus $M$, White $P$, et al. Measuring the "triple aim" in transition care: a systematic review. Pediatrics 2014;134:e1648-61.

17. Colver A, Longwell S. New understanding of adolescent brain development: relevance to transitional healthcare for young people with long term conditions. Arch Dis Child 2013;98:902-7. 


\section{Chapter}

Failed transition to independence in young adults with epilepsy

RPJ Geerlings, LMC Gottmer-Welschen, JEM Machielse, AJA de Louw, AP Aldenkamp Submitted 


\section{Abstract}

\section{Objective}

This study evaluated patient-related variables and measures of loneliness correlated to 'failed transition to independence' in adults, 25-30 years of age, with (childhood-onset) epilepsy.

\section{Materials and methods}

Patients with (childhood-onset) epilepsy and 25-30 years of age were recruited from Epilepsy Center Kempenhaeghe. Inclusion criteria were: diagnosis of (childhood-onset) epilepsy, and an (estimated) IQ $>70$. Patients were sent one questionnaire and informed consent was obtained from all participants. Questions included the patient's level of functioning and satisfaction on three transitional domains (medical status, educational/vocational status, independence/ separation from their parents), satisfaction with their friendships, and the validated De JongGierveld Loneliness Scale. 'Transition to independence' was defined and categorized in a continuum with scores ranging from 0 ('Failed transition') to 4 for all patients. A Bivariate Correlation analysis was used to compute correlations between patient characteristics and failed transition to independence.

\section{Results}

59 patients were included in the analysis, of which 19 (32.2\%) had a failed transition to independence. A statistically significant correlation was found between transition to independence and the social loneliness scale $(p=0.047)$ and the total loneliness scale $(p=0.04)$, and for the patients self-reported satisfaction with their independence/separation from parents $(p=0.01)$ and friendships $(p=0.04)$.

\section{Conclusions}

Adults with epilepsy with a failed transition to independence experience loneliness and are not satisfied with their current developmental and social situation. 


\section{Introduction}

Chronic (childhood-onset) epilepsy continuing into adulthood can have major consequences for normal development on several domains. Epilepsy, comorbid conditions and the side-effects of antiepileptic drugs can affect the psychosocial outcome of children with epilepsy as they grow into adulthood. ${ }^{1}$ For example, Kobau et al. ${ }^{2}$, Espinola-Nadurille et al. ${ }^{3}$ and Suurmeijer et al. ${ }^{4}$ found that patients with epilepsy were less satisfied with their social life and experienced more loneliness compared to controls. Sillanpää et al. ${ }^{5}$ and Sillanpää and Cross ${ }^{1}$ found that adults with childhood-onset epilepsy had a lower educational status, a lower social participation, were less likely to be married, and had more problems in participating in daily activities compared to healthy adults. Chin et al. ${ }^{6}$ showed that patients with epilepsy (without cognitive disabilities or comorbid conditions) had more problems with social interactions and maintaining relationships compared to controls. Even after 35 years of follow-up, a significant poor social outcome was still found in patients with benign childhood-onset epilepsy. ${ }^{7}$

It is hypothesized that the above mentioned psychosocial problems have their onset during adolescence and early adulthood in which friendships, social networks, and independence have to be developed. ${ }^{8}$ Further, during adolescence, patients with continuing seizures have to transfer from paediatric to adult care. Epilepsy transition clinics have been developed to cope with this shift in health care, and to stimulate psychosocial transition; i.e. aid adolescents with epilepsy to become independent. ${ }^{9-13}$ In our multidisciplinary Epilepsy Transition Clinic for adolescents and young adults with epilepsy (15 to 25 years of age), multidisciplinary advice is provided for specific medical and psychosocial transitional problems, such as future perspectives in employment and housing. ${ }^{10,13}$ The goal of this multidisciplinary transition clinic is not only to ease the transition to adult care, but also to stimulate independence among adolescents and young adults with epilepsy. In this multidisciplinary transition clinic we noticed that many young adults with epilepsy were still living at home with their parents and were not motivated at all to start living independently. These young adults seemed to fail transitioning to independence, a problem also noticed in the adult outpatients clinic. When adult patients with epilepsy remain dependent on the care of their parents into adulthood, they gradually tend to lose the initiative of selfcare, and develop a passive coping style for problem solving later in life, the so called 'learned helplessness'. ${ }^{14}$

For this study, we were interested in adults, 25 to 30 years of age, with (childhoodonset) epilepsy. Except for demographic and epilepsy-related characteristics, we were especially interested in the social participation and feelings of loneliness among participants. Loneliness is defined as the discrepancy between the relationships a person has in terms of intimacy and interpersonal affection, and the relationships a 
person wants. Loneliness can be further subdivided into social loneliness, defined as missing a broad social network, and emotional loneliness, defined as missing an intimate relationship. ${ }^{15}$ As these definitions suggest, people with many friends can still experience loneliness when their friendships do not meet their social or emotional needs.

The age limit of 25 to 30 years of age was not strictly evidence based, but chosen with the idea that patients had just been through an important phase in life and had either successfully developed independence or failed the transition to independence. As mentioned above, it is known that in patients who have become passive in problem solving, the situation can finally become chronically with acceptance of the situation and the negative consequences instead of taking action. ${ }^{16}$

\section{Objective}

This study evaluated epilepsy-related characteristics and measures of loneliness correlated to 'failed transition to independence' in adults aged 25-30 years with (childhood-onset) epilepsy.

\section{Materials and methods}

\section{Inclusion and exclusion criteria}

All patients in this study were recruited from Epilepsy Center Kempenhaeghe (The Netherlands), a specialized tertiary referral center for patients with epilepsy. Patients with (childhood-onset) epilepsy, who were having regular appointments at our outpatient clinic currently or in the past, were invited to participate in this study. All patients were 25 to 30 years of age. In patients who had their full scale intelligence quotient tested in the past, and were diagnosed with intellectual disabilities (Full Scale Intelligence Quotient $<70$ ) were not invited to participate. Patients were excluded from this study if they had ever visited our multidisciplinary Kempenhaeghe Epilepsy Transition Clinic for adolescents with epilepsy, because a transition intervention might have influenced the psychosocial outcomes we were interested in. After data collection, patients who had only completed primary school as their highest level of education, in combination with dependency on financial governmental support, were excluded from data analysis, because of a high probability of an intelligence quotient $<70$. 


\section{Study design}

One questionnaire was sent to all patients who met the inclusion criteria. The questionnaire contained questions regarding the patient's current medical, educational/vocational status and independence. To be more specific: date of diagnosis of epilepsy, seizure frequency, number and type of antiepileptic drugs (AEDs), current and past treatment options (AEDs, vagus nerve stimulator, ketogenic diet, epilepsy surgery), the health care provider which facilitated regular appointments for epilepsy care (e.g., epileptologist, neurologist, or general practitioner) and the number of visits per year, hospital admittance because of epileptic seizures, highest completed education level, current education or employment, financial income, financial guardianship, relationships, housing, level of independence by self-reported completing household tasks, medication intake and making appointments with health care workers, satisfaction with friendships, and experience of emotional and social loneliness by the validated De Jong-Gierveld loneliness scale (See Appendix B). ${ }^{15}$ The De Jong-Gierveld loneliness scale consists out of eleven questions, however, the word 'loneliness' is not mentioned in this questionnaire to avoid measurement bias. Five questions refer to social loneliness, and six questions refer to emotional loneliness. Negative answers ('no'/'more-or-less') to questions regarding social loneliness (questions $1,4,7,8,11$ ) and positive answers ('yes'/'more-or-less') to items regarding emotional loneliness (questions 2, 3, 5, 6, 9, 10) were counted and determined the social loneliness score or emotional loneliness score, respectively. Missing answers were referred to as the 'missing social loneliness score' or 'missing emotional loneliness score'. The total loneliness score is the sum of the social and the emotional loneliness score, and is only valid if the 'missing' scores were zero. Further, the loneliness score was also categorized as 'not lonely' (score 0 to 2), 'moderate lonely' (score 3 to 8), 'severe lonely' (score 9 or 10), 'very severe lonely' (score 11). ${ }^{15}$ We also asked patients to report their own satisfaction within three transitional domains; medical status, educational/vocational status, independence/ separation from parents. We used these transitional domains before in our previous study ${ }^{10}$, and for this study the satisfaction with friendships was added to the list. Self-reported satisfaction within the four above mentioned transitional domains was converted into a score of -2 (not satisfied at all); -1 (not satisfied) or 0 (satisfied).

'Transition to independence' was defined according to the patient's age when start living independent from their parents, and categorized with scores ranging from 0 to 4 for all patients. Adult patients still living at home with their parents received the minimum score of 0 , whereas patients living independent from their parents were scored from 1 to 4 , according to their age at the moment of leaving the parental home. Table 6.1 provides a complete overview of the categorization of '(failed) transition to independence'. Data of all patients who gave written informed consent and fully completed the questionnaire were entered in an IBM SPSS database. 
Table 6.1 Definitions of 'failed transition to independence'.

\begin{tabular}{llc}
\hline & Definition & Number of patients $(n)$ \\
\hline Score 0 & Failed transition: adults still living at home with their parents. & $19(32.2 \%)$ \\
Score 1 & Start living independently $>25-30$ years of age. & $13(22.0 \%)$ \\
Score 2 & Start living independently 21-25 years of age. & $13(22.0 \%)$ \\
Score 3 & Start living independently 18-21 years of age. & $9(15.3 \%)$ \\
Score 4 & Start living independently <18yrs of age. & 0 \\
Unknown & Data not reported & $5(8.5 \%)$ \\
\hline
\end{tabular}

\section{Statistical analysis}

All statistical analyses were performed by IBM SPSS Version 21. We used descriptive statistics to compute percentages (\%) and frequencies $(n)$ of categorical variables. Means are presented with median, standard deviation (SD) and range.

We used a Bivariate Correlation analyses to determine patient characteristics and loneliness scores correlated to a failed transition to independence. All analysis were one-tailed. The nonparametric data was reported with the Spearman's rho Correlation Coefficient $(r)$. A $p$-value $<0.05$ was defined as statistically significant.

\section{Ethics}

This study was approved by the Medical Ethics Committee of Kempenhaeghe. Patients could participate voluntarily. Written informed consent was obtained from all participants.

\section{Results}

\section{Patient characteristics}

One hundred and eighty-five patients were invited to participate in this study. Finally, 59 patients (31.9\%) met our inclusion criteria, fully completed the questionnaire and gave written informed consent.

The patient characteristics are shown in Table 6.2. Twenty-three men (39.0\%) and 36 women $(61.0 \%)$ participated in this study. The mean age was 28.2 years (median=28.2, SD=1.25). The mean full scale intelligence quotient was 94.5 (median=91.0, SD=15.5). Nineteen patients (32.2\%) were still living at home with their parents, whereas 2 patients (3.4\%) were living in a supported accommodation and 38 patients (64.4\%) were living independently (either with or without additional support) or together with a partner. 
Table 6.2 Demographic and psychosocial patient characteristics.

\begin{tabular}{|c|c|c|c|c|}
\hline & & Median & SD & Range \\
\hline \multicolumn{5}{|l|}{ Gender } \\
\hline Men & $23(39 \%)$ & & & \\
\hline Women & $36(61 \%)$ & & & \\
\hline Autism spectrum disorder & $8(13.6 \%)$ & & & \\
\hline Mean age (years) & 28.2 & 28.2 & 1.25 & $25.7-30.4$ \\
\hline Mean Full Scale Intelligence Quotient (FSIQ) & 94.5 & 91.0 & 15.5 & $77-126$ \\
\hline \multicolumn{5}{|l|}{ Living arrangements } \\
\hline At home with parents & $19(32.2 \%)$ & & & \\
\hline Supported accommodation & $2(3.4 \%)$ & & & \\
\hline Independently, with support & $2(3.4 \%)$ & & & \\
\hline Independently, without support & $6(10.2 \%)$ & & & \\
\hline Living together (relationship) & $30(50.8 \%)$ & & & \\
\hline Employment & $42(71.2 \%)$ & & & \\
\hline \multicolumn{5}{|l|}{ Financial income } \\
\hline Job/salary & 41 (69.5\%) & & & \\
\hline Governmental support & $16(27.1 \%)$ & & & \\
\hline Parents & $2(3.4 \%)$ & & & \\
\hline \multicolumn{5}{|l|}{ Self-reported independence in: } \\
\hline Household chores & $57(96.6 \%)$ & & & \\
\hline Medication intake & $49(83.1 \%)$ & & & \\
\hline Making medical appointments & $52(88.1 \%)$ & & & \\
\hline Over all & $55(93.2 \%)$ & & & \\
\hline \multicolumn{5}{|l|}{ Transportation } \\
\hline Driving license, driving allowed & $23(39.0 \%)$ & & & \\
\hline Driving license, driving not allowed & $5(8.5 \%)$ & & & \\
\hline Public transport & $13(22.0 \%)$ & & & \\
\hline Transport organized for people with disabilities & $3(5.1 \%)$ & & & \\
\hline Bicycle/scooter & $6(10.2 \%)$ & & & \\
\hline Parental transport & $9(15.3 \%)$ & & & \\
\hline \multicolumn{5}{|l|}{ Patient's own satisfaction with: } \\
\hline Medical domain & -0.56 & 0 & 0.70 & -2 to 0 \\
\hline Educational/occupational status & -0.76 & -1 & 0.82 & -2 to 0 \\
\hline Independence/separation & -0.46 & 0 & 0.65 & -2 to 0 \\
\hline Friendships/social skills & -0.46 & 0 & 0.65 & -2 to 0 \\
\hline
\end{tabular}

Data are presented as number $(n, \%)$. Means are presented with median, standard deviation (SD) and range.

Participants had a mean age at diagnosis of epilepsy of almost 9 years (median=9.37, $S D=5.14$ ), with a mean duration of epilepsy of 19.2 years (median=19.2, $S D=5.15$ ). Cryptogenic localization-related epilepsy was the most common type of epilepsy ( $n=26,44.1 \%)$, followed by symptomatic localization-related epilepsy ( $n=15,25.4 \%$ ), idiopathic generalized epilepsy in 9 patients (15.3\%). Thirty patients $(50.8 \%)$ were seizure-free over one year, and the mean number of seizure-free years was 3.66 (median=1.22, SD=4.90, range $0-20$ ).

Six patients $(10.2 \%)$ reported they did not necessarily need to visit a health care worker regularly from now on because of seizure-freedom, whereas 53 patients $(89.8 \%)$ still had regular appointments with health care workers, with a mean number of 1.47 visits per year (median=1.00, SD=0.96, range $0-4$ ). Seven patients $(11.9 \%$ ) had 
been admitted to a hospital last year due to epilepsy. A full overview of the epilepsyrelated characteristics is shown in Table 6.3.

Table 6.3 Epilepsy-related patient characteristics.

\begin{tabular}{|c|c|c|c|c|}
\hline & & Median & SD & Range \\
\hline Mean age at diagnosis of epilepsy (years) & 8.97 & 9.37 & 5.14 & $0.0-19.0$ \\
\hline Mean duration of epilepsy (years) & 19.2 & 19.2 & 5.15 & $8.86-27.3$ \\
\hline \multicolumn{5}{|l|}{ Type of epilepsy } \\
\hline \multicolumn{5}{|l|}{ Localization-related epilepsy } \\
\hline Idiopathic & $7(11.9 \%)$ & & & \\
\hline Symptomatic & $15(25.4 \%)$ & & & \\
\hline Cryptogenic & $26(44.1 \%)$ & & & \\
\hline \multicolumn{5}{|l|}{ Generalized epilepsy } \\
\hline Idiopathic & $9(15.3 \%)$ & & & \\
\hline Symptomatic & $1(1.7 \%)$ & & & \\
\hline Not yet classified & $1(1.7 \%)$ & & & \\
\hline \multicolumn{5}{|l|}{ Under follow-up for epilepsy at: } \\
\hline Neurologist Epilepsy Center Kempenhaeghe & $48(81.4 \%)$ & & & \\
\hline External neurologist & $5(\%)$ & & & \\
\hline Seizure free, medical follow-up not indicated & $6(10.2 \%)$ & & & \\
\hline Mean number of visits per year & 1.47 & 1.00 & 0.96 & $0-4$ \\
\hline Hospital admittance last 12 months due to epilepsy & $7(11.9 \%)$ & & & \\
\hline \multicolumn{5}{|l|}{ Number of AEDs } \\
\hline 0 & $7(11.9 \%)$ & & & \\
\hline 1 & $20(33.9 \%)$ & & & \\
\hline 2 & $22(37.3 \%)$ & & & \\
\hline 3 & $7(11.9 \%)$ & & & \\
\hline 4 & $3(5.1 \%)$ & & & \\
\hline \multicolumn{5}{|l|}{ Self-reported AED adherence } \\
\hline Yes & $36(61.0 \%)$ & & & \\
\hline Forget AEDs sometimes & $17(28.8 \%)$ & & & \\
\hline No current AED treatment & $6(10.2 \%)$ & & & \\
\hline \multicolumn{5}{|l|}{ Other treatment options } \\
\hline Vagal Nerve Stimulator & $6(10.2 \%)$ & & & \\
\hline Epileptic Surgery & $3(5.1 \%)$ & & & \\
\hline Ketogenic Diet & 0 & & & \\
\hline \multicolumn{5}{|l|}{ Seizure frequency } \\
\hline Daily & $3(5.1 \%)$ & & & \\
\hline Weekly & $9(15.3 \%)$ & & & \\
\hline Monthly & $7(11.9 \%)$ & & & \\
\hline Yearly & $10(16.9 \%)$ & & & \\
\hline Seizure-free $>1$ year & $30(50.8 \%)$ & & & \\
\hline \multicolumn{5}{|l|}{ Seizure-free } \\
\hline Mean number of days & 1337 & 444 & 1789 & $0-7305$ \\
\hline Mean number of years & 3.66 & 1.22 & 4.90 & $0-20$ \\
\hline
\end{tabular}

Data are presented as number $(n, \%)$. Means are presented with median, standard deviation (SD) and range. 
Loneliness scores and information about friendships are provided in Table 6.4.Thirtynine patients $(66.1 \%)$ had a relationship. Fifty-two patients $(88.1 \%)$ reported that they were satisfied with the number of friendships. The mean self-reported emotional loneliness score was 1.27 (median=0, SD=2.17), the mean social loneliness score was 1.19 (median=1, SD=1.43), and the mean total loneliness score was 2.66 (median=1, $\mathrm{SD}=3.37)$. When categorized, 37 patients $(62.7 \%)$ reported not being lonely at all, 16 patients $(27.1 \%)$ reported moderate loneliness, 5 patients $(8.5 \%)$ experienced severe loneliness, and one patient $(1.7 \%)$ reported the maximum loneliness score of 11 points.

Table 6.4 Loneliness scores and social patient characteristics.

\begin{tabular}{|c|c|c|c|c|}
\hline & & Median & SD & Range \\
\hline Friends with diagnosis epilepsy & $13(25.0 \%)$ & & & \\
\hline In a relationship & $39(66.1 \%)$ & & & \\
\hline Satisfied with number of friendships & $47(79.7 \%)$ & & & \\
\hline \multicolumn{5}{|l|}{ Asking friends for: } \\
\hline Help in general & $33(55.9 \%)$ & & & \\
\hline Going out & $46(78.0 \%)$ & & & \\
\hline Discussing personal problems & $46(78.0 \%)$ & & & \\
\hline Mean emotional loneliness score & 1.47 & 0 & 2.17 & $0-6$ \\
\hline Mean social loneliness score & 1.19 & 1 & 1.43 & $0-5$ \\
\hline Mean total loneliness score & 2.66 & 1 & 3.37 & $0-11$ \\
\hline \multicolumn{5}{|l|}{ Loneliness scale } \\
\hline No loneliness (0-2) & $37(62.7 \%)$ & & & \\
\hline Moderate loneliness (3-8) & $16(27.1 \%)$ & & & \\
\hline Severe loneliness (9-10) & $5(8.5 \%)$ & & & \\
\hline Very severe loneliness (11) & $1(1.7 \%)$ & & & \\
\hline
\end{tabular}

Data are presented as number $(n, \%)$. Means are presented with median, standard deviation (SD) and range.

\section{Correlations}

A statistically significant correlation was found between 'transition to independence' and the social loneliness scale $(r=-0.230, p=0.047)$ and the total loneliness scale $(r=-0.249, p=0.04)$. This means, the lower transition to independence was scored, the higher the social loneliness score and the total loneliness score, thus the more loneliness was experienced. The emotional loneliness score was not significantly correlated to a transition to independence.

A statistically significant correlation was also found for the patients self-reported satisfaction with their independence/separation from parents $(r=0.289, p=0.01)$ and friendships $(r=0.218, p=0.04)$, meaning the lower the transition to independence was scored, the less patients were satisfied with their own independence/separation and friendships. 


\section{Discussion}

With this study we found that social loneliness and a higher overall score on the validated De Jong-Gierveld loneliness scale were correlated with failed transition to independence. The results also showed that patients with failed transition were not satisfied with their friendships and with the situation of still living at home with their parents.

The outcomes of this study reflect a troublesome situation in adults with epilepsy who have a failed transition to independence. On the first place, social problems, e.g., feelings of loneliness and lack of support/friendships are a frequent, but often underrecognized condition in patients with epilepsy. In this study 22 out of 59 patients (37.3\%) reported feeling lonely in some extent, of which 6 patients $(10.2 \%)$ were (very) severe lonely. Unfortunately, comparative numbers for this specific age group cannot be found in the Dutch population.

Patients with a failed transition reported feeling lonely both socially and in general, and were not satisfied at all with their friendships. This outcome indicates that the number of friendships (the social network) and the quality of friendships (reflected by the experiencing of feelings of loneliness) did not fulfill their needs. Remarkably, emotional loneliness was not correlated to transition to independence. This might reflect that patients still living at home either experience emotional support by their parents, or that they feel ashamed to admit being emotional lonely. The latter explanation is most likely, as patients also reported not being satisfied with the situation of living at home with their parents.

Second, based on prior observations in our multidisciplinary Epilepsy Transition Clinic and in our adult outpatient clinic, we had the clinical impression that adults with a failed transition to independence/separation accepted the situation of still living at home with their parents as being beneficial. However, this study indicated the exact opposite, namely that adult patients with epilepsy who still live at home with their parents were not satisfied at all with the situation, both developmentally and socially.

Several studies found reduced social skills and social competences among patients with epilepsy compared to a control group. ${ }^{17-21}$ Reduced skills and competences in developing friendships and social networks, and experiencing feelings of loneliness can hypothetically be caused by the family environment, as parental overprotection of children with epilepsy may lead to decreased social activities and social interactions. ${ }^{17,18,20-22}$ Subsequently, adult patients with epilepsy lack sufficient social skills and social competences to develop friendships, and experience feelings of loneliness because the friendships they have do not fulfill their needs. ${ }^{22}$ Another reasonable explanation is that patients with epilepsy experience problems in participating in social activities such as leisure activities or getting out with friends. ${ }^{2}$ Kobau et al. $^{2}$ found that over $25 \%$ of adults with epilepsy have difficulty in 
participating in social activities, and that $13.9 \%$ of the patients with epilepsy is unable to get out, which are almost twice the numbers found in adults without epilepsy. Causes for avoidance of social participation, and thus social isolation, may for example include fear of having seizures in public places, difficulties in obtaining and maintaining a suitable job and job-related social interaction with peers, or stigma. ${ }^{2,32}$ Another third substantial problem to participate in social activities is transportation to get to places (e.g., restrictions in driving). Kobau et al. ${ }^{2}$ described that patients with epilepsy are unable to use any type of transportation three and a half times more often than adults without epilepsy.

Although risk factors for failed transition or loneliness were not analyzed in this study, we hypothesize that these are merely found in the family environment of patients with epilepsy (e.g., parental overprotection or an unsupportive family environment) and with persistent patient characteristics (e.g., lack of social competences, or a low intelligence level). ${ }^{10,17,18,21}$ Our previous study analyzing risk factors for poor psychosocial outcome in adolescents and young adults with epilepsy showed that an unsupportive family environment is associated with an adverse future outcome. In accordance with the study of Kokkonen et al. ${ }^{17}$ we found no evidence that epilepsy (in terms of seizure frequency or age at onset of epilepsy) was primarily correlated with failed transition to independence, however, it should be noted that in our study population 30 patients (50.8\%) had seizure-freedom over one year (range 0-20 years).

Preventive measures and interventions for loneliness, such as training of social competences, can be challenging. First, loneliness can be difficult to notice, as many people feel ashamed of admitting being socially isolated. ${ }^{16}$ This might be reflected by the results of this study; 22 patients $(37.3 \%)$ reported positive scores on the De JongGierveld loneliness scale, but $79.7 \%(n=47)$ of the patients reported 'yes' to the question: 'Are you satisfied with the number of friendships?' that was included in our questionnaire. This might indicate that patients feel ashamed of reporting not having friends, or that these friendships did not fulfill their needs. Second, evidence is still conflicting, as some studies suggest that self-help groups or the improvement of social skills increase social networks, as others conclude that interventions were not successful in a population of social isolated people with multiple problems, because the interventions lacked attention for specific conditions and circumstances. ${ }^{22,23}$ Nevertheless, the first step is to evaluate the social participation and social network, and feelings of loneliness during a consultation with a health care worker. ${ }^{3}$

Clinically, we advise health care workers (e.g., parental overprotection or an unsupportive family environment) to pay attention to loneliness in adolescents and young adults with epilepsy who fail to separate from their parents. It is also advisable to evaluate social participation and social networks of young adults with epilepsy, but with the idea in mind that patients might feel ashamed admitting loneliness. Since 
evidence of interventions to improve the social network is conflicting, we suggest to improve the separation and independence from parents, as leaving a chronically poor functioning family seems the first step in improving the social skills and reducing feelings of loneliness. ${ }^{18,21}$

\section{Strengths and limitations}

To the best of our knowledge, this is the first study indicating a correlation between young adults with epilepsy with a failed transition to independence and the satisfaction with their social network. The results of this study are useful for health care workers who notice that adolescents and young adults tend to fail transition to independence.

This study also has some limitations. First, the use of questionnaires limited the characteristics (e.g., family environment) explored in this study, and the answers can be subject to recall or response bias.

Second, as it was impossible to conduct a non-responder analysis to evaluate which patients were actually participating in this study and which were not responding, selection bias cannot be completely ruled out.

Further, this study showed correlations between patient characteristics and transition to independence, but predictors for failed transition to independence could not be identified.

\section{Conclusions}

Failed transition to independence is correlated with social loneliness and with a higher overall score on the De Jong-Gierveld loneliness scale. Patients reported that they were not satisfied with their independence/separation and friendships, reflecting a troublesome chronic situation. We found no evidence that epilepsy was primarily correlated with a failed transition to independence. 


\section{References}

1. Sillanpaa M, Helen Cross J. The psychosocial impact of epilepsy in childhood. Epilepsy Behav 2009;15 Suppl 1:S5-10.

2. Kobau R, Luncheon C, Zack MM, et al. Satisfaction with life domains in people with epilepsy. Epilepsy Behav 2012;25:546-51.

3. Espinola-Nadurille M, Crail-Melendez D, Sanchez-Guzman MA. Stigma experience of people with epilepsy in Mexico and views of health care providers. Epilepsy Behav 2014;32:162-9.

4. Suurmeijer TP, Reuvekamp MF, Aldenkamp BP. Social functioning, psychological functioning, and quality of life in epilepsy. Epilepsia 2001;42:1160-8.

5. Sillanpaa M, Haataja L, Shinnar S. Perceived impact of childhood-onset epilepsy on quality of life as an adult. Epilepsia 2004;45:971-7.

6. Chin RF, Cumberland PM, Pujar SS, et al. Outcomes of childhood epilepsy at age 33 years: a population-based birth-cohort study. Epilepsia 2011;52:1513-21.

7. Jalava $M$, Sillanpaa $M$, Camfield $C$, et al. Social adjustment and competence 35 years after onset of childhood epilepsy: a prospective controlled study. Epilepsia 1997;38:708-15.

8. Camfield P, Camfield C, Pohlmann-Eden B. Transition from pediatric to adult epilepsy care: a difficult process marked by medical and social crisis. Epilepsy Curr 2012;12:13-21.

9. Appleton RE, Chadwick D, Sweeney A. Managing the teenager with epilepsy: paediatric to adult care. Seizure 1997;6:27-30.

10. Geerlings RP, Aldenkamp AP, Gottmer-Welschen LM, et al. Developing from child to adult: Risk factors for poor psychosocial outcome in adolescents and young adults with epilepsy. Epilepsy Behav 2015;51:182-90.

11. Iyer A, Appleton R. Transitional services for adolescents with epilepsy in the U.K.: a survey. Seizure 2013;22:433-7.

12. Jurasek L, Ray L, Quigley D. Development and implementation of an adolescent epilepsy transition clinic. J Neurosci Nurs 2010;42:181-9.

13. Geerlings RP, Aldenkamp AP, Gottmer-Welschen LM, et al. Evaluation of a multidisciplinary epilepsy transition clinic for adolescents. Eur J Paediatr Neurol 2016 (In press).

14. Seligman ME. Learned helplessness. Annu Rev Med 1972;23:407-12.

15. de Jong Gierveld J, van Tilburg T. [A shortened scale for overall, emotional and social loneliness]. Tijdschr Gerontol Geriatr 2008;39:4-15.

16. Machielse JEM. Sociaal isolement bij ouderen: een typologie als richtlijn voor effectieve interventies. [Social isolation among older people: a typology as guide for effective interventions]. Journal of social intervention: Theory and Practice 2011;20:40-61.

17. Kokkonen J, Kokkonen ER, Saukkonen AL, et al. Psychosocial outcome of young adults with epilepsy in childhood. J Neurol Neurosurg Psychiatry 1997;62:265-8.

18. Koponen A, Seppala U, Eriksson K, et al. Social functioning and psychological well-being of 347 young adults with epilepsy only--population-based, controlled study from Finland. Epilepsia 2007;48:907-12.

19. Hamiwka LD, Hamiwka LA, Sherman EM, et al. Social skills in children with epilepsy: how do they compare to healthy and chronic disease controls? Epilepsy Behav 2011;21:238-41.

20. Jakovljevic V, Martinovic Z. Social competence of children and adolescents with epilepsy. Seizure 2006;15:528-32.

21. Tse E, Hamiwka L, Sherman EM, et al. Social skills problems in children with epilepsy: prevalence, nature and predictors. Epilepsy Behav 2007;11:499-505.

22. McCagh J, Fisk JE, Baker GA. Epilepsy, psychosocial and cognitive functioning. Epilepsy Res 2009;86: 1-14.

23. Machielse JEM. Vrijwillige inzet bij sociaal geïsoleerden met multiproblematiek: mogelijkheden, voorwaarden en rollen. [Volunteering to social isolated people with multiple problems: possibilities, conditions and roles]. Journal of social intervention: Theory and Practice 2013;22:5-23. 


\section{Appendix B}

\section{The De Jong-Gierveld loneliness scale. ${ }^{15}$}

Question: Please indicate for each of the 11 statements, the extent to which they apply to your situation, the way you feel now. Please, circle the appropriate answer.

\begin{tabular}{|l|l|l|}
\hline 1 & There is always someone I can talk to about my day-to-day problems. & Yes/more-or-less/no \\
\hline 2 & I miss having a really close friend. & Yes/more-or-less/no \\
\hline 3 & I experience a general sense of emptiness. & Yes/more-or-less/no \\
\hline 4 & There are plenty of people I can lean on when I have problems. & Yes/more-or-less/no \\
\hline 5 & I miss the pleasure of the company of others. & Yes/more-or-less/no \\
\hline 6 & I find my circle of friends and acquaintances too limited. & Yes/more-or-less/no \\
\hline 7 & There are many people I can trust completely. & Yes/more-or-less/no \\
\hline 8 & There are enough people I feel close to. & Yes/more-or-less/no \\
\hline 9 & I miss having people around me. & Yes/more-or-less/no \\
\hline 10 & I often feel rejected. & Yes/more-or-less/no \\
\hline 11 & I can call on my friends whenever I need them. & Yes/more-or-less/no \\
\hline
\end{tabular}


Chapter 7

General discussion 
Chapter 7 


\section{General discussion}

The aim of this thesis was to gain more insight in the medical and psychosocial transitional problems in adolescents and young adults with epilepsy, and in the longterm and long-lasting effects of multidisciplinary transition interventions. Different studies were performed within our tertiary referral epilepsy centre Kempenhaeghe (Heeze, the Netherlands). These studies resulted in a description of the process and outcomes of our multidisciplinary Epilepsy Transition Clinic and especially in the effects of transition interventions, in the identification of risk factors for an adverse future psychosocial outcome in adolescents and young adults with epilepsy, and in a description of patients' characteristics correlated with a 'failed transition to independence' in young adults with (childhood-onset) epilepsy.

\section{Study population}

Patients included in the studies described in Chapter 3, Chapter 4 and Chapter 5 were recruited from the Kempenhaeghe multidisciplinary Epilepsy Transition Clinic. This transition clinic has a multidisciplinary approach for medical and psychosocial developmental issues during transition from adolescence to adulthood. Patients visiting the transition clinic are 15 to 25 years of age. Four health care workers (a neurologist/epileptologist, a clinical neuropsychologist, a social worker and an educationalist/vocational counselor) staff the transition clinic. All patients get consecutive appointments with the above mentioned health care workers (described as 'the carousel'), wherein the neurologist and the neuropsychologist work closely together in one appointment. Finally a tailored and personalized advice is made and discussed with the patient. Chapter 3 provides a more detailed description of the study population and the methods and procedures of the multidisciplinary Epilepsy Transition Clinic at the specialized referral centre for patients with epilepsy.

This chapter summarizes the main findings of this thesis. Thereafter, the results are discussed, and implications for clinical practice and suggestions for future research will be made. 


\section{Main findings}

The main findings described in this thesis are:

- Most medical health care workers focus mainly on the medical diagnosis and the transition from paediatric to adult medical care during adolescence. Limited attention seems to be paid to important psychosocial and developmental issues on other transitional domains: e.g., finishing education and finding a suitable job, development of independence/separation from parents, development of one's own social network (Chapter 2).

- A multidisciplinary Epilepsy Transition Clinic is strongly recommendable in the management of medical, psychosocial and developmental issues in adolescents and young adults with epilepsy during the years of transition (Chapter 3 ).

- There is still no consensus or guideline indicating the best multidisciplinary staffing for an epilepsy transition clinic (Chapter 2, Chapter 3).

- Several patient-related barriers (e.g., fear of leaving a familiar health care worker for an unknown adult neurologist for regular appointments) and health-carerelated barriers (e.g., the lack of preparation for transition from paediatric to adult health care) have to be overcome to enable the implementation of transition clinics and the transition from paediatric to adult care (Chapter 2).

- Patients with a chronic refractory epilepsy and a high seizure frequency, with a low intelligence level and living in unsupportive family conditions are at risk for a future adverse psychosocial outcome (Chapter 4).

- Multidisciplinary transition interventions demonstrate long-lasting effects, and have a positive influence on improvement in the medical domain, on the educational/vocational outcome and on reducing the overall risk for psychosocial failure (Chapter 5).

- Young adults with (childhood-onset) epilepsy and a 'failed transition to independence' experience more loneliness and especially social loneliness compared to patients who had a 'successful transition to independence'. In addition, these young adults also reported a troublesome situation of being dissatisfied with their current situation of still living at home with their parents and their friendships, illustrating that this situation is not a comforting choice, but the result of medical and psychosocial aberration during adolescence (Chapter 6). 


\section{Epilepsy versus other chronic diseases}

\section{Is transition in epilepsy comparable to transition in other childhood- onset chronic illnesses continuing into adulthood?}

Patients with epilepsy as well as those with other childhood-onset chronic disorders face developmental and transitional challenges during adolescence: both experience physical, social and physiological challenges, and both have to transfer from paediatric to adult health care. ${ }^{1,2}$ On one hand, all adolescents with chronic illnesses transitioning into adulthood seem to struggle with the acceptance of the chronic condition, with treatment adherence, and with self-management when disease management during adolescence is shifting from parental care to the patient's responsibility. ${ }^{1,2}$ On the other hand, epilepsy can not easily be compared to other chronic illnesses. The heterogeneity of the condition itself, the side-effects of antiepileptic drugs or seizures on the cognitive functioning, and the presence of comorbid conditions such as autism spectrum disorder, intellectual disabilities, behavioral disorders or ADHD, make it difficult, if not impossible, to compare epilepsy to other chronic childhood-onset conditions transitioning into adulthood. Further, epilepsy or some of the above mentioned comorbid conditions can either continue or remit during adolescence, which is uncommon in, for example, diabetes mellitus type I, chronic kidney disease or cardiac disease. Furthermore, the developmental milestones of patients with epilepsy can not be compared with other conditions using the transition rating scales, such as the Rotterdam Transition Profile ${ }^{3}$, as many goals on this scale are impossible to achieve for all patients with epilepsy (e.g., selfmanagement of finance, independent living and household tasks).

Although we must conclude that comparing the outcome of transition between epilepsy and other chronic childhood-onset illnesses is difficult, we know from several studies that for example the medical condition of patients with renal disease improved with the implementation of transition clinics, ${ }^{4,5}$ and we have no arguments that this might be any different for patients with epilepsy.

With respect to the medical and psychosocial outcomes of patients with epilepsy, most studies compared data of patients with epilepsy to healthy controls or to data of the general population, demonstrating the negative impacts of epilepsy on rates of employment and socioeconomic status, long-lasting intimate relationships, coping strategies and quality of life in general. ${ }^{6-14}$ Especially patients with severe epileptic syndromes, those using polytherapy, and those with intellectual disabilities show a worse outcome than controls. Only a few studies can be found addressing and comparing social and medical outcome of patients with epilepsy to another chronic condition. For example, Austin et al. ${ }^{15}$ found that children with epilepsy had a lower quality of life in the psychological, social and educational domain, but a higher quality 
of life in the physical domain compared to children with asthma. Another study of Austin et al. ${ }^{16}$, again comparing children with epilepsy to those with asthma, showed that children with epilepsy were at risk of behavioral problems, especially girls with severe epileptic syndromes. Wirrell et al. ${ }^{17}$ found that adults with childhood-onset absence epilepsy and continuing epileptic seizures had an outcome worse than controls with juvenile rheumatoid arthritis.

Thus, although difficult to compare, patients with epilepsy seem to face more difficulties during transition to adulthood, and reflect a higher risk for poor long-term psychosocial and medical outcome compared to other chronic conditions. This seems especially true for patients with severe epileptic syndromes and a high seizure frequency, and for those with intellectual disabilities. Those patient characteristics are in line with the risk factors for long-term poor psychosocial outcome found in Chapter 4 of this thesis.

\section{Consequences of failed transition}

\section{What are the consequences of failed medical transition for society?}

Teenagers with a failed medical transition are at risk of a poor medical outcome, in terms of poor self-management and lower rates of medication adherence. A failed medical transition can even lead to a complete withdrawal of essential medical or psychosocial care. ${ }^{18}$ Discontinuity of medical and psychosocial care can subsequently lead to poorer seizure control with negative consequences for independence and social participation, such as education/employment, and avoidance of social activities because of fear of having seizures. ${ }^{19-23}$ These difficulties are especially problematic in epilepsy, as adolescents with epilepsy tend to have less effective coping strategies compared to controls. ${ }^{13}$ Finally, a failed medical transition can lead to negative consequences for the society, leading to more pressure on the governmental health care programs and thus to higher demands of financial recourses.

Due to recent changes in the organization of the health care system in The Netherlands, patients with chronic diseases are more dependent on local governmental municipalities for financial support or materials. This thesis provided more insight in transitional problems and the psychosocial and societal functioning of adolescents and young adults with epilepsy. The studies in this thesis were financially supported by the province of Noord-Brabant (The Netherlands). The rationale behind the financial sponsorship is that early recognition of those at risk for long-term adverse psychosocial outcome would ideally lead to improvement of their situation, and thus decrease the demands of governmental health care programs and financial resources. Subsequently, lower governmental supports and needs will lead to a reduction in health care costs. Second, patients with a failed medical transition are also vulnerable for a poor psychosocial transition, eventually leading to lack of 
independence and consequently to societal problems in the range of behavioral problems and substance abuse. Hence, medical transition problems can lead to societal dropout.

\section{Risk factors for transition}

\section{What are the most important risk factors for transition?}

Chapter $\mathbf{4}$ of this thesis identified four risk factors for an adverse future outcome, namely an unsupportive and unstable family environment, ongoing seizures with a high seizure frequency and a low intelligence. Further, we evaluated in Chapter 6 that a 'failed transition to independence' is associated with social loneliness and with feelings of loneliness in general, and that patients with a failed transition to independence are dissatisfied with their current situation and their friendships.

The family environment was found to be a risk factor in Chapter 4, and further discussed in Chapter 6 as being the most important factor in influencing the development of social skills and social competences in patients with epilepsy. ${ }^{10,24}$ Further, Jayalakshmi et al. ${ }^{25}$ found that an unsupportive family in patients with juvenile myoclonic epilepsy led to lower medication adherence causing poor seizure control and thereafter affecting the psychosocial outcome.

When it comes to the intelligence level, Jayalakshmi et al. ${ }^{25}$ and Kokkonen et al. ${ }^{10}$ found that this is also the risk factor for poor social development. Third, as discussed above, epilepsy itself is a risk factor for transition, especially in cases with high seizure frequency.

For clinical practice a 'persona' may be useful to give practical-clinical markers of patients at risk. A 'persona' is a description of a typical person representing a certain domain, disease, or role. The persona at risk for transitional problems (and especially the family practitioner may take a role as guardian) will typically come from an unstable family environment, will have a limited intelligence (and thus have a low education background) and have an active epilepsy. The process leading to failed transition is not a process of leisureliness and a laid back personality, as young adults with failed transition are lonely and are particularly distressed about their situation. It is simply missing the changes for future development in the sensitive period (adolescence). Therefore pre-transition help during paediatric care may boost transitional interventions during adolescence. 


\section{Interventions in transition}

\section{What is the best staffing for a multidisciplinary epilepsy transition clinic?}

Literature showed a great variability in the staffing of the described transition clinics (Chapter 2), and no quantitative evidence, nor a clinical guideline ${ }^{26}$ or consensus for the most optimal staffing of epilepsy transition clinics exists. ${ }^{21-23,27-30}$ The models of these transition clinics are based on clinical experience and expert opinions, and it is in fact difficult to prove in a clinical trial what the best staffing for a transition clinic should be. Such a trial should test and compare different models to determine which health care workers, except for the referring paediatrician and the adult health care worker, are essential.

Except for the medical transition, the reviewed literature also showed multiple psychosocial and developmental problems in adolescents with epilepsy during transition. ${ }^{27}$ Adolescents with epilepsy (with or without comorbid disorders) are prone to develop a poor long-term outcome. ${ }^{7,31}$ However, attention for psychosocial issues seems insufficient during the years of transition. Therefore, the optimal staffing of an epilepsy transition clinic should consist out of both medical and psychosocial experts with knowledge of adolescents and developmental issues. As described in Chapter 3, our multidisciplinary Kempenhaeghe Epilepsy Transition Clinic ('the carousel') is staffed with a neurologist/epileptologist experienced both in paediatric and in adult care, a clinical neuropsychologist, a social worker and an educational/occupational specialist, all experienced in counseling adolescents. This multidisciplinary staffing was chosen to cover the most important transitional developmental domains and developmental problems, in addition to the medical domain.

Summarized, up to now the staffing and models of transition clinics can only be compared in the literature. Due to unpredictable seizures, comorbid conditions and specific developmental challenges in adolescents with epilepsy, the interventions and transition programs in other chronic illnesses, as reviewed by Prior et al. ${ }^{32}$, might not be generalizable to transition clinics for adolescents with epilepsy. Most important are the collaboration between paediatric and adult health care workers, the planning of a shift in health care, the empowerment of youth with epilepsy during transition, and to be able to intervene in both medical and psychosocial transition. ${ }^{2}$ 


\section{At what age should the transition intervention start?}

The expert opinion is to start the awareness and planning of the transition process from paediatric to adult care as early as possible. ${ }^{21,33}$ Transition itself is a gradual and individual process, and should not be marked by age alone, but rather by the development of independence and readiness of self-management of each individual adolescent with epilepsy. ${ }^{34} \mathrm{~A}$ method to measure transition readiness is the validated Transition Readiness Assessment Questionnaire (TRAQ). ${ }^{35}$ The TRAQ measures selfmanagement skills and self-advocacy in adolescents with special health care needs, and determines the need for additional educational support and interventions. ${ }^{35} \mathrm{~A}$ comparable tool to use for transition screening in health care shift is the Ready Steady Go. ${ }^{33}$ However, the use of the TRAQ, the Ready Steady Go and similar tools to asses transition readiness may not be helpful in all patients with epilepsy, especially when intelligence of the child and the parents is limited. Therefore we suggest to develop multiple assessment tools for adolescents with epilepsy, one for patients with normal intellectual abilities and one for patients with intellectual disabilities. Such a tool, the Dutch Epilepsie Groeiwijzer, is currently being developed for children with epilepsy with or without intellectual disabilities, and makes children and their caretakers aware of the upcoming developmental issues and the transition in health care.

In conclusion, awareness of transition in health care should start as early as possible, but transition itself depends on the individual developmental achievements. We hypothesize that transition interventions are less successful in adults with epilepsy as problems have become chronically and long-lasting and are less affected by interventions. However, it was beyond the scope of this thesis to study effectiveness of transition interventions in adults.

\section{Is referral to a multidisciplinary epilepsy transition clinic necessary for all adolescents with epilepsy?}

There is no ready answer to this question as it was not subject to a specific study in this thesis. On the one hand we now have identified those at risk (Chapter 4), being a subset of patients with chronic epilepsy. Undoubtedly, these are patients that should visit such transition clinics. Beyond this we are uncertain. There is no evidence that adolescents with chronic epilepsy should visit a transition clinic in the absence of the aforementioned risk factors. An intervention could increase dependence of care (and costs) and increase processes such as 'learned helplessness', which are in contrast with the empowerment-aim of a transition clinic. On the other hand, based on our clinical experience rather than on the results of clinical studies, even in patients with no obvious risk factors we could have specific medical or psychosocial transitional hindrances. There may be issues such as driving licenses, appropriate drug treatment of young women who come into the child-bearing age. Even in seizure free patients the issue may be the delicate balance of advantages and disadvantages of drug withdrawal. Further, the objective of transitional care is not only to provide medical 
and psychosocial care, but also to provide adolescents with epilepsy and their parents an opportunity to reflect and being able to discuss with experts all their issues, worries and plans that are pertinent being on the threshold of adulthood. Finally, a transition clinic can emphasize the need for continuation of medical care, and facilitate the transition to an adult neurologist.

\section{Is transition intervention tertiary care?}

Epilepsy transition clinics are a relatively new concept, and not yet widely implemented and recognized. Since medical and psychosocial assistance during transition seems useful, and drop-outs of regular medical care should be avoided, we advise to widely implement transition clinics. Every patient with a chronic illness should have the opportunity to visit a transition clinic at least once. For patients with epilepsy, the question is not whether a multidisciplinary epilepsy transition clinic should be implemented out of the specialized hospital setting, but whether this is possible. The guideline for patients with epilepsy ${ }^{26}$ now recommends all secondary referral hospitals to provide psychosocial support for all patients with epilepsy. According to this guideline, specialized tertiary referral centers must provide diagnostic facilities to evaluate the consequences of seizures on cognitive functioning and learning problems, development and behavior disorders. In addition, tertiary referral hospitals must provide multidisciplinary support by social workers or psychologists whenever social problems, learning disorders or educational/vocational problems are present. Transition clinics belong to this category of care, and it seems therefore rational that they are organized by (not necessarily situated within) tertiary care.

An alternative, discussed by Steinbeck et al. ${ }^{36}$, is to develop 'adolescent and young adult medicine' (AYAM) as a special and specific area of medical practice, as geriatric medicine is. However, AYAM specialists are not yet a recognized specialty. Training programs do not yet exist, and models and methods of AYAM care have to be developed. $^{36}$

\section{How to proceed from here?}

\section{Implications for clinical practice}

- A assessment tool (the Dutch 'Epilepsie Groeiwijzer') to make children with epilepsy and their caregivers aware of upcoming transitional hindrances and developmental milestones, is currently developed and will be implemented digitally.

- A good communication about the patient's psychosocial and medical wellbeing is of utmost importance for all health care workers and health care organizations 
caring for youth with epilepsy. E-health technology is an important aspect of health care, and a shared electronic patient file management could optimize the communication between hospitals and other health care settings and societal actors (e.g., community nurses, social workers).

We therefore advice to build such a platform with basically three aims:

1) A digital meeting place for adolescents with epilepsy. Adolescents are used to process information through the channels of social media. One week after the Kempenhaeghe transition clinic opened an internet information portal with also an educational video, this was shared through all kind of social media.

2) A portal or dedicated electronic patient file, allowing information transfer to dedicated caregivers. This portal may also allow information transfer from medical care to 'third parties' such as education or the family practitioner. Of course this can only be opened (selectively) if the patient gives permission and this seems helpful for the transition process.

3) An educational platform used for psycho-medical education including for example e-counseling.

\section{Implications for future research}

- Future research must focus on the development of well-validated transition readiness questionnaires for youth with epilepsy, on the validation of existing measures, and reaching consensus on outcomes of successful transition.

- $\quad$ Future studies should focus on patients with 'benign' childhood-onset epilepsies with complete seizure remission during adolescence. Evidence is conflicting whether these patients have a normal or poor psychosocial outcome compared to healthy controls.

- We identified patients at risk for poor psychosocial outcome and young adults with failed transition experiencing loneliness. The next step should be to develop and evaluate interventions and preventive measures for patients at risk for poor future outcome and failed transition.

- The most optimal staffing of a multidisciplinary epilepsy transition clinic should be part of future research.

- There is still no evidence regarding the efficacy and effectiveness of transition interventions comparing adolescents with epilepsy after a transition intervention to a control group. 


\section{References}

1. Brand B, Dunn S, Kulkarni R. Challenges in the management of haemophilia on transition from adolescence to adulthood. Eur J Haematol 2015;95 Suppl 81:30-5.

2. Aldiss S, Ellis J, Cass $\mathrm{H}$, et al. Transition From Child to Adult Care--'It's Not a One-Off Event': Development of Benchmarks to Improve the Experience. J Pediatr Nurs 2015;30:638-47.

3. Donkervoort M, Wiegerink DJ, van Meeteren J, et al. Transition to adulthood: validation of the Rotterdam Transition Profile for young adults with cerebral palsy and normal intelligence. Dev Med Child Neurol 2009;51:53-62.

4. Harden PN, Walsh G, Bandler N, et al. Bridging the gap: an integrated paediatric to adult clinical service for young adults with kidney failure. BMJ 2012;344:e3718.

5. Prestidge $\mathrm{C}$, Romann A, Djurdjev $\mathrm{O}$, et al. Utility and cost of a renal transplant transition clinic. Pediatr Nephrol 2012;27:295-302.

6. Sillanpaa $\mathrm{M}$, Jalava $\mathrm{M}$, Kaleva $\mathrm{O}$, et al. Long-term prognosis of seizures with onset in childhood. $\mathrm{N}$ Engl J Med 1998;338:1715-22.

7. Sillanpaa M, Haataja L, Shinnar S. Perceived impact of childhood-onset epilepsy on quality of life as an adult. Epilepsia 2004;45:971-7.

8. Jalava M, Sillanpaa M, Camfield $C$, et al. Social adjustment and competence 35 years after onset of childhood epilepsy: a prospective controlled study. Epilepsia 1997;38:708-15.

9. Geerts A, Brouwer O, van Donselaar C, et al. Health perception and socioeconomic status following childhood-onset epilepsy: the Dutch study of epilepsy in childhood. Epilepsia 2011;52:2192-202.

10. Kokkonen J, Kokkonen ER, Saukkonen AL,et al. Psychosocial outcome of young adults with epilepsy in childhood. J Neurol Neurosurg Psychiatry 1997;62:265-8.

11. Baker GA, Spector S, McGrath Y, et al. Impact of epilepsy in adolescence: a UK controlled study. Epilepsy Behav 2005;6:556-62.

12. Chin RF, Cumberland PM, Pujar SS, et al. Outcomes of childhood epilepsy at age 33 years: a population-based birth-cohort study. Epilepsia 2011;52:1513-21.

13. Reeve DK, Lincoln NB. Coping with the challenge of transition in older adolescents with epilepsy. Seizure 2002;11:33-9.

14. Koponen A, Seppala U, Eriksson K, et al. Social functioning and psychological well-being of 347 young adults with epilepsy only--population-based, controlled study from Finland. Epilepsia 2007;48:907-12.

15. Austin JK, Smith MS, Risinger MW, et al. Childhood epilepsy and asthma: comparison of quality of life. Epilepsia 1994;35:608-15.

16. Austin JK, Dunn DW, Huster GA. Childhood epilepsy and asthma: changes in behavior problems related to gender and change in condition severity. Epilepsia 2000;41:615-23.

17. Wirrell EC, Camfield CS, Camfield PR, et al. Long-term psychosocial outcome in typical absence epilepsy. Sometimes a wolf in sheeps' clothing. Arch Pediatr Adolesc Med 1997;151:152-8.

18. Crowley R, Wolfe I, Lock K, et al. Improving the transition between paediatric and adult healthcare: a systematic review. Arch Dis Child 2011;96:548-53.

19. Jakovljevic V, Martinovic Z. Social competence of children and adolescents with epilepsy. Seizure 2006;15:528-32.

20. Lewis SA, Noyes J. Effective process or dangerous precipice: qualitative comparative embedded case study with young people with epilepsy and their parents during transition from children's to adult services. BMC Pediatr 2013;13:169.

21. Iyer A, Appleton R. Transitional services for adolescents with epilepsy in the U.K.: a survey. Seizure 2013;22:433-7.

22. Khan A, Baheerathan A, Hussain N, et al. Transition of children with epilepsies to adult care. Acta Paediatr 2013;102:216-21.

23. Jurasek L, Ray L, Quigley D. Development and implementation of an adolescent epilepsy transition clinic. J Neurosci Nurs 2010;42:181-9.

24. Hamiwka LD, Hamiwka LA, Sherman EM, et al. Social skills in children with epilepsy: how do they compare to healthy and chronic disease controls? Epilepsy Behav 2011;21:238-41.

25. Jayalakshmi S, Padmaja G, Vooturi S, et al. Impact of family support on psychiatric disorders and seizure control in patients with juvenile myoclonic epilepsy. Epilepsy Behav 2014;37:7-10. 
26. Epilepsie'. Richtlijn Epilepsie Nederlandse Vereniging voor Neurologie. 2015; available from: http://epilepsie.neurologie.nl

27. Geerlings RP, Aldenkamp AP, de With PH, et al. Transition to adult medical care for adolescents with epilepsy. Epilepsy Behav 2015;44:127-35.

28. Carrizosa J, An I, Appleton R, et al. Models for transition clinics. Epilepsia 2014;55 Suppl 3:46-51.

29. Appleton RE, Chadwick D, Sweeney A. Managing the teenager with epilepsy: paediatric to adult care. Seizure 1997;6:27-30.

30. Smith PE, Myson V, Gibbon F. A teenager epilepsy clinic: observational study. Eur J Neurol 2002; 9:373-6.

31. Camfield P, Camfield C, Pohlmann-Eden B. Transition from pediatric to adult epilepsy care: a difficult process marked by medical and social crisis. Epilepsy Curr 2012;12:13-21.

32. Prior $M$, McManus $M$, White $P$, et al. Measuring the "triple aim" in transition care: a systematic review. Pediatrics 2014;134:e1648-61.

33. Nagra A, McGinnity PM, Davis N, et al. Implementing transition: Ready Steady Go. Arch Dis Child Educ Pract Ed 2015;100:313-20.

34. Camfield P, Camfield C. Transition to adult care for children with chronic neurological disorders. Ann Neurol 2011;69:437-44.

35. Sawicki GS, Lukens-Bull K, Yin X, et al. Measuring the transition readiness of youth with special healthcare needs: validation of the TRAQ--Transition Readiness Assessment Questionnaire. J Pediatr Psychol 2011;36:160-71.

36. Steinbeck K, Towns S, Bennett D. Adolescent and young adult medicine is a special and specific area of medical practice. J Paediatr Child Health 2014;50:427-31. 
Chapter 8

Summary 
Chapter 8 


\section{Summary}

Epilepsy is a heterogenic neurological disorder, mainly characterized by recurrent and often unpredictable seizures. Epileptic seizures are mostly accompanied by loss of consciousness and jerking limb movements. Further, comorbid conditions such as behavioural disorders and physical and mental disabilities (e.g., learning problems, autism spectrum disorders or ADHD) are common among patients with epilepsy.

Both epilepsy and the comorbid conditions may have a profound impact on the lives of patients with epilepsy and their families. Several studies indicated that, for example, unemployment and social isolation are more common among patients with epilepsy compared to healthy controls. It is hypothesized that these problems have their onset before or during adolescence. Adolescence is an important period in life, in which the adolescent develops socially, emotionally, and physically, and is expected to become independent from parents. Many patients with epilepsy seem to have difficulties in achieving these goals, as unpredictable epileptic seizures or associated comorbid conditions can negatively influence independent living and learning disorders can lead to difficulties in education or employment. These problems during adolescence have an impact on adult life.

Except for the transition to independence, adolescents with chronic epilepsy reaching the adult age also have to move from paediatric to adult medical care. In recent years, increasing attention is given to this transition phase. Multidisciplinary epilepsy transition clinics have been implemented to support adolescents with epilepsy during the transition phase, and to ease the transition from child to adult medical care.

\section{Study population}

A multidisciplinary Epilepsy Transition Clinic was set up at specialized epilepsy centre Kempenhaeghe in 2012. This clinic is staffed with a neurologist/epileptologist, a clinical neuropsychologist, a social worker and an educationalist/vocational counsellor to explore medical as well as psychosocial problems during transition. The neurologist and neuropsychologist work together in a single consultation, after which the adolescent has appointments with the social worker and educationalist/vocational counsellor. This procedure of set appointments is called 'the carousel'. After 'the carousel', a personal advice is made by the health care workers and discussed with the patient. This advice may include a medical work-up (EEG, MRI, neuropsychological assessment, genetic counselling), or short-term follow-up by one of the health care workers.

The patients included in the studies described in Chapter 3, Chapter 4 and Chapter 5 were recruited from this multidisciplinary transition clinic.

The goal of this thesis was to explore medical and psychosocial transitional problems in adolescents and young adults with chronic epilepsy, and the long-term and longlasting effects of multidisciplinary transitional care. More specifically, this thesis 
focused on the methods, process and long-term outcome of our multidisciplinary Epilepsy Transition Clinic and on transition interventions. We also studied risk factors for poor psychosocial outcome, and patient characteristics related to a 'failed transition to independence' (Chapter 6).

\section{Main findings}

Chapter 2 reviewed the literature on psychosocial and medical issues during transition to adulthood. More attention should be paid to psychosocial problems during the transition from paediatric to adult care. There is still no consensus about the setting and staffing of an epilepsy transition clinic, and several models of transition clinics were described, all with their advantages and disadvantages. Health care workers in the paediatric and adult care should overcome several barriers and work together closely, in order to develop and improve transition clinics for youth with epilepsy.

Chapter 3 focused on transitional care for both medical and psychosocial issues. This chapter described the multidisciplinary Kempenhaeghe Epilepsy Transition Clinic, staffed by a neurologist, a clinical neuropsychologist, an educationalist/vocational counsellor and a social worker. The methods and results of our transition clinic are described, including the 'carousel' of appointments with the health care workers, and the number of diagnostic work-ups (MRI, neuropsychological assessment, EEG, laboratory work-up, genetic counselling). A total of 117 patients who visited our transition clinic were included. Outcome is described in terms of changed diagnosis, altered treatment options for epilepsy, further consultations by a health care worker, and the number of referrals from paediatric to adult care. Based on the results, we strongly recommend an appointment at a multidisciplinary epilepsy transition clinic during adolescence and early adulthood. A multidisciplinary approach may include specific attention for psychosocial problems and a medical diagnostic work-up, in order to optimize future medical and psychosocial outcome.

Chapter 4 reported a study identifying risk factors for poor psychosocial outcome in adolescents and young adults with epilepsy. Scores on three transitional domains were individually determined for every patient according to one's maximum level of functioning, namely for medical status, educational/occupational status, and independence/separation/identity, along with individual risk profile scores for poor psychosocial outcome. Patients with poor family support and an unstable family environment, ongoing seizures (chronic refractory epilepsy), a high seizure frequency and a low intelligence level are at risk for adverse future psychosocial outcome. These risk factors combined are able to classify $55.1 \%$ of the patients at risk for an adverse psychosocial outcome correctly. Ideally, early recognition of patients at risk for a poor psychosocial outcome could lead to early interventions and preventive measures. 
Chapter 5, described the medical and psychosocial status of adolescents with epilepsy after long-term follow-up, and evaluates the long-term effects of a multidisciplinary transition intervention compared to patient-related (intrinsic) factors on the improvement in medical and psychosocial outcome. We re-allocated the previously defined scores on the medical, educational/vocational domain, and the level of independence/separation/identity, together with the overall risk profile score. Thirtyfour out of 66 (51.5\%) patients had an improved psychosocial outcome after an average follow-up of almost two years. A discriminant analyses showed that the transition interventions are a relative strong predictor of improvement in medical outcome $(56.1 \%)$, educational/vocational outcome $(53.0 \%)$ and improvement in the overall risk score (54.5\%). Based on the overall improvement of psychosocial outcome in most patients, and the influence of a transition intervention on medical, educational/vocational outcome and the overall risk score, it is likely that adolescents with epilepsy benefit from visiting a multidisciplinary epilepsy transition clinic.

Chapter 6 described the medical and psychosocial functioning, independence, and social participation and loneliness among adults (25-30 years) with (childhood-onset) epilepsy. The main goal of this study was to find correlates for 'failed transition to independence' in adults with (childhood-onset) epilepsy. The validated De JongGierveld Loneliness scale was used to reflect the self-reported social, emotional and total loneliness score. A total of 59 patients participated in this study. We identified nineteen patients out of 59 participants (32.2\%) who were still living at home with their parent(s) and thus had completely failed a transition to independence (score 0 ); forty participants were scored ranging from 1 to 4 based on their age when start living independently. A Bivariate Correlation analyses showed a statistically significant correlation between transition to independence and the social loneliness score $(p=0.047)$ and the total loneliness score $(p=0.04)$, and for the patients self-reported satisfaction with their independence/separation from parents $(p=0.01)$ and friendships $(p=0.04)$. This outcome reflects that adults with epilepsy with a failed transition to independence experience social loneliness and loneliness in general, and are not satisfied with their current dependent and social situation.

Finally, Chapter 7 reviewed and discussed the most important findings of this thesis, and addressed the implications for clinical practice and for future research. 


\section{Chapter 9}

Samenvatting 
Chapter 9 


\section{Samenvatting}

Epilepsie kent vele vormen, maar is bovenal een aandoening die bestaat uit aanvallen. De aanvallen zijn meestal onvoorspelbaar en gaan vaak gepaard met schokken in ledematen en met bewustzijnsverlies. Daarnaast komen bij patiënten met epilepsie vaker dan gemiddeld fysieke of intellectuele beperkingen en gedragsproblemen voor, zoals leerproblemen, autisme of ADHD.

Zowel epilepsie als de bijkomende beperkingen kunnen grote gevolgen hebben voor het dagelijks leven van de patiënt en zijn of haar familie. Uit meerdere onderzoeken blijkt dat bijvoorbeeld werkeloosheid en sociaal isolement vaker voorkomen bij patiënten met epilepsie dan bij een gezonde controlepopulatie. De oorzaak voor deze problemen lijkt voor of tijdens de adolescentie te ontstaan.

Tijdens deze levensfase wordt namelijk van jongeren verwacht dat ze leren om zelfstandig te worden zich fysiek, sociaal en emotioneel ontwikkelen. Toch is deze ontwikkeling bij patiënten met epilepsie niet altijd vanzelfsprekend. Vanwege de onvoorspelbare aanvallen of bovengenoemde bijkomende beperkingen kan het voor jongeren met epilepsie lastig zijn om zelfstandig te functioneren. Door leer- of concentratiestoornissen kunnen ze zich bijvoorbeeld moeilijk focussen op een studie of werk. De achterstand die ze tijdens de adolescentie oplopen blijft vaak aanwezig op volwassen leeftijd.

Behalve de ontwikkeling naar zelfstandigheid, moeten adolescenten met chronische epilepsie bij het bereiken van de volwassen leeftijd ook de overstap maken van kinderarts naar een neuroloog voor volwassen. Dat betekent ook de overgang van samen met ouders naar de arts, naar alleen naar de arts. De laatste jaren is er steeds meer aandacht voor adolescenten met epilepsie tijdens deze overgang naar volwassenheid en volwassen gezondheidszorg (de transitiefase). Zogenaamde multidisciplinaire transitiepoliklinieken voor jongeren met epilepsie ondersteunen jongeren tijdens deze fase in hun groei naar zelfstandigheid en streven ernaar om deze overgang zo goed mogelijk te laten verlopen.

\section{Studiepopulatie}

Academisch Centrum voor Epileptologie Kempenhaeghe heeft sinds 2012 een multidisciplinaire transitiepolikliniek voor jongeren met epilepsie. In deze transitiepolikliniek werken een neuroloog/epileptoloog, een klinisch neuropsycholoog, een maatschappelijk werker en een onderwijskundige samen om het functioneren op de belangrijkste medische en psychosociale transitiedomeinen te evalueren. De neuroloog en neuropsycholoog werken samen tijdens één afspraak, waarna de adolescent ook gesprekken krijgt met maatschappelijk werk en de onderwijskundige. Deze werkwijze wordt 'de carrousel' genoemd. Na een bezoek aan alle hulpverleners wordt een persoonlijk advies geformuleerd en direct erna 
besproken met de adolescent. Dit advies kan zowel diagnostisch zijn (bijvoorbeeld aanvullend onderzoek middels EEG, MRI, neuropsychologisch onderzoek of genetisch onderzoek) of bestaan uit behandeling of begeleiding door een van de hulpverleners. Via onze multidisciplinaire epilepsie transitiepoli hebben we patiënten geïncludeerd voor Hoofdstuk 3, Hoofdstuk 4 en Hoofdstuk 5.

Het doel van dit proefschrift was om meer inzicht te krijgen in medische en maatschappelijke problematiek tijdens de transitie (overgang) van kinderarts naar volwassen gezondheidszorg bij adolescenten en jongvolwassenen met chronische epilepsie. In dit proefschrift wordt verder ingegaan op de methoden, uitkomsten en lange-termijn effecten van de multidisciplinaire Epilepsie Transitiepolikliniek in het Academisch Centrum voor Epileptologie Kempenhaeghe en de lange termijn effecten van transitie interventies. Daarnaast hebben we onderzoek gedaan naar risicofactoren voor een slechte psychosociale uitkomst op lange termijn, en beschreven we patiëntkenmerken van jongvolwassenen met een mislukte zelfstandigheidsontwikkeling ('failed transition') (Hoofdstuk 6).

\section{Belangrijkste bevindingen}

Hoofdstuk 2 is een review, waarin een overzicht wordt gegeven van psychosociale en medische transitieproblematiek. In deze review wordt duidelijk dat het van uiterst belang is dat tijdens transitiefase niet alleen aandacht wordt geschonken aan medische problematiek, maar juist ook aan onderliggende of bijkomende psychosociale problematiek. Verder worden de voor- en nadelen van verschillende modellen van transitiepoliklinieken beschreven. Hieruit blijkt dat er nog geen richtlijn is voor de opzet van een dergelijke polikliniek. Het belangrijkste aandachtspunt bij het implementeren en verder optimaliseren van transitiezorg voor jongeren met epilepsie is een goede samenwerking tussen pediatrische zorg en volwassen zorg.

Hoofdstuk 3 beschrijft de werkwijze en uitkomsten van de multidisciplinaire Kempenhaeghe Epilepsie Transitiepolikliniek. In deze transitiepolikliniek zijn een neuroloog, klinisch neuropsycholoog, maatschappelijk werker en onderwijskundige werkzaam. Bijzonder aan deze opzet is dat de focus niet alleen ligt op de medische problematiek, maar met name op het psychosociaal functioneren tijdens de transitiefase. In dit hoofdstuk komen de methoden van de Kempenhaeghe Epilepsie Transitiepolikliniek verder aan bod, zoals de 'carrousel' van afspraken die jongeren doorlopen, en het aantal aanvullende onderzoeken (MRI, neuropsychologisch onderzoek, EEG, bloedonderzoek, genetisch onderzoek) dat heeft plaatsgevonden. In totaal zijn 117 patiënten geïncludeerd die de 'carrousel' van de transitiepolikliniek hebben doorlopen. De uitkomst wordt uitgedrukt in het aantal veranderde diagnoses, aantal veranderingen in behandeling van epilepsie, vervolgafspraken bij een 
zorgverlener én het aantal verwijzingen van pediatrische naar volwassen gezondheidszorg. Op basis van deze resultaten is een verwijzing naar een multidisciplinaire epilepsie transitiepolikliniek aan te raden. Het voordeel van revisie van diagnose en bijkomende psychosociale problematiek tijdens de adolescentie of jongvolwassen leeftijd is dat problemen idealiter vroegtijdig onderkend en behandeld kunnen worden.

In Hoofdstuk 4 worden risicofactoren gevonden voor een slechte psychosociale uitkomst bij jongeren en jongvolwassenen met epilepsie. Het functioneren van patiënten werd individueel bepaald en gescoord, waarbij ook rekening werd gehouden naar het hoogst haalbare niveau van functioneren op drie transitiedomeinen: medische status, onderwijs/werk status, en de identiteitsontwikkeling en onafhankelijkheid van ouders. Daarnaast werd ook een individuele risicoprofielscore bepaald die het risico op een slechte psychosociale uitkomst op lange termijn weergeeft. Met dit onderzoek werden vier risicofactoren voor een slechte psychosociale uitkomst gevonden, namelijk: 1) een lager intelligentieniveau, 2) patiënten die weinig steun van familie hebben en zich in zogenaamde systeempathologie bevinden, 3) het doormaken van herhaaldelijke aanvallen en 4) een hoge aanvalsfrequentie. De combinatie van deze risicofactoren kan $55.1 \%$ van de patiënten met een verhoogd risico correct classificeren. Idealiter kan het vroegtijdig herkennen van hoog-risicopatiënten leiden tot vroegtijdige interventies en preventieve maatregelen.

Hoofdstuk 5 beschrijft de langdurige follow-up van medische en psychosociale uitkomst van patiënten die de multidisciplinaire transitiepolikliniek hebben bezocht. Deze studie onderzocht het medische en psychosociale functioneren van patiënten met epilepsie en vergeleek de effecten van een multidisciplinaire transitie interventie met de invloed van patiënt-gerelateerde (intrinsieke) eigenschappen op een verbetering van medisch en psychosociaal functioneren. De eerder beschreven scores op de drie transitiedomeinen (medische status, onderwijs/werk status, en de identiteitsontwikkeling en onafhankelijkheid van ouders) werden opnieuw toegekend, net als de risicoprofielscore. In drieënveertig van de 66 patiënten (51.5\%) was het algemeen functioneren verbeterd na een follow-up van ongeveer 2 jaar. Een beschrijvende discriminant analyse toonde aan dat transitie interventies relatief sterke voorspellers zijn van een verbetering in medisch functioneren (56.1\%), onderwijs/werk (53.0\%) en het algemeen functioneren (54.5\%). Op basis van de beschrijvende resultaten en het effect van de transitie interventie lijkt een multidisciplinaire transitie behandeling zinvol te zijn.

Hoofdstuk 6 beschrijft het medisch en psychosociaal functioneren, zelfstandigheid, sociale participatie en eenzaamheid onder volwassenen (25-30 jaar) met (chronische) epilepsie. Meer specifiek beschrijft deze studie in welke mate bepaalde 
patiëntkenmerken en gevoelens van eenzaamheid gecorreleerd zijn met een 'mislukte transitie naar zelfstandigheid' in volwassenen met (chronische) epilepsie. De gevalideerde De Jong-Gierveld eenzaamheidsschaal werd gebruikt om sociale, emotionele en totale eenzaamheidsscores te meten. In totaal werden 59 patiënten geïncludeerd in dit onderzoek. Negentien van de 59 deelnemers aan deze studie (32.2\%) woonden nog thuis bij hun ouder(s) ondanks het bereiken van de volwassen leeftijd, en hadden dus een 'mislukte transitie naar zelfstandigheid' (score 0). De zelfstandigheid van de overige patiënten werd gescoord van 1 tot 4 op basis van de leeftijd waarop zij zelfstandig zijn gaan wonen. Een correlatie analyse toonde een statistisch significante correlatie aan tussen 'transitie naar zelfstandigheid' en de sociale eenzaamheidsscore $(p=0.047)$ en de totale eenzaamheidsscore $(p=0.04)$ op de De Jong-Gierveld eenzaamheidsschaal. Verder bleek 'transitie naar zelfstandigheid' ook gecorreleerd met onvrede over de situatie op gebied van zelfstandigheid/ separatie van ouders $(p=0.01)$ en vriendschappen $(p=0.04)$. De uitkomst van deze studie geeft duidelijk aan dat volwassenen met epilepsie en een mislukte ontwikkeling van zelfstandigheid wel degelijk sociale eenzaamheid en eenzaamheid in het algemeen ervaren en niet tevreden zijn met hun huidige situatie op gebied van zelfstandigheid en sociale participatie.

In Hoofdstuk 7 worden de belangrijkste bevindingen van dit proefschrift samengevat en worden de belangrijkste adviezen voor de kliniek en voor nader onderzoek weergegeven. 


\section{Chapter 10}

Valorisation 
Chapter 10 


\section{Valorisation}

Globally about 15 million children suffer from epilepsy, and a considerable number of children continue to have lifelong seizures. In fact, epilepsy is the most common childhood-onset chronic condition transitioning into adulthood. ${ }^{1-4}$ Past studies indicated that childhood-onset epilepsy transitioning into adulthood has a profound effect on the patients' long-term psychosocial outcome. Ongoing seizures and associated comorbid conditions, directly or indirectly, tend to impair the patient's perspectives for education, future employment, and social participation and relationships, as patients with epilepsy are often restricted in daily activities, e.g., in career and job opportunities, housing, driving license, and certain hobbies or social activities. $^{5-7}$ Without a doubt, patients with epilepsy benefit from optimizing seizure control. However, several studies indicated that even patients with 'benign' childhood epilepsies with complete seizure remission during adolescence suffer long-term negative consequences of epilepsy, and have a psychosocial outcome which is far worse than that of a healthy control population. ${ }^{8,9}$

With emerging adulthood, adolescents with chronic epilepsy have to undergo a transition from paediatric to adult health care. Epilepsy transition clinics have been described to ease such a transition. ${ }^{4,10-13}$ Since the first description of an epilepsy transition clinic in $1997^{4}$, interest in youth with epilepsy and the processes of transition gradually increased. However, still little quantitative data exists regarding transition outcomes. ${ }^{10}$ Furthermore, an epilepsy transition clinic is still not mentioned in the Dutch clinical guidelines. ${ }^{14}$

This thesis contributed to the improvement of transition for adolescents and young adults with epilepsy. More specifically, this thesis focused on the methods and process of epilepsy transitional care, on the psychosocial impact of epilepsy as a chronic neurologic condition transitioning into adulthood, on the short-term and the long-term effects of a transition intervention, and described the characteristics of adult patients with epilepsy who had a 'failed transition to independence'.

\section{Results and relevance}

The results of this thesis contributed to improvement of epilepsy transitional care in several ways.

\section{Literature review}

The literature review in Chapter 2 made us aware of the fact that attention for epilepsy-related psychosocial issues is often inadequate or even absent compared to medical health care during the years of transition. Further, this chapter provided more insight in the patient-related factors (e.g., fear of leaving the familiar paediatrician) 
and health-care-related factors (e.g., lack of preparation for transition in medical care) that block the improvement of the medical transition from paediatric to adult epilepsy care. $^{15-17}$

\section{Multidisciplinary epilepsy transition clinic with special attention for psychosocial issues}

The multidisciplinary Kempenhaeghe Epilepsy Transition Clinic described in Chapter 3 has special attention for psychosocial care in adolescents with epilepsy during the years of transition. The aim of this multidisciplinary approach is not only to optimize seizure control, but also to provide adolescents and young adults with epilepsy with appropriate advice concerning typical age-related issues, e.g., in developing independence, social and societal participation and academic/vocational achievement. The rationale behind this multidisciplinary approach is to make patients and their caregivers aware of medical and specific developmental transitional problems in patients with chronic epilepsy, and to provide tailor-made advice, in order to improve their long-term medical and psychosocial outcome.

\section{Risk factors for poor psychosocial outcome}

The outcome of Chapter 4 helps to identify adolescents with epilepsy at risk for future adverse psychosocial outcome. The benefit of this study, compared to past studies, is that we focused only on adolescents and young adults in transition to adulthood, and that we paid special attention to specific transitional issues, e.g., selfesteem/independence, housing, study opportunities and employment. Hopefully, and ideally, early recognition of adolescents and young adults with epilepsy at risk for adverse psychosocial outcome can lead to early and precisely aimed interventions, and improve the chances and future perspectives of these patients.

\section{Long-term effects of a multidisciplinary transition intervention}

Chapter 5 revealed the long-term effects of a multidisciplinary transition intervention compared to patient-related intrinsic factors on the improvement in medical and psychosocial outcome after years of follow-up. Three previously defined transitional domains (medical, educational/occupational status and independence/separation/ identity) were re-evaluated, and the psychosocial outcome of most of the patients had improved at follow-up. Compared to patient-related intrinsic factors, the transition interventions are a relative strong predictor of improvement in medical outcome, educational/vocational outcome, and improvement in the overall risk score after long-term follow-up. 


\section{Adults with epilepsy and a failed transition to independence}

Chapter 6 of this thesis, showed that adults with epilepsy and a failed transition to independence experience more social loneliness and loneliness in general on the De Jong-Gierveld loneliness scale. Instead of taking advantage of still living with their parents, patients with a failed transition reported dissatisfaction with their current living situation and their social participation.

Summarized, this thesis provided more insight in the (lack of) general organization of transitional epilepsy care for adolescents and young adults with epilepsy, patients at risk for a future adverse psychosocial outcome, the results of a transition intervention, and the social participation and feelings of loneliness among adult patients with a failed transition to independence.

With the recent changes in the organization of the Dutch health care system, patients with epilepsy have to obtain funded resources and materials more frequently from local governmental organizations, e.g., local municipalities. This research program was funded by the province of Noord-Brabant (The Netherlands), with the idea in mind that further research and more insight in transitional problems might improve the psychosocial and societal functioning of patients with epilepsy. Improvement in societal participation and prevention of an adverse outcome might thereby decrease the pressure and demands on governmental health care programs and financial resources. Preferably, this might lead to decreased hospital (re)admissions, and a considerable reduction in health care costs on the long-term. ${ }^{18}$

\section{Target groups}

The main goal of our research was to optimize transitional care for youth with chronic epilepsy in order to improve their long-term medical and psychosocial outcome (e.g., participation, future career opportunities). Except for patients with epilepsy and their relatives, the results of this thesis are especially of interest for medical health care workers involved in adolescents with epilepsy during the transition from paediatric to adult care. Involved health care workers may include pediatricians, neurologists, general practitioners, nurse specialists, neuropsychologists, educationalists and social workers. Further, with the development of future career opportunities, social networks and friendships, the results of this thesis might also be of interest for teachers and employers of adolescents with chronic childhood-onset epilepsy. 


\section{Innovation}

In the last two decades the medical transition process of youth with chronic conditions received more attention. However, evidence was clearly lacking for patients with chronic childhood-epilepsy compared to other chronic illnesses. The results of this thesis contributed to the knowledge of multidisciplinary transitional care for adolescents with epilepsy, patients with epilepsy at risk for a poor psychosocial outcome and the long-term effects of a transition intervention. Further, we gained more insight in the functioning and social participation and feelings of loneliness among adults with epilepsy and a failed transition to independence.

\section{Implementation}

The results of this thesis can be used to ease the medical transition from paediatric to adult health care for adolescents with epilepsy during the years of transition. To implement transition clinics for adolescents and young adults with epilepsy, it is recommendable that pediatricians and adult neurologists/epileptologists work closely together. 


\section{References}

1. Lewis SA, Noyes J. Effective process or dangerous precipice: qualitative comparative embedded case study with young people with epilepsy and their parents during transition from children's to adult services. BMC Pediatr 2013;13:169.

2. Lewis SA, Noyes J, Mackereth S. Knowledge and information needs of young people with epilepsy and their parents: Mixed-method systematic review. BMC Pediatr 2010;10:103.

3. Asato MR, Manjunath R, Sheth RD, et al. Adolescent and caregiver experiences with epilepsy. J Child Neurol 2009;24:562-71.

4. Appleton RE, Chadwick D, Sweeney A. Managing the teenager with epilepsy: paediatric to adult care. Seizure 1997;6:27-30.

5. Sillanpaa M, Helen Cross J. The psychosocial impact of epilepsy in childhood. Epilepsy Behav 2009;15 Suppl 1:S5-10.

6. Chin RF, Cumberland PM, Pujar SS, et al. Outcomes of childhood epilepsy at age 33 years: a population-based birth-cohort study. Epilepsia 2011;52:1513-21.

7. Jalava M, Sillanpaa M, Camfield C, et al. Social adjustment and competence 35 years after onset of childhood epilepsy: a prospective controlled study. Epilepsia 1997;38:708-15.

8. Camfield PR, Camfield CS. What Happens to Children With Epilepsy When They Become Adults? Some Facts and Opinions. Pediatr Neurol 2014;51:17-23.

9. Geerts A, Brouwer O, van Donselaar C, et al. Health perception and socioeconomic status following childhood-onset epilepsy: the Dutch study of epilepsy in childhood. Epilepsia 2011;52:2192-202.

10. Carrizosa J, An I, Appleton R, et al. Models for transition clinics. Epilepsia 2014;55 Suppl 3:46-51.

11. Borlot F, Tellez-Zenteno JF, Allen A, et al. Epilepsy transition: Challenges of caring for adults with childhood-onset seizures. Epilepsia 2014;55:1659-66.

12. Iyer A, Appleton R. Transitional services for adolescents with epilepsy in the U.K.: a survey. Seizure 2013;22:433-7.

13. Smith PE, Myson V, Gibbon F. A teenager epilepsy clinic: observational study. Eur J Neurol 2002; 9:373-6.

14. 'Epilepsie'. Richtlijn Epilepsie Nederlandse Vereniging voor Neurologie. 2015; available from: http://epilepsie.neurologie.nl (Last visit: January 11, 2016).

15. Kuchenbuch $\mathrm{M}$, Chemaly N, Chiron $\mathrm{C}$, et al. Transition and transfer from pediatric to adult health care in epilepsy: a families' survey on Dravet syndrome. Epilepsy Behav 2013;29:161-5.

16. Camfield PR, Gibson PA, Douglass LM. Strategies for transitioning to adult care for youth with LennoxGastaut syndrome and related disorders. Epilepsia 2011;52 Suppl 5:21-7.

17. Schultz RJ. Parental experiences transitioning their adolescent with epilepsy and cognitive impairments to adult health care. J Pediatr Health Care 2013;27:359-66.

18. Arbaje Al, Kansagara DL, Salanitro AH, et al. Regardless of age: Incorporating principles from geriatric medicine to improve care transitions for patients with complex needs. J Gen Intern Med 2014; 29:932-9. 
Dankwoord 


\section{Dankwoord}

En dan is mijn proefschrift al af! lk kan zeggen dat alles echt in sneltreinvaart is verlopen, maar wel met af en toe een hobbel in de weg. Ik had hier dan ook niet gestaan zonder de begeleiding van een goede promotor en copromotoren, en mijn dierbare familie en lieve vrienden die altijd achter me staan. Dat mijn dankwoord relatief kort is, wil niet zeggen dat ik jullie minder dankbaar ben voor jullie individuele bijdrage aan dit proefschrift en steun die ik van jullie heb gekregen daarbuiten.

Een aantal personen wil ik in het bijzonder bedanken, omdat ze, op wat voor manier dan ook, een belangrijke bijdrage hebben geleverd aan dit proefschrift.

Allereerst wil ik de leden van de beoordelingscommissie bedanken voor het lezen en beoordelen van mijn proefschrift.

Mijn promotor en copromotoren wil ik graag extra bedanken voor al hun tijd die ze in mijn begeleiding hebben gestoken, en hun waardevolle adviezen.

Prof. dr. A.P. Aldenkamp, promotor, Beste Bert. Ik waardeer het heel erg dat ik de kans heb gekregen om promotieonderzoek te doen op Kempenhaeghe, bedankt voor je vertrouwen in mij. Ik kijk met veel bewondering terug op de creatieve oplossingen die je telkens wist te bedenken om het onderzoek goed op stoom te houden, ik heb hier erg veel van geleerd. Mede hierdoor is het mij gelukt om binnen twee jaar te promoveren.

Dr. A.J.A. de Louw, copromotor, Beste Anton. Op de momenten dat het even tegen zat wist je altijd doortastend te werk te gaan, en mij toch weer te motiveren om door te gaan. Een no-nonsense houding in combinatie met de flexibiliteit die ik kreeg om mijn werk wat anders in te delen waren precies wat ik nodig had op zulke momenten. De kritische noot die je telkens wist te plaatsen bij de inhoud van het onderzoek én bij de uiteindelijke publicaties waren erg waardevol en hebben zeker bijgedragen aan de kwaliteit van dit proefschrift.

Dr. L.M.C. Gottmer-Welschen, copromotor, Beste Laura. Ondanks dat jij jezelf voor de eerste keer copromotor mag noemen, vind ik dat je me super goed hebt begeleid, vaak met een persoonlijke touch, voor een extra praatje was er altijd tijd. Je enthousiasme en je inzet voor dit onderzoek (en andere onderzoeken op Kempenhaeghe) en je oplossingsgerichte houding als het onderzoek wat minder goed dreigde te lopen maken je tot een super copromotor. Dat je een enorme doorzetter bent is afgelopen jaar wel gebleken. 
Dr. AL van Staa, Beste AnneLoes. Het mag best eens gezegd worden: je enthousiasme en inzet voor de transitiezorg in Nederland en daar buiten vind ik bewonderenswaardig. Je bent hiermee een inspiratie voor de mensen om je heen.

Prof. dr. J.E.M. (Anja) Machielse, Dr. S. (Sveta) Zinger, Prof. Dr. P.H.N. de With, die als coauteur hebben bijgedragen aan mijn proefschrift. Bedankt voor de bijdrage aan mijn artikelen vanuit jullie expertisegebied, dat heeft het resultaat naar een hoger niveau gebracht.

Collega's Kempenhaeghe. Hoe groot was de omslag voor mij van het werk in een druk ziekenhuis naar de rust de landelijke sfeer van ons gebouw De Boondert op Kempenhaeghe. Bedankt voor alle tips and tricks die ik kon toepassen tijdens mijn werk en in de laatste fase van mijn promotieonderzoek en de gezellige (maar relatief korte) tijd die we samen op Kempenhaeghe hebben doorgebracht.

Vrienden en vriendinnen. Dankjewel voor jullie oprechte interesse in het onderzoek en daarbuiten. Amy, je nieuwe baan past goed bij je ;-). Andrea, met je relaxte noproblem-houding en grote dosis relativeringsvermogen als het op carrière maken aan komt. Vieke, veur twieë sjtaon met beide veut in de Riekelse klei! (;) Esther en Charlotte, bedankt dat jullie vandaag mijn paranimfen willen zijn. Esther, dankjewel voor de positieve energie die je altijd uitstraalt. Charlotte, bedankt voor die twee tips die je me hebt gegeven, weet je nog welke? ;-)

Pap*. Ich weit zeker desse vandaag mèt kieks, en ich hûb gin promotie nuudig om te weite desse aevegood 'hiel gruuëts' op mich gewaes zous zin. Maar ich weit auch det die eine besjlissing dich extra stolz haaj gemaakt.

Mam en Peter (Petter), Milou, familie. Mam en Petter, jullie staan altijd voor me klaar en niets is jullie ooit teveel. Mam, je hebt de laatste jaren laten zien dat je altijd overal het beste van weet te maken en je weet hiermee mij te motiveren om dat ook te doen. Samen met Petter heb je een fijn nieuw 'thuis' voor ons opgebouwd. Ik kan het niet vaak genoeg zeggen: bedankt voor alles.

Lieve Ruud. Toen het ter sprake kwam dat ik een dankwoord moest schrijven voor mijn proefschrift, heb je zelf al meerdere keren de grap gemaakt dat mijn dankwoord aan jou eigenlijk zou moeten bestaan uit een los addendum als bijlage bij mijn proefschrift (dat wás ook een grapje, toch?), maar ik hoop dat je ook tevreden bent met dit bescheiden stukje. Niets is minder waar: ook buiten dit promotieonderzoek steun jij me onvoorwaardelijk, je staat altijd voor me klaar en je hebt altijd geduld met mij (of doet net alsof), en meestal lukt het je heel goed om mij 'effe terug te fluiten' zoals je dat zelf noemt. Ik hoop dat je ook zonder dit dankwoord (of een apart addendum) weet wat je voor mij betekent. Bedankt voor alles! 
Curriculum Vitae 


\section{Curriculum Vitae}

Rianne Petronella Johanna Geerlings werd op 25 december 1985 geboren in Beesel. In 2004 behaalde zij haar Gymnasium B diploma aan het Bisschoppelijk College Broekhin in Roermond. Van 2004 tot 2011 studeerde zij geneeskunde aan de Universiteit Maastricht. In het laatste jaar van de studie geneeskunde deed zij een klinische stage (gezondheidsparticipatie, GEZP) en een wetenschapsstage (Wetenschapsparticipatie, WESP) in de neurologie. Tijdens deze stages schreef ze haar

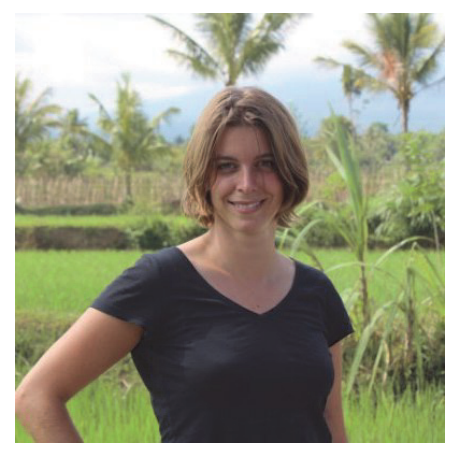
eerste wetenschappelijke publicaties. Na haar afstuderen werkte zij ruim twee jaar als arts-assistent (ANIOS) neurologie in het Orbis Medisch Centrum (thans Zuyderland Medisch Centrum) in Sittard en in het Catharina Ziekenhuis in Eindhoven. In juni 2014 startte zij bij het Academisch Centrum voor Epileptologie Kempenhaeghe (Heeze) als PhD-student met het onderzoek naar transitieproblematiek bij jongeren met chronische epilepsie onder supervisie van prof. dr. A.P. Aldenkamp, dr. A.J.A. de Louw en dr. L.M.C. Gottmer-Welschen. De resultaten van het onderzoek staan in dit proefschrift beschreven. In 2015 en 2016 was zij tutor van tweedejaarsstudenten geneeskunde aan de Universiteit Maastricht.

Rianne woont samen met haar vriend Ruud Geraedts in Roermond. In haar vrije tijd houdt ze van paardrijden en tijdens haar vakanties gaat ze het liefst backpacken in Afrika of Azië.

Rianne Petronella Johanna Geerlings was born on December $25^{\text {th }} 1985$ in Beesel, The Netherlands. In 2004 she graduated her secondary school education at the Bisschoppelijk College Broekhin in Roermond (The Netherlands). She studied medicine at Maastricht University (Maastricht, The Netherlands) from 2004 to 2011. During the last year of her study, she did a participation in health care (GEZP) and a research internship (WESP) in Neurology. During this research internship she wrote her first publications. After graduating, she started working as a resident at the Department of Neurology at the Orbis Medical Center (now named Zuyderland Medical Center) in Sittard (The Netherlands) and the Catharina Hospital in Eindhoven (The Netherlands). In June 2014, she started her PhD-research in transition in adolescents and young adults with childhood-onset epilepsy under the supervision of prof. dr. A.P. Aldenkamp, dr. A.J.A. de Louw and dr. L.M.C. Gottmer-Welschen in Academic Centre for Epileptology Kempenhaeghe (Heeze, The Netherlands). The results of this research are described in this thesis. In 2015 and 2016 she participated in the education of second year medical students at Maastricht University (The Netherlands).

Rianne lives together with Ruud Geraedts in Roermond, The Netherlands. She likes horse riding, and prefers to spend her holidays backpacking in Africa or Asia. 
List of publications 


\section{List of publications}

\section{In this thesis}

Geerlings RPJ, Gottmer-Welschen LMC, Machielse JEM, de Louw AJA, Aldenkamp AP. Failed transition to independence in young adults with epilepsy - Submitted.

Geerlings RPJ, Aldenkamp AP, Gottmer-Welschen LMC, de With PHN, Zinger S, van Staa AL, de Louw AJA. Long-term effects of a multidisciplinary transition intervention from paediatric to adult care in patients with epilepsy - Submitted.

Geerlings RPJ, Aldenkamp AP, Gottmer-Welschen LMC, de With PHN, Zinger S, van Staa AL, de Louw AJA. The evaluation of a multidisciplinary epilepsy transition clinic for adolescents. Eur J Paediatr Neurol. 2016;20:385-92.

Geerlings RPJ, Aldenkamp AP, Gottmer-Welschen LMC, de With PHN, Zinger S, van Staa AL, de Louw AJA. Developing from child to adult: risk factors for poor psychosocial outcome in adolescents and young adults with epilepsy. Epilepsy Behav. 2015;51:182-90.

Geerlings RPJ, Aldenkamp AP, de With PHN, Zinger S, Gottmer-Welschen LMC, de Louw AJA. Transition to adult medical care for adolescents with epilepsy. Epilepsy Behav. 2015;10:127-35.

\section{Other publications}

Geerlings RPJ, Aldenkamp AP, Gottmer-Welschen LMC, de Louw AJA. Response to 'Letter to the Editor, Epilepsy Transition: Let's start planting the seed' by Borlot F, Andrade DM. Eur J Paediatr Neurol. - Submitted.

Geerlings RPJ, van Domburg PHMF, van Dam DW. Invasieve aspergillose van de orbitale apex. Tijdschr Infect 2015;10:79-83.

Geerlings RPJ, van Domburg PHMF. Neuro-imaging: uw diagnose? (Meningoencefalitis op basis van neuroborreliose). Tijdschr Neurol Neurochir 2014;115:236-9.

Geerlings RPJ, van Domburg PHMF. Orbitale apex syndroom door aspergillose. Tijdschr Neurol Neurochir 2014;115:176-81.

Haane DY, de Ceuster LM, Geerlings RPJ, Dirkx TH, Koehler PJ. Cluster headache and oxygen: is it possible to predict which patients will be relieved? A prospective crosssectional correlation study. J Neurol. 2013;260:2596-605. 
Geerlings RPJ, Pompe SM, Koehler PJ. Dysfagie bij Avellis syndroom (lateraal medulla oblongata infarct). Ned Tijdschr Geneeskd. 2012;156:A3689.

Geerlings RPJ*, Haane DY*, Koehler PJ. Rebound following oxygen therapy in cluster headache. Cephalalgia 2011;31:1145-9. * Both authors contributed equally

Geerlings RPJ, Koehler PJ, Haane DY, Stam AH, de Vries B, Boon EM, Haan J. Head tremor related to CACNA1A mutations. Cephalalgia 2011;31:1315-9. 